\title{
Comportamento Complexo na formação de bolhas de ar em líquidos
}

\author{
Viviane da Silva Mendes Piassi
}

17 de julho de 2007 


\section{Agradecimentos}

Ao prof. Sartorelli pela orientação e paciência.

À minha mãe pela presença em todos os momentos. À meu pai que sempre apoiou todas minhas iniciativas. À Luiza pelo amor incondicional. Ao Aldo.

Aos meus familiares e aos irmãos do coração Cadu, Vivi, Eli, Lud e Andreza.

Aos colegas do LFNL pelo convívio e pelas sempre construtivas críticas. Ao Luís pelo apoio em tantos momentos. Aos amigos queridos, sempre pacientes e prestativos, e aos Edits que tão bem me receberam.

À Capes, ao CNPq e à FAPESP pelo apoio financeiro.

E a todos que de alguma forma colaboraram com este trabalho. 


\section{Resumo}

Investigamos a dinâmica da formação de bolhas de ar em líquidos viscosos utilizando diferentes parâmetros de controle. Caracterizamos o sistema tomando o fluxo de ar injetado no sistema e o comprimento da mangueira que conecta o sistema de controle de fluxo com o bico injetor como parâmetros de controle. A mangueira corresponde a um elemento dissipativo do sistema. Identificamos rotas de adição de período com e sem a presença de comportamento caótico, regiões de travamento de freqüência e evidências de caos homoclínico.

Construímos modelos matemáticos que descrevem bem os resultados experimentais. Com o mapa cúbico explicamos a forma de atratores observados em uma rota de adição de períodos. Com o modelo de mapa descontínuo explicitamos algumas propriedades da dinâmica da formação de bolhas como a biestabilidade de atratores. Desenvolvemos também um modelo baseado na dinâmica integra-edispara que nos levou a resultados condizentes com as propriedades dos mapas da família de Arnold.

Desenvolvemos também uma nova técnica experimental para estudar o comportamento do sistema medindo a onda de pressão, gerada pelo borbulhamento na mangueira conectora. 


\section{Abstract}

We have investigated the air bubble formation in viscous fluid with some control parameters. We have characterized the sistem using the air flow and the length of the hose that connects the air flow control system and the injector nozzle as control parameters. The hose corresponds to a system dissipative element. We have found period adding routes with and without chaotic behavior, frequency locking, and evidences of homoclinic chaos.

We have elaborated mathematic models that emule the experimental data. With cubic model we have explained atractors observerd in a period adding route. With a discontinous model we have elucidated some bubble formation dynamic properties as bistability. We have also developed intergrate-and-fire like model that have led us to results in accordance with the maps properties of Arnold family.

We also developed a new experimental technique to study the sistem behavior by measuring the bubbling pressure wave inside the hose 


\section{Sumário}

1 Introdução 1

2 Aspectos Teóricos 4

2.1 Estudo de sistemas dinâmicos . . . . . . . . . . . . . . . . . 4

2.2 Seção de Poincaré . . . . . . . . . . . . . . . . . . 5

2.3 Reconstruções do espaço de fase . . . . . . . . . . . . . . . . . 6

2.4 Mapas ......................... 8

2.5 Bifurcações . . . . . . . . . . . . . . . . . . 10

2.6 Órbitas homoclínicas. . . . . . . . . . . . . . . . 12

2.7 Mapa do círculo . . . . . . . . . . . . . . . . . 15

2.8 Dinâmica integra-e-dispara . . . . . . . . . . . . . . 18

2.9 Formação de bolhas em líquidos. . . . . . . . . . . . . . . . . . 19

2.10 Mapas descontínuos . . . . . . . . . . . . . . . 21

3 Aparato Experimental 25

3.1 Sistema Pneumático . . . . . . . . . . . . . . . 26

3.2 Sistema de controle da vazão . . . . . . . . . . . . . . . . 26

3.3 Sistema de Aquisição . . . . . . . . . . . . . . . . . . . 27

3.4 Perturbação do sistema . . . . . . . . . . . . . . . . . . . . . 29

4 Resultados e Discussões 30

4.1 Bolha de Bifurcação e Adição de Período . . . . . . . . . . . . . 30

4.1.1 Diagramas de Bifurcação . . . . . . . . . . . . . 30 
4.1.2 Reconstruções de primeiro retorno . . . . . . . . . . . . . . . 35

4.2 O mapa cúbico descontínuo . . . . . . . . . . . . . . . . . 38

4.3 Análise de imagens de bolhas em formação . . . . . . . . . . . . . . 42

4.4 Modelo para adição de período e biestabilidade . . . . . . . . . . . 44

4.5 Caos homoclínico . . . . . . . . . . . . . . . . . . . 52

4.6 A influência da perturbação sonora. . . . . . . . . . . . . . . 60

4.6.1 Espaço de parâmetros . . . . . . . . . . . . . 69

5 Considerações Finais $\quad 73$

6 Referências Bibliograficas $\quad 75$

$\begin{array}{lll}7 & \text { Apêndices } & 78\end{array}$ 


\section{Capítulo 1}

\section{Introdução}

Nas últimas décadas o entendimento dos fenômenos envolvendo comportamento caótico em sistemas dinâmicos de poucos graus de liberdade teve um desenvolvimento surpreendente. Em sistemas cuja dinâmica apresenta sensibilidade às condições iniciais não é possível fazer previsões a longo prazo sobre sua evolução, mesmo sendo pequenas as variações das condições iniciais. Alguns exemplos de sistemas dinâmicos que apresentam comportamento caótico são variações climáticas [Lorenz, 1980], torneiras pingando [Sartorelli et al., 1994], formação de bolhas [Tufaile, 2000], circuito de Chua e oscilações em semicondutores.

Baseando-se no experimento da Torneira Gotejante, construído no Laboratório de Fenômenos Não-Lineares (LFNL) [Sartorelli et al., 1994], Tufaile desenvolveu o experimento do Tubo Borbulhador [Tufaile, 2000] para estudar a formação de bolhas de ar em soluções viscosas.

O estudo da dinâmica de formação de bolhas de ar é importante para o entendimento de fluxos bifásicos tais como dispersão de gases em líquidos, formação de bolhas em equipamentos de limpeza, cavitação em válvulas e bombas hidráulicas, etc. A formação de bolhas tem uma forte influência no funcionamento de equipamentos onde ocorre transferência de massa e calor pela interação entre gases e líquidos. O estudo do tamanho e do tempo de formação de bolhas pode contribuir para aumentar a eficiência desses equipamentos.

A aplicação da Teoria do Caos para o estudo de formação de bolhas foi feita 
primeiramente por Tritton [Tritton et al., 1994] que utilizou um medidor de fluxo anemométrico para obter dados sobre a dinâmica de formação de bolhas. Nesse trabalho, porém, o método de medição é invasivo e a caracterização feita para o comportamento caótico é subjetiva. Uma técnica não invasiva foi utilizada por Mittoni [Mittoni et al., 1998] que mediu o tempo de formação de bolhas com um transdutor de pressão. No campo da Engenharia Química, o Chaos Research Group ( $C R G$ ), da Universidade do Tenessee estuda desde 1992 a dinâmica de uma coluna de bolhas de ar formada por um bico, procurando estudar a rota para o Caos via duplicação de período e técnicas de controle de Caos.

Foram observados comportamento periódico e quase-periódico, bifurcações e regime caótico, seja variando a vazão de ar, ou aplicando uma perturbação periódica ao sistema com vazão fixa [Tufaile et al, 2000]. Foi feito o estudo da relação entre a formação de bolhas e a viscosidade da solução sendo mostrado que para soluções mais viscosas o sistema apresenta maior estabilidade, e com maior definição das transições do regime de borbulhamento. Também foi estudada a indução de veias líquidas utilizando bolhas e a estabilidade de fluidos, com viscosidades diferentes, sobrepostos, além da formação de antibolhas. Atratores obtidos com este experimento foram comparados com atratores de Hénon, já que em alguns casos, apresentam comportamentos semelhantes caracterizados através de planos simbólicos [Tufaile et al., 2000b]

Neste trabalho nos ocupamos de um sistema bifásico, constituído por colunas de bolhas de ar formadas dentro de um líquido viscoso. No experimento montado no LFNL, medimos os intervalos de tempo entre bolhas consecutivas que se formam no bico soprador. Uma seqüência de intervalos nos permite construir uma série temporal com a qual podemos analisar o comportamento do sistema, cujas técnicas de análise são as mesmas utilizadas no experimento da Torneira Gotejante [Gonçalves, 1996; Pinto, 1999] que incluem a construção de diagramas de bifurcação e reconstruções dos espaços de fase por meio de mapas de retorno. Também foram obtidas imagens das bolhas com uma câmera de vídeo VHS.

A dinâmica do sistema em baixa vazão foi caracterizada levando em conta 
uma propriedade geométrica do aparato experimental, isto é, o comprimento da mangueira conectora do bico soprador ao sistema pneumático. Modelos matemáticos foram desenvolvidos para representar a dinâmica com mapas descontínuos e nãolineares.

Outra questão estudada foi o efeito de uma perturbação na dinâmica de formação de bolhas. A perturbação aplicada foi uma onda sonora no alto da coluna de borbulhamento. Características de mapas circulares foram identificadas e um modelo foi desenvolvido para representar os dados experimentais. Analisando a influência da onda sonora a partir de sincronização de osciladores identificamos patamares de travamento de freqüência onde o valor do tempo entre bolhas permanece inalterado mesmo sob variação da quantidade de ar injetado no bico.

Assim, investigamos como um sistema de duas fases evolui de um comportamento periódico para um comportamento caótico através de suas características temporais e espaciais. 


\section{Capítulo 2}

\section{Aspectos Teóricos}

\subsection{Estudo de sistemas dinâmicos}

O estudo de sistemas dinâmicos envolve o acompanhamento temporal de alguma variável significativa do sistema e a elaboração de modelos que consigam descrever sua evolução espaço-temporal. Para esse fim podemos utilizar um sistema autonômo de equações diferenciais de primeira ordem

$$
\frac{d \vec{x}(t)}{d t}=f[\vec{x}(t), a]
$$

onde $a$ representa um conjunto de parâmetros independentes do tempo $t$ que caracteriza o sistema, os chamados parâmetros de controle. Todas as soluções deste sistema podem ser representadas num espaço $D$-dimensional, chamado espaço de fases. O conjunto dessas soluções é denominado fluxo.

Se o sistema for linear, dadas as condições iniciais $\left(\vec{x}_{0}, t_{0}\right)$ é possível encontrar soluções analíticas para as equações, o que não acontece se o sistema for não-linear já que estes sistemas são tipicamente caóticos.

Um sistema é definido como caótico se apresenta sensibilidade às condições iniciais, ou seja, duas condições iniciais que diferem de $\Delta d_{0}$, após um tempo $t$ terão entre si uma diferença de $\Delta d=\Delta d_{0} e^{\lambda t}$, onde $\lambda>0$ é o expoente de Lyapunov, divergindo exponencialmente não importando quão pequeno seja $\Delta d_{0}$. Este tipo 
de comportamento normalmente inviabiliza a obtenção de soluções analíticas pois estas não são periódicas ou sequer assintóticas.

Em sistemas dissipativos uma propriedade importante é que embora apresentem soluções não assintóticas as trajetórias possíveis ao sistema permanecem confinadas a uma região finita com dimensão menor que a do espaço de fases. Estas trajetórias confinadas são chamadas de atratores. Em sistemas conservativos não existem atratores e as trajetórias visitam todo o espaço de fases.

Um sistema dinâmico pode apresentar vários tipos de movimento, entre eles pontos de equilíbrio, soluções periódicas e quase periódicas além do movimento caótico. Um ponto de equilíbrio ocorre quando o fluxo é constante e independente do tempo. Uma solução periódica apresenta trajetórias independentes do tempo caracterizadas por um período característico $\tau$, enquanto soluções quase periódicas são formadas pela soma de soluções periódicas com períodos incomensuráveis.

Pontos fixos ou soluções periódicas podem ser estáveis ou instáveis de acordo com seu comportamento nas proximidades da solução. Se o sistema sempre retorna ao estado estacionário após uma perturbação esse estado é chamado estável, mas se o sistema se afasta do estado original então é instável.

\subsection{Seção de Poincaré}

Um dos pontos que tornou Poincaré tão conhecido foi a introdução de métodos qualitativos em áreas onde o estudo era dominado há muito tempo por métodos quantitativos. Uma das mais importantes inovações de Poincaré foi um meio mais simples de observar trajetórias contínuas bastante complexas. Ao invés de estudar a trajetória propriamente no espaço de fases $D$-dimensional ele mostrou que a maioria da informação realmente importante sobre a dinâmica do sistema está presente nos pontos em que a trajetória cruza uma superfície $\mathcal{S}$ de dimensão $D-1$. A ordem destes pontos de intersecção $\left(x_{n}, y_{n}\right)$ define o que chamamos de mapa.

Um exemplo é mostrado na figura 2.1 onde o sistema tem dimensão 3. A figura mostra a superfície $\mathcal{S}$ que é um plano definido por um valor constante do eixo $x_{3}$. 


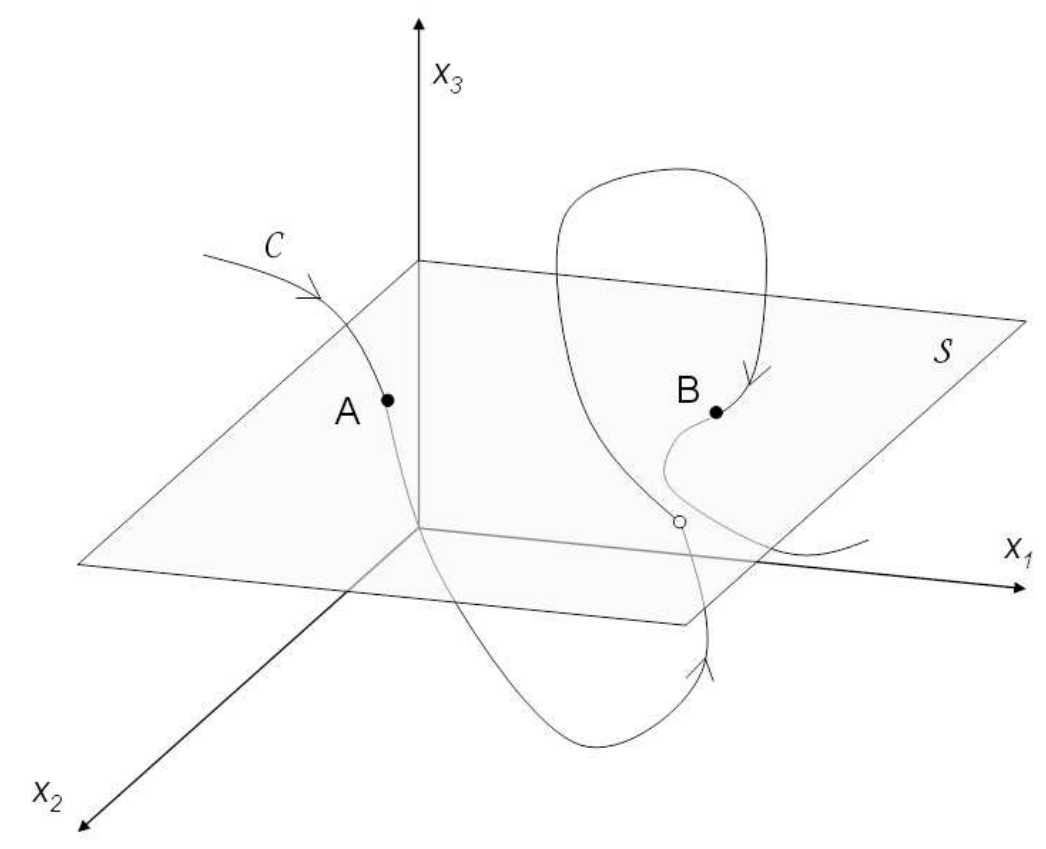

Figura 2.1: O esquema representa a construção de uma seção de Poincaré a partir de uma trajetória contínua no espaço de fases. A ordem com que a trajetória cruza o plano de intersecção $\mathcal{S}$ define o mapa.

A cada vez que a trajetória $C$ cruza o plano $\mathcal{S}$ de cima para baixo este ponto é marcado, como os pontos $A$ e $B$ na figura 2.1. Assim, se $A$ representa o $n$-ésimo cruzamento de cima para baixo, então o ponto $B$ representa o cruzamento $n+1$. O mapa de Poincaré é então um mapa bidimensional $\mathcal{F}$ que mapeia $A$ em $B$, $\mathcal{F}(A)=B$.

O mapa de Poincaré é a primeira vista similar a um mapa estroboscópico. No entanto, é preciso notar que as intersecções da trajetória na superfície $\mathcal{S}$ não são igualmente espaçadas no tempo.

\subsection{Reconstruções do espaço de fase}

Em um sistema experimental nem sempre é possível obter medidas de todas as variáveis dinâmicas. Se fosse possível identificar todas as variáveis e obter essas medidas, uma grande quantidade de dados seria gerada o que se tornaria im- 
praticável.

No entanto, a construção de sucessivos mapas de Poincarè, considerando-se que fosse possível a obtenção de todas as variáveis do sistema, permitiria diminuir a dimensão de cada novo mapa obtido preservando as características importantes do sistema. Se seguirmos esse processo, podemos chegar à uma única variável que contenha toda a informação dinâmica importante ao sistema.

Assim, com apenas as medidas de uma variável podemos obter as informações necessárias para compreender o comportamento do sistema dinâmico.

\section{Séries temporais}

Takens demonstrou que o espaço de fase reconstruído a partir dos vetores $\zeta$, obtidos com a medida da série temporal de uma única variável dinâmica $x$, de um sistema dinâmico $D$-dimensional, amostrada a intervalos constantes de valor $\tau$ :

$$
\zeta(t)=x(t), x(t+\tau), \ldots, x(t+(m-1) \tau)
$$

possui as mesmas propriedades topológicas que o espaço de fase original do sistema, desde que a dimensão de imersão $m$, utilizada para reconstruir o espaço de fase a partir do conjunto de vetores $\{\zeta\}$, seja maior ou igual a $D$.

\section{Séries de eventos e Mapas de Retorno.}

Em muitos sistemas dinâmicos as medidas que podem ser realizadas experimentalmente se relacionam com uma sequência de eventos, tais como gotas que caem de uma torneira, disparos de neurônios ou bolhas se formando em um bico, que é o objeto de estudo deste trabalho. Sauer fez uma generalização do Teorema de Takens onde mostrou que o mesmo tipo de análise feita a séries temporais pode ser aplicada a sistemas com dinâmica representada por eventos [Argyris, 1994].

Como uma série de eventos não reproduz exatamente o espaço de fase, precisamos utilizar técnicas de reconstrução. Uma das técnicas mais importantes de reconstrução do espaço de fases é o mapa de retorno. Adotando um atraso na série podemos criar vetores no espaço de imersão e o número de componentes desses 
vetores dá a dimensão do espaço de imersão. O mapa de primeiro retorno é criado pelas duplas $\left(x_{n}, x_{n+1}\right)$, o de segundo retorno pelas duplas $\left(x_{n}, x_{n+2}\right)$ e assim por diante.

\subsection{Mapas}

Também podemos estudar o comportamento de sistemas dinâmicos descritos por séries de integrais finitas, ou mapas. O sistema é então descrito por uma função com tempo discreto, do tipo:

$$
\vec{X}_{n+1}=f\left(\vec{X}_{n}\right)
$$

que nos permite, conhecendo uma condição inicial 0 , determinar todos os demais estados $n$ do sistema, $(0,1,2, \ldots, m-1, m)$. No caso de mapas, os pontos fixos são determinados fazendo:

$$
\vec{X}^{*}=f\left(\vec{X}^{*}\right)
$$

A estabilidade desses pontos pode ser encontrada construindo a matriz Jacobiana $J$ com elementos:

$$
J_{i j}=\left.\frac{\partial f_{i}\left(X_{1, n}, X_{2, n}, \ldots, X_{M, n}\right)}{\partial X_{j}}\right|_{X=X^{*}}
$$

onde $f_{i}\left(X_{1, n}, X_{2, n}, \ldots, X_{M, n}\right)=X_{i, n+1}$. Os autovalores $\lambda$ da matriz tomada no ponto fixo determinam sua estabilidade, $|\lambda|<1$ identifica uma variedade estável enquanto $|\lambda|>1$, a variedade instável. Se tomarmos como exemplo o mapa logístico, usualmente definido para $X_{n}$ entre 0 e 1 ,

$$
X_{n+1}=f\left(X_{n}\right)=a X_{n}\left(1-X_{n}\right)
$$

existem dois pontos fixos de período 1, um deles é a solução trivial da equação 2.6 ,

$$
X_{\alpha}^{*}=0,
$$

e o outro ponto fixo será dado por

$$
X_{\beta}^{*}=1-\frac{1}{a} .
$$


A matriz $J$ possui apenas um elemento, já que o mapa é unidimensional e a estabilidade dos pontos fixos são determinadas de acordo com o parâmetro a.A derivada da função 2.6 nos dá a condição de estabilidade que para as órbitas de período 1 é:

$$
\left|f^{\prime}(X)\right|=|a(1-2 x)|<1
$$

A figura 2.2 mostra a função $f(X)$ da equação 2.6 em função de $X$ para o parâmetro $a=2.5$. Para este valor de parâmetro temos o ponto fixo $X_{\alpha}^{*}=0$ instável e o ponto fixo $X_{\beta}^{*}=0,6$ estável.

Para $0<a<1$ o ponto fixo $X_{\alpha}^{*}$ é estável, ou seja, $f^{\prime}\left(X_{\alpha}^{*}\right)=a \leq 1$, enquanto o segundo ponto fixo $X_{\beta}^{*}$ não existe. Acima de $a=1$ o ponto $X_{\alpha}^{*}$ passa a ser instável. $X_{\beta}^{*}$ é estável para $1 \leq a \leq 3$ pois $\left|f^{\prime}\left(X_{\beta}^{*}\right)\right| \leq 1$ enquanto para $a>3$ temos $\left|f^{\prime}\left(X_{\beta}^{*}\right)\right|>1$ e o ponto fixo $X_{\beta}^{*}$ é instável.

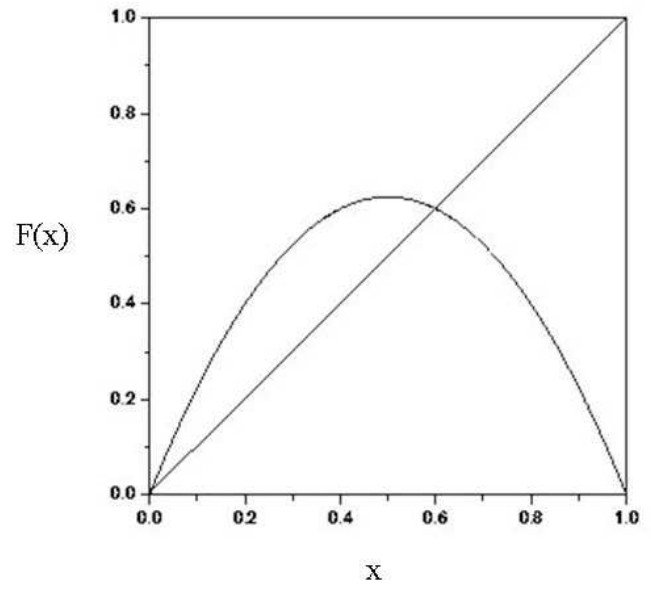

Figura 2.2: Função do mapa logístico para $a=2.5$.

Análise semelhante pode ser feita para identificar a estabilidade de órbitas com período maior que 1. Para identificar o ponto fixo de período 2 por exemplo fazemos

$$
X_{n+2}=f\left(X_{n+1}\right)=f\left(f\left(X_{n}\right)\right)
$$

que nos fornece, no caso do mapa logístico uma função de ordem 4, com duas novas soluções identificando os valores de X para a órbita de período 2 . 
A importância da utilização de mapas nesse trabalho se deve ao fato que ao observarmos um sistema dinâmico periodicamente, ou a cada ocorrência de um determinado evento, obtemos uma série que pode ser tratada como um mapa.

\subsection{Bifurcações}

A variação de qualquer parâmetro de controle em um sistema dinâmico pode causar alterações qualitativas em sua dinâmica. Tais mudanças, chamadas bifurcações, podem ocorrer com pequenas alterações desses parâmetros modificando a estabilidade e até o número de estados estacionários do sistema. Bifurcações podem ser locais, modificando o comportamento do sistema apenas em uma vizinhança muito pequena de estados estacionários, ou globais, causando mudanças drásticas em todo o espaço. Para analisarmos as alterações no comportamento do sistema de acordo com a mudança de um parâmetro de controle podemos construir um diagrama de bifurcação. A figura 2.3 mostra um diagrama de bifurcação obtido para o mapa logístico, equação 2.6. Várias bifurcações podem ser identificadas quando variamos os parâmetros de um sistema. No caso do mapa logístico observamos tanto o surgimento de órbitas periódicas como comportamento caótico.

\section{Bifurcação tipo duplicação de período}

A bifurcação tipo duplicação de período, conhecida também como bifurcação flip é caracterizada pela transição de um estado estável a outro com comportamento estável de periodicidade dobrada acompanhado de um estado instável com periodicidade igual ao estado anterior. Esta bifurcação ocorre para o mapa logístico para o parâmetro de controle $a=3,0$, veja figura 2.3.

\section{Bifurcação tipo sela-nó}

Em uma bifurcação tipo sela-nó, dois pontos fixos são criados simultâneamente, um deles estável e outro instável. O termo sela-nó deriva desse tipo de bifurcação 


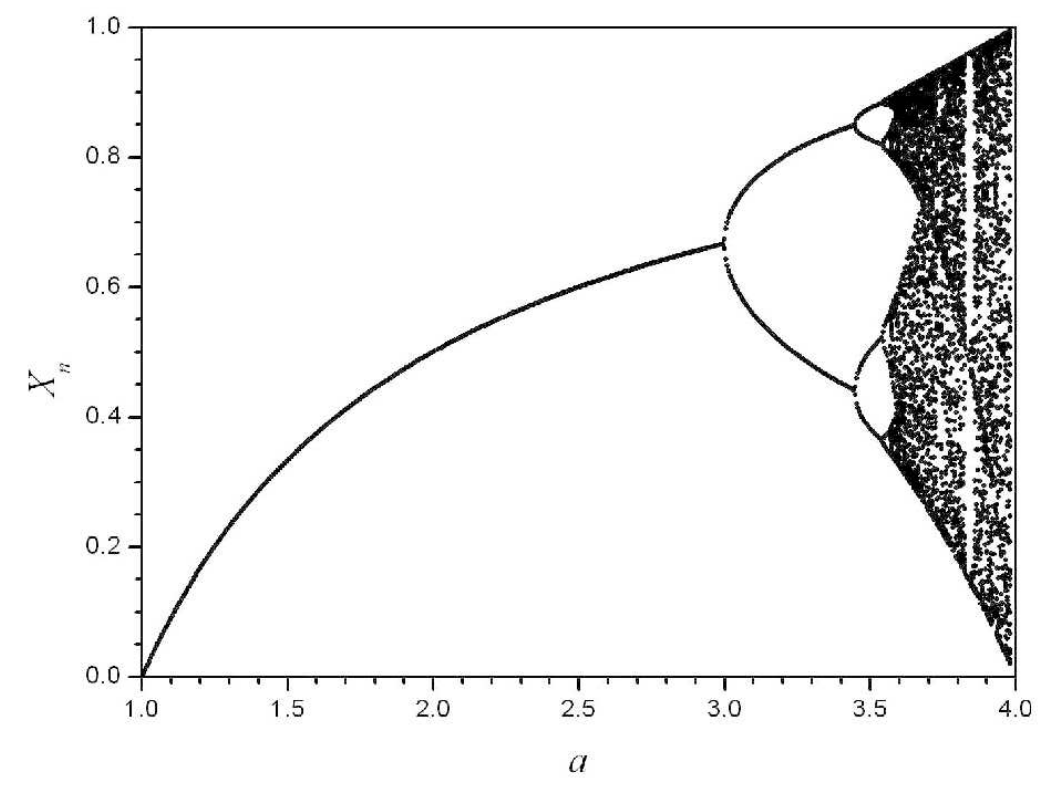

Figura 2.3: Diagrama de bifurcação do mapa do logístico.

num espaço bidimensional, onde a órbita instável é um ponto de sela e a órbita estável é um ponto fixo tipo nó.

Em sistema unidimensionais, como o mapa logístico por exemplo, esta bifurcação recebe o nome de bifurcação tangente. Isto porque para que esta bifurcação ocorra a derivada do mapa $f_{a}^{\prime}(x)$ no momento da bifurcação sela-nó deve ser +1 , e portanto o gráfico da função $f(x)$ tangencia a diagonal $y=x$.

A figura 2.4 mostra uma ampliação do diagrama de bifurcação do mapa logístico evidenciando a bifurcação sela-nó que ocorre em torno de $a=3,83$ onde surge uma órbita de período 3 estável e outra instável.

\section{Bifurcação transcrítica.}

Uma bifurcação transcrítica é bem diferente da duplicação de período e da selanó. O que ocorre é um encontro entre duas órbitas, uma estável e outra instável, provocando com isso a troca de estabilidade entre elas. 


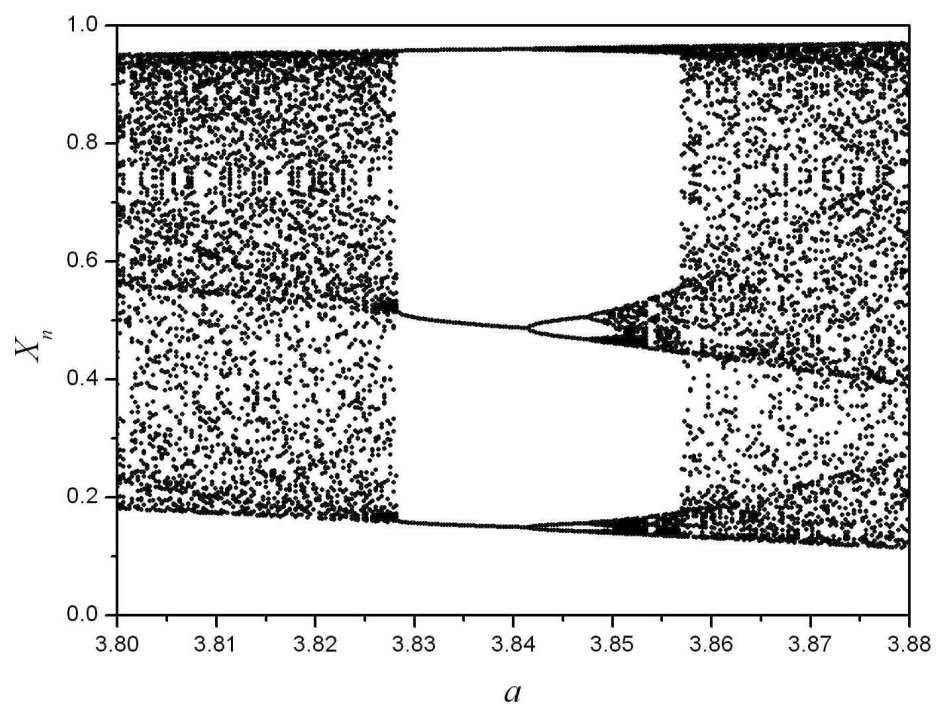

Figura 2.4: Diagrama de bifurcação do mapa do logístico para $3,8<a<3,88$ evidenciando a ocorrência de uma bifurcação sela-nó.

\section{Bifurcação de Hopf.}

Nesse tipo de bifurcação ocorre o surgimento de órbitas quase periódicas a partir de pontos fixos estáveis (que se tornam instáveis), provocando uma mudança qualitativa em uma região pequena do espaço.

A figura 2.5 mostra um esquema representativo desse tipo de bifurcação. É dentro da região pontilhada que ocorre a mudança no comportamento do sistema, externamente a esta linha, tudo permanece inalterado. Acima, todas as órbitas tendem ao ponto fixo estável indicado pelo ponto interno à região delimitada. Abaixo a figura representa o sistema após a bifurcação. O antigo ponto fixo estável se torna instável e ocorre o surgimento de um ciclo-limite (comportamento quaseperiódico) estável.

\section{6 Órbitas homoclínicas.}

O estudo de órbitas homoclínicas é já há algum tempo de grande relevância no estudo de sistemas dinâmicos. Uma órbita homoclínica surge quando ocorre cruza- 


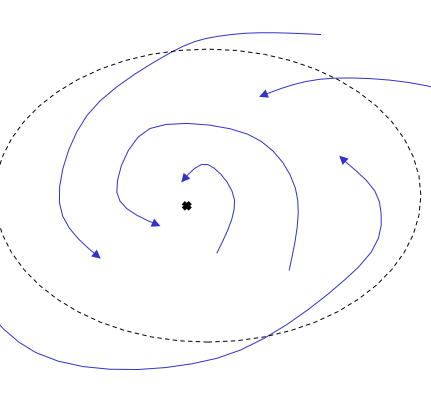

Figura 2.5: Esquema representando a alteração local do espaço devida a uma bifurcação tipo Hopf.Em (a) vemos um ponto fixo estável e todas as órbitas tendem a ele. Em (b), após a bifurcação de Hopf, vemos que o ponto fixo se tornou instável enquanto o ciclo limite se tornou estável.

mento ou conexão entre as variedades de um mesmo ponto fixo. Uma característica desse tipo de sistema é a presença de pontos fixos tipo sela, que podem também apresentar variedades com dimensão maior que um. Um ponto fixo bastante interessante observado com certa freqüência em sistemas como lasers [Zeni et al., 1998] e modelos de neurônios é o ponto fixo sela-foco. A figura 2.6 mostra um esboço de pontos sela-foco em 3 dimensões.

Uma órbita homoclínica é observada para o modelo de laser auto excitável estudado por Pisarchik [Pisarchik et al., 2001]. O sistema possui dimensão 6 e tem a presença de um ponto fixo sela-foco. A figura 2.7 mostra uma projeção bidimensional dessa órbita que apresenta duas espirais em torno do ponto fixo 


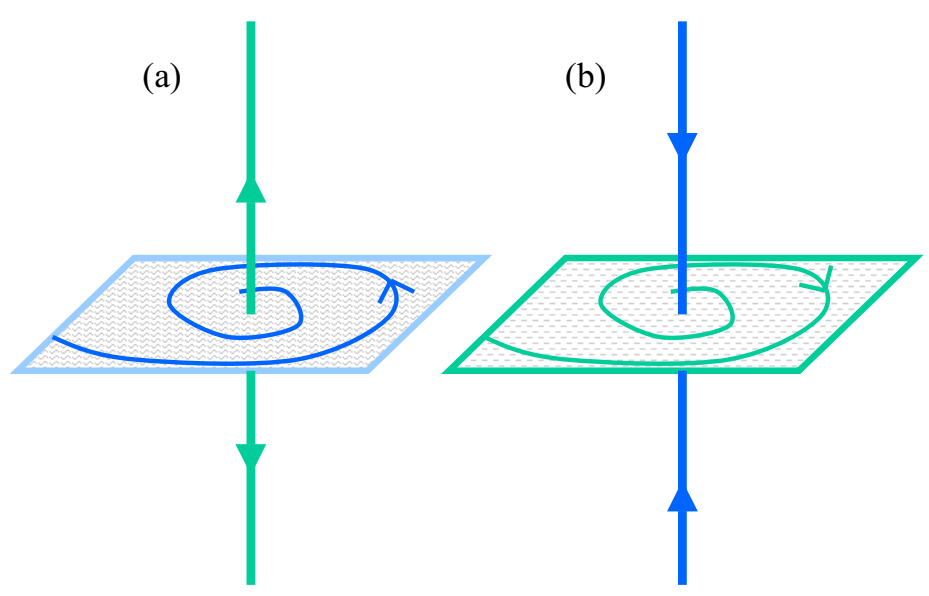

Figura 2.6: Esboços de pontos fixos sela-foco em dimensão 3. Em (a) a variedade estável é um plano e possui dois auto-valores complexos enquanto a variedade instável é unidimensional com auto-valor real. Em (b) é a variedade instável que possui auto-valores complexos sendo a estável real. 


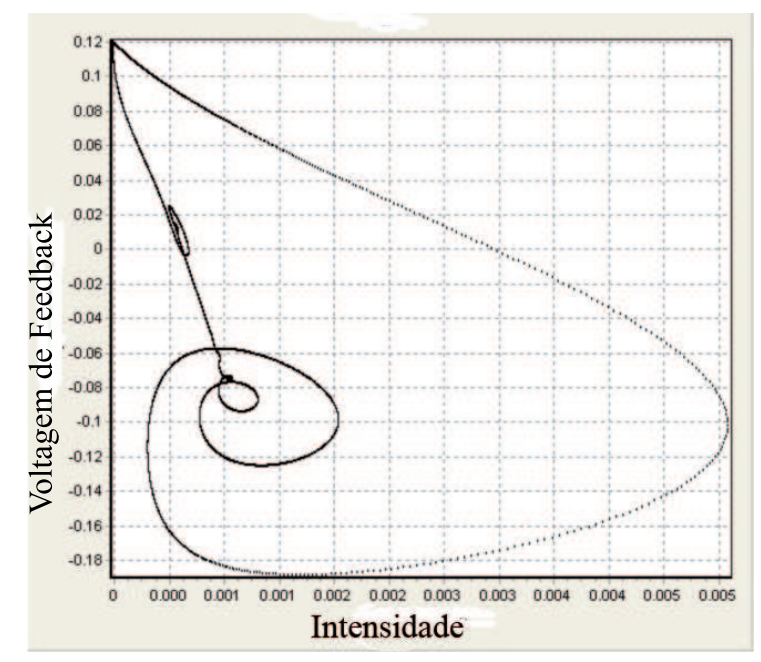

Figura 2.7: Espaço de fase de um modelo de laser com feedback.

indicando que tanto a variedade estável como a instável apresentam característica de foco.

Se o espaço de fase de um sistema apresenta esse tipo de órbita, uma alteração de parâmetros ligados à dissipação do sistema pode alterar o número de ciclos que a órbita dá em torno do ponto fixo, caracterizando uma bifurcação local, sem alterar globalmente o comportamento do sistema dinâmico.

\subsection{Mapa do círculo}

Mapas são de grande relevância para o estudo da formação de bolhas de ar em líquidos viscosos. O mapa do círculo é um importante exemplo pois modela a dinâmica de formação de bolhas ar sob ação de uma perturbação sonora [Tufaile, 2000]. Um outro exemplo importante são os mapas descontínuos onde se observa rotas de adição de período semelhantes às observadas para a formação de bolhas em regimes de baixa vazão de ar [Piassi, 2002].

O mapa do círculo bidimensional pode ser obtido da equação de movimento de um rotor periodicamente forçado por uma força externa [Argyris, 1994],

$$
\begin{aligned}
& \theta_{n+1}=\theta_{n}+\Omega-\frac{K}{2 \pi} \operatorname{sen}\left(2 \pi \theta_{n}\right)+b r_{n} \\
& r_{n+1}=b r_{n}-\frac{K}{2 \pi} \operatorname{sen}\left(2 \pi \theta_{n}\right),
\end{aligned}
$$




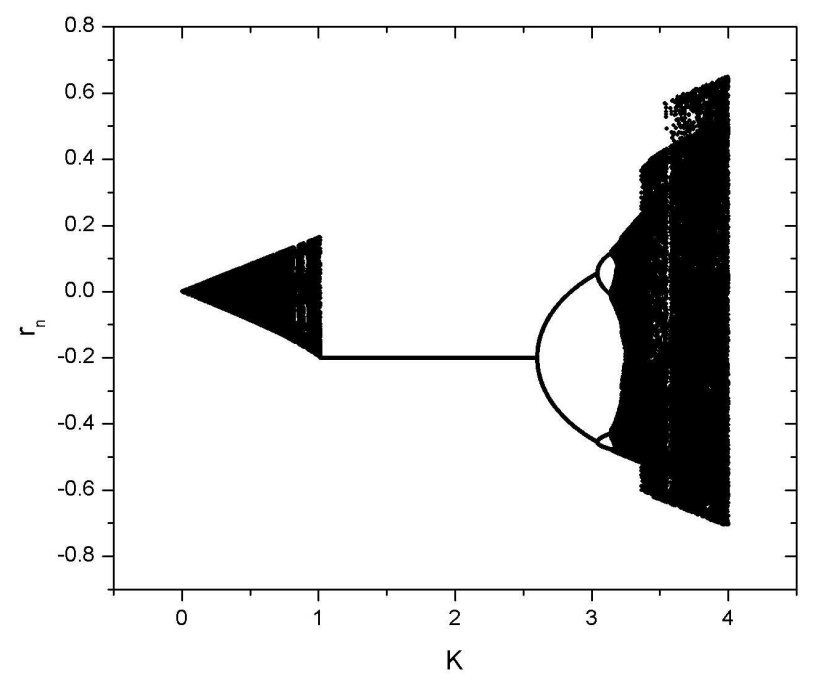

Figura 2.8: Diagrama de bifurcação $r_{n}$ vs. $K$ do mapa do círculo sendo $\Omega=5,2$ $(\bmod 1)=0,2$ e $b=0,2$. Em $K=0$, observa-se uma bifurcação tipo Hopf onde um ponto fixo estável deixa de existir dando origem a uma família de órbitas quase periódicas [Sartorelli et al., 1994].

onde $\theta_{n}$ é o ângulo de rotação imediatamente anterior ao $n$-ésimo forçamento e $r_{n}$ é proporcional à velocidade angular correspondente. Se interpretarmos $\theta_{n}$ e $r_{n}$ como coordenadas polares, podemos considerar a equação 2.11 a representação de um mapa do círculo dissipativo onde a constante $b$ regula o amortecimento e $K$ é uma medida para a intensidade do impulso externo não linear. Este sistema é equivalente a dois osciladores acoplados e os parâmetros $K$ e $\Omega$ representam a intensidade de acoplamento e a relação entre as freqüências dos osciladores, respectivamente.

Se olharmos apenas a variável $r$ do mapa do círculo podemos analisar o sistema por meio da série $\left\{r_{1}, r_{2}, \ldots, r_{n}\right\}$ construindo diagramas de bifurcação $r_{n} v s . K$, como o da figura 2.8 e mapas de retorno $r_{n+1}$ vs. $r_{n}$. 


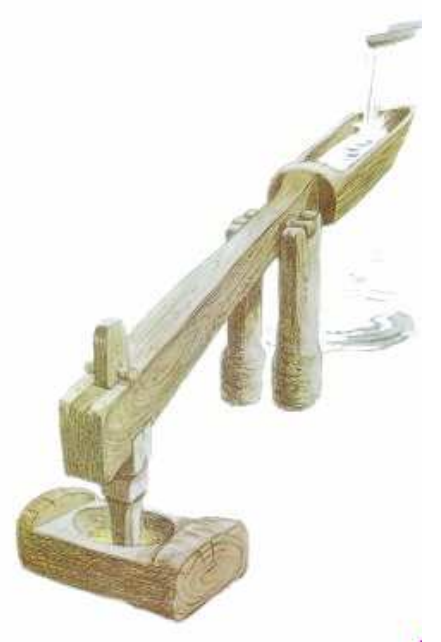

Figura 2.9: O monjolo é uma máquina rudimentar muito utilizada no Brasil colonial para a moenda de grãos, como o milho e o trigo. Seu funcionamento depende da água que enche o cocho elevando a haste com o pilão. Ao derramar a água o pilão cai socando o grão. Este mecanismo representa um modelo mecânico de um oscilador tipo integra-e-dispara.

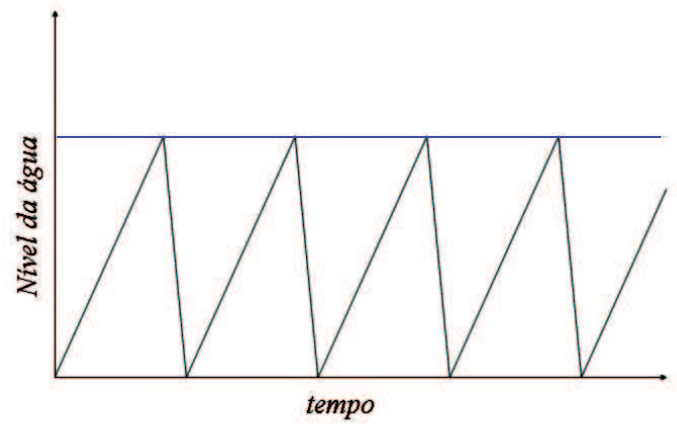

Figura 2.10: Evolução temporal do comportamento integra-e-dispara baseado no modelo de oscilador da figura 2.9. O nível de água no cocho aumenta até que ao alcançar um nível máximo diminui rapidamente, reiniciando o processo. 


\subsection{Dinâmica integra-e-dispara}

A dinâmica integra-e-dispara é usualmente associada a sistemas onde se observam disparos, como por exemplo bolhas se formando periodicamente. Este tipo de sistema apresenta duas escalas de tempo características, com intervalos de movimento lento, tempo de integração $T_{i}$, e rápido, tempo de disparo $T_{d}$, sendo $T_{i}>T_{d}$. No caso da formação de bolhas podemos associar o tempo de crescimento da bolha com o tempo de integração. O tempo de disparo neste caso é representado apenas pelo escape da bolha e tende a zero $T_{d} \rightarrow 0$.

Um exemplo simples desse tipo de oscilador é o monjolo, figura 2.9, instrumento utilizado por muito tempo na moenda de grãos como milho e trigo. Esse mecanismo é composto por um tronco de madeira acoplado a um eixo horizontal. Em um de seus braços temos o sistema pilador e no outro um cocho preenchido continuamente por um fluxo de água. O volume de água no cocho atinge um limiar onde o torque devido ao cocho $\tau_{c}$ se torna igual ao torque do pilador, $\tau_{p}$. Nesse instante o cocho desce permitindo o rápido escoamento da água e reiniciando um novo ciclo.

A cada ciclo, o nível da água no cocho aumenta e diminui em uma oscilação com dois tempos característicos. O tempo que o cocho leva até ser preenchido e o tempo de esvaziamento do cocho. A figura 2.10 mostra o nível de água no cocho ao longo do tempo considerando que o aumento e também a diminuição do nível de água sejam lineares.

Além de tornar o tempo de disparo tendendo a zero uma outra alteração possível a ser feita neste tipo de sistema é a criação de um tempo de nucleação, onde o sistema permanece no nível zero antes de iniciar a integração. Se colocarmos uma função periódica como limiar para o disparo é possível obter mapas descontínuos que modelam alguns tipos de comportamento observados em experimentos com bolhas de ar [Liger-Belair, 2005]. 


\subsection{Formação de bolhas em líquidos.}

Apesar da formação de bolhas de ar ser um fenômeno bastante comum sua dinâmica não é nada simples e usualmente utilizam-se modelos fenomenológicos para compreendê-la. Os modelos existentes para formação de bolhas são adequados apenas para casos particulares. Para a formação das bolhas à vazão baixa e constante, Davidson [Davidson et al., 1960] apresenta um modelo que supõe que:

1. a bolha se forma mantendo o formato esférico;

2. o líquido em torno da bolha está em repouso, ou seja, a circulação do líquido é desprezível;

3. o movimento de uma bolha não é afetado pela bolha anterior a ela;

4. a bolha se destaca ao atingir um raio máximo $R$;

5. a bolha se move, todo o tempo, com a velocidade de Stokes apropriada a seu tamanho.

Assim, o movimento do centro de massa de uma bolha que se forma longe das paredes de um reservatório com as condições acima, apresenta velocidade $v$ com valor dado pela equação:

$$
v=\frac{2 r^{2} g}{9 \nu}
$$

onde $r$ é o raio da bolha, $g$ a aceleração da gravidade e $\nu$ a razão entre a viscosidade do líquido e sua densidade. A relação entre o volume $V$ da bolha e o fluxo $Q$ de gás nos permite escrever:

$$
V=Q t=\frac{4 \pi r^{3}}{3}
$$

Levando em conta que durante a formação da bolha, a velocidade $v$ corresponde à velocidade de crescimento radial, rescrevemos a equação 2.12 substituindo $\mathrm{r}$ obtido pela equação 2.13 :

$$
\frac{d r}{d t}=\frac{2 g}{9 \nu}\left(\frac{3 Q}{4 \pi}\right)^{\frac{2}{3}} t^{\frac{2}{3}}
$$

integrando $r$ de 0 a $R$, o valor máximo do raio da bolha, e $t$ entre 0 e $T$, o tempo de formação da bolha temos: 


$$
T=\left(\frac{15 \nu R}{2 g}\right)^{\frac{3}{5}}\left(\frac{4 \pi}{3 Q}\right)^{\frac{2}{5}}
$$

onde $R$ representa o raio máximo alcançado pela bolha ao se desprender. Podemos então perceber que a relação entre o tempo de formação de bolhas $T$ e o fluxo $Q$, ou vazão volumétrica de ar é hiperbólico.

Para vazão de ar mais alta, as cinco condições acima não são aplicáveis e o comportamento do sistema, isto é $T(Q)$ da equação 2.15 , pode ser diferente. É necessário, então, analisar um número maior de parâmetros como no modelo apresentado por Zhang e Shoji [Zhang e Shoji, 2001]. As forças consideradas nesse modelo são:

\begin{tabular}{|c|c|}
\hline Empuxo & $F_{E}=V\left(\rho_{l i q}-\rho_{\text {gas }}\right) g$ \\
\hline Momento do Fluxo de gás & $F_{M}=\rho_{g a s} \frac{Q^{2}}{\pi R_{b}^{2}}$ \\
\hline Força de Tensão Superficial & $F_{\sigma}=2 \pi R_{b} \sigma$ \\
\hline Força de massa adicional & $F_{I}=\left(\rho_{g a s}+\frac{11}{16} \rho_{l i q}\right) \frac{d}{d t}\left(V \frac{d s}{d t}\right)$ \\
\hline Força de arrasto & $F_{D}=\frac{1}{2} \rho_{l i q} \pi r^{2} C_{D}\left(\frac{d s}{d t}-v_{w}\right)\left|\frac{d s}{d t}-v_{w}\right|$ \\
\hline
\end{tabular}

onde $\rho_{l i q}$ e $\rho_{\text {gas }}$ são as densidades do líquido e do gás, respectivamente; $\sigma$ é o coeficiente de tensão superficial; $s$ a posição do centro da bolha em relação ao bico; $C_{D}$ é a constante de arraste; e a velocidade média $v_{w}$ que vem da força de arrasto causada pela subida da bolha anterior.

Durante a formação de uma bolha, em um bico com raio $R_{b}$ e fluxo constante $Q$, temos a seguinte relação:

$$
F_{E}+F_{M} \geq F_{\sigma}+F_{I}+F_{D}
$$

de modo que a velocidade da bolha é igual a velocidade de crescimento radial. $\mathrm{Na}$ fase seguinte, a bolha deixa o orifício mas permanece presa por um menisco que aumenta com o tempo, nesse estágio temos:

$$
F_{E}+F_{M}=F_{\sigma}+F_{I}+F_{D}
$$


O menisco da bolha colapsa quando seu comprimento se torna maior ou igual ao diâmetro do bico:

$$
l=2 R_{b}
$$

Substituindo as equações 2.13 e 2.14 no conjunto de equações 2.16 podemos escrever a resultante das forças atuantes na bolha durante sua formação:

$$
\text { Resultante }=A+B t-C t^{-\frac{2}{3}}
$$

onde $A$ é a soma das forças de momento do gás e de tensão superficial, $A=$ $F_{M}+F_{\sigma}, B$ vem da força de empuxo, $B=\left(\rho_{l i q}-\rho_{g a s}\right) g Q$, sendo $g$ a aceleração gravitacionale. A constante $C$ engloba constantes obtidas da força de massa adicional e da força de arrasto e depende da velocidade $v_{a n t}$ com que se formou a bolha anterior,

$$
C=18,5 \frac{\rho_{l i q} \pi}{2}\left(\frac{3 Q}{4 \pi}\right)^{1 / 3}\left(\frac{3 \mu}{2 \rho_{l i q}}\right)^{3 / 5}\left(\frac{4 \pi}{3 Q}\right)^{2 / 5}\left[\left(\frac{9 \mu}{2 g \rho_{l i q}}\right)^{2 / 3} v_{\text {ant }} 4 / 3-\frac{1}{9}\left(\frac{3 Q}{4 \pi}\right)^{2 / 3}\right]
$$

Quando esta função resultante apresenta valores acima de zero a bolha é puxada para cima provocando seu escape do bico.

\subsection{Mapas descontínuos}

Tomemos como exemplo de mapa descontínuo a função linear por partes

$$
P(x)= \begin{cases}0,5+0.6 x & \text { se } x<0 \\ -0,5-0.4 x & \text { se } x \geq 0\end{cases}
$$

criando o mapa $P_{\phi}(x)$ dado por:

$$
P_{\phi}(x)=-\phi+P(x)
$$

onde $\phi$ é um parâmetro de controle que corresponde ao deslocamento vertical de $P(x)$ 
A figura 2.11 mostra essa função ressaltando em detalhe a região invariante, ou seja, a região para a qual o sistema evolui, dada qualquer condição inicial $x_{0}$. A primeira iterada do máximo valor de $P_{\phi}$ define o limite máximo da região invariante, $X_{M A X}$. No caso do mapa 2.23 o máximo se dá para $x=-\epsilon \operatorname{com} \epsilon$ tendendo a zero. Assim,

$$
X_{M A X}=\lim _{\epsilon \rightarrow 0}\left(P_{\phi}(-\epsilon)\right)=-\phi+0,5 .
$$

Iterando $X_{M A X}$ obtemos o limite inferior da região invariante,

$$
X_{M I N}=P_{\phi}\left(X_{M A X}\right)=-\phi-0,7
$$

A dinâmica dentro dessa região invariante é melhor compreendida através do estudo das iteradas de um intervalo menor $\Delta$ escolhido como sendo o ramo à direita da descontinuidade, ou seja, onde $0 \leq x \leq X_{M A X}$. Para $\phi=0$ o intervalo $\Delta$ é o maior possível. Aumentando o valor de $\phi$ o intervalo $\Delta$ diminui tendendo a zero quando $\phi$ tende a 0,5 .

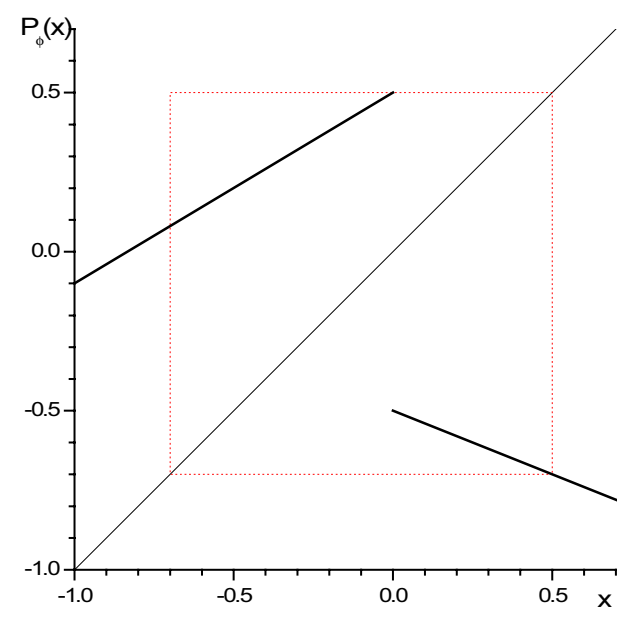

Figura 2.11: Mapa $2.23 \operatorname{com} \phi=0$. O retângulo vermelho indica a região invariante onde $-0,7 \leq x \leq 0,5$.

A figura 2.12(a) mostra graficamente duas iteradas sucessivas do mapa 2.23 para $\phi=0$. 
Como o módulo da derivada da função 2.23 é sempre menor que 1, o intervalo $\Delta$ sofre um encolhimento a cada iterada. Como as derivadas à esquerda e à direita da descontinuidade tem sinais diferentes, observamos também uma inversão.

Este comportamento também pode ser percebido na figura 2.12(b) que mostra a função de retorno desse intervalo $\Delta$. Podemos notar que nem todo o intervalo $\Delta$ é visitado pela função de retorno (encolhimento) e que a derivada da função é negativa (inversão). O cruzamento com a diagonal indica a existência de um ponto fixo de período 2 .

Evolução equivalente à mostrada para $\phi=0$ foi feita para $\phi=0,1$ e $\phi=0,25$. A figura 2.13 mostra as funções de retorno para estes dois valores de $\phi$.

Para $\phi=0,1$, figura 2.13(a), parte do intervalo $\Delta$ necessita de mais uma iterada para retornar ao lado direito da descontinuidade. Dessa maneira, o que vemos na função de retorno são dois ramos, ambos cruzando a diagonal. O ramo à esquerda indica a existência ainda da órbita de período 2 e o ramo à direita indica a existência de uma órbita de período 3. Neste caso as duas órbitas coexistem caracterizando o que chamamos de biestabilidade.

Quando $\phi=0,25$, figura 2.13(b) todo o intervalo $\Delta$ necessita de 3 iteradas para retornar e a função de retorno do intervalo mostra novamente apenas um ramo que cruza a diagonal identificando uma órbita de período 3.

Aumentando mais o parâmetro $\phi$ surgem órbitas de períodos maiores ao mesmo tempo que o intervalo $\Delta$ vai diminuindo. Este aumento na periodicidade caracteriza uma rota de adição de período. 

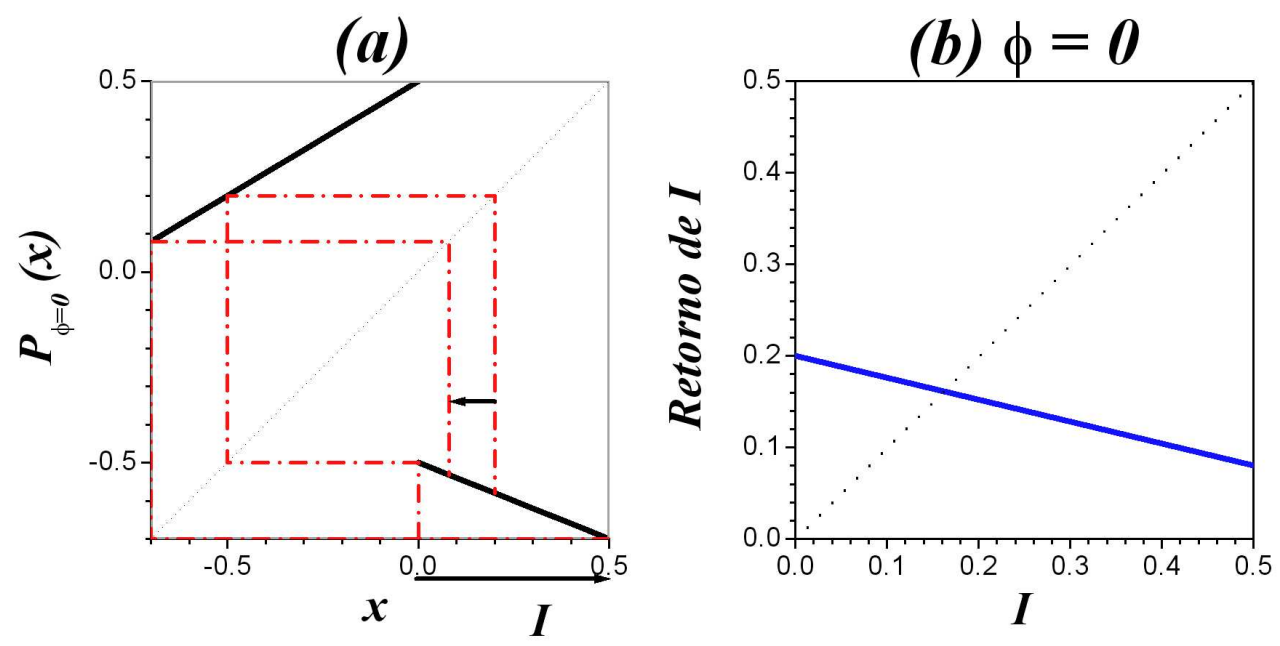

Figura 2.12: Em (a) o mapa $P_{\phi}$ para $\phi=0$ dentro do intervalo invariante e duas iteradas consecutivas do intervalo $\Delta$ definido para $0 \leq x \leq 0,5$. Em (b) a funcção de retorno do intervalo $\Delta$ para $\phi=0$ mostra a inversão do intervalo e seu encolhimento.
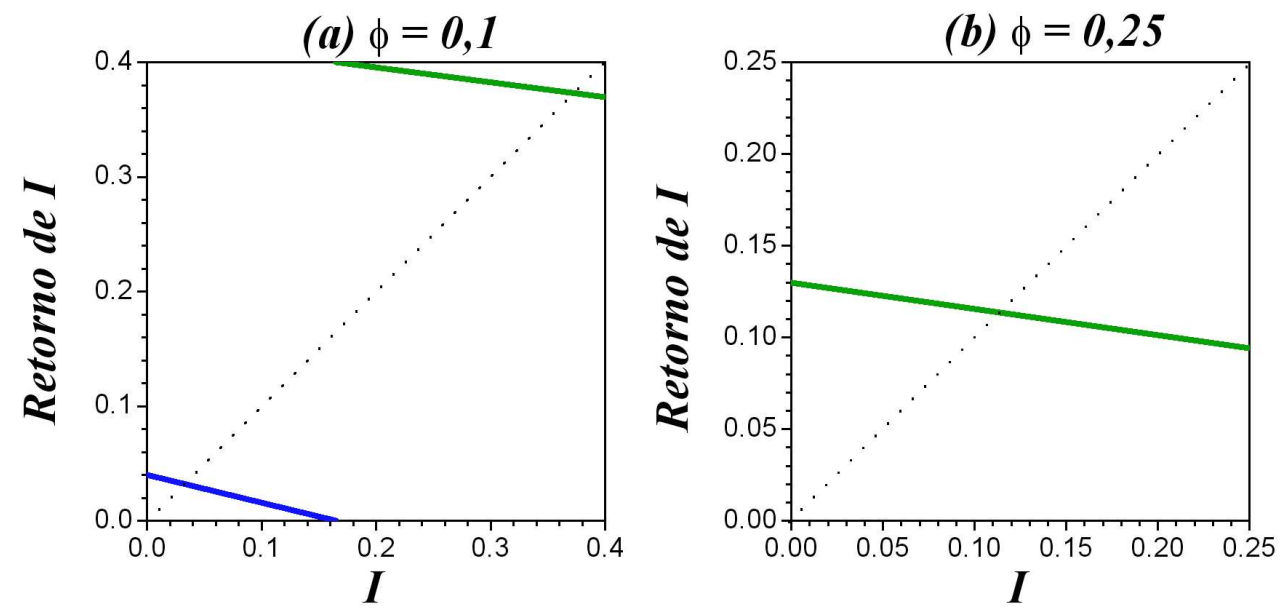

Figura 2.13: Função de retorno do intervalo $\Delta$. Em (a), para $\phi=0,1$ temos $\Delta$ definido como $0 \leq x \leq 0,4$, neste caso parte do intervalo retorna após 2 iteradas (azul) e parte necessita de 3 iteradas para retornar (verde). Em (b), $\phi=0,25$ e $\Delta$ está definido como $0 \leq x \leq 0,25$, aqui todo o intervalo retorna após 3 iteradas. 


\section{Capítulo 3}

\section{Aparato Experimental}

A figura 3.1 mostra uma representação do aparato experimental que consiste de um tubo de acrílico, com $11.0 \mathrm{~cm}$ de diâmetro e $70 \mathrm{~cm}$ de altura, aberto na parte superior e fechado na base por uma tampa de PVC. Nesse tubo colocamos uma solução de 1 parte de água e 4 partes de glicerina.

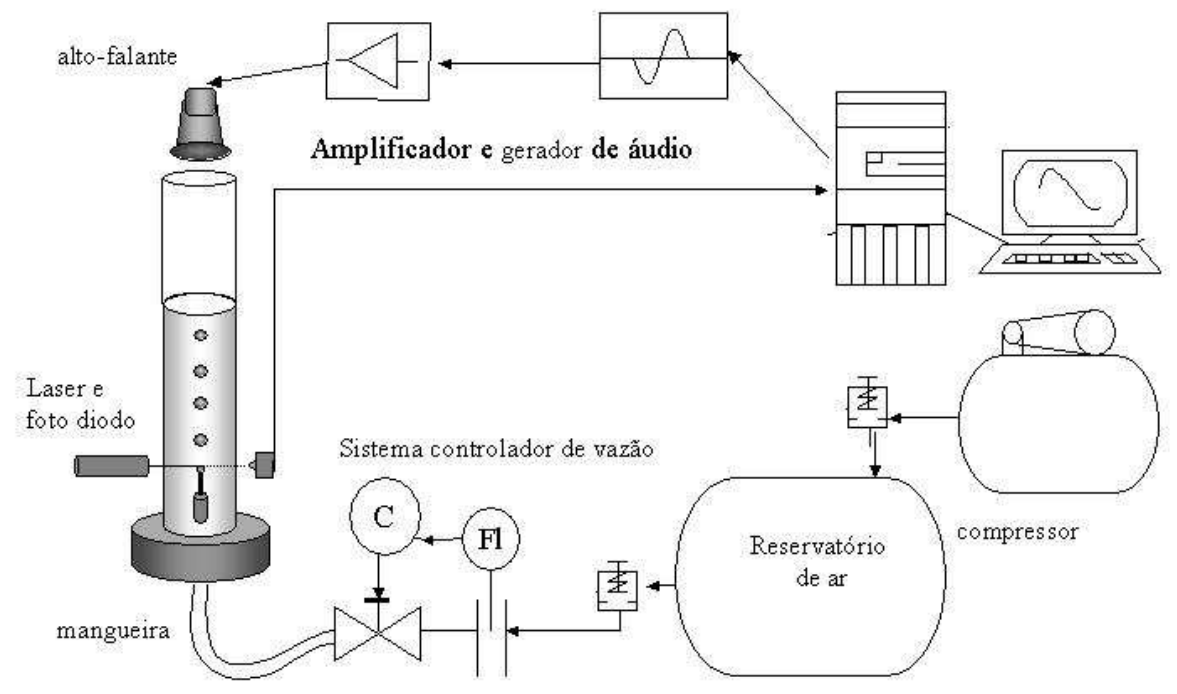

Figura 3.1: Esquema representando o aparato experimental original.

Na base de PVC existem conexões para a entrada e o escoamento da solução. 
Uma seringa hipodérmica fixa no centro da base constitui a parte principal do bico borbulhador. Uma agulha de $37 \mathrm{~mm}$ de comprimento e $0,72 \mathrm{~mm}$ de diâmetro interno também é conectada à seringa completando o bico borbulhador.

\subsection{Sistema Pneumático}

O sistema pneumático consiste em um compressor de ar conectado a um reservatório que fornece ar ao sistema de controle de vazão. O compressor tem um reservatório de 75 litros de capacidade e está calibrado para manter a pressão entre $0,5 \mathrm{MPa}(70 \mathrm{psi})$ e $0,8 \mathrm{MPa}(100 \mathrm{psi})$. Dois filtros de ar foram colocados na saída do compressor para garantir a qualidade do ar enviado para o reservatório; o primeiro filtro é responsável por reter a água enquanto o segundo filtro, coalescente, retém o oleo evaporado do compressor. O reservatório capacitivo tem capacidade para 200 litros de ar e está regulado para uma pressão de 0,4 MPa (60 psi). A saída de ar do reservatório está conectada a uma válvula controladora de pressão calibrada para $70 \mathrm{kPa}(10 \mathrm{psi})$ que envia o ar diretamente ao sistema controlador de vazão.

A conexão entre o sistema controlador e o bico borbulhador é feita com uma mangueira flexível com diâmetro interno de $3 \mathrm{~mm}$. Utilizamos neste trabalho oito mangueiras com comprimentos diferentes, sendo a menor de $10 \mathrm{~cm}$ e a maior de 300 $\mathrm{cm}$ de comprimento. A finalidade foi identificar com mais detalhe o surgimento de bifurcações de adição de período em função do comprimento da mangueira conectora.

\subsection{Sistema de controle da vazão}

O sistema de controle de vazão consiste de um medidor de vazão AALBORG Instruments $\&$ Controls conectado a um controlador BTC que controla uma válvula solenóide PSV5 AALBORG Instruments \& Controls.

O funcionamento do medidor de vazão é através do aquecimento de uma pe- 
quena parte do fluxo de ar separada por um tubo capilar de aço inoxidável, mantendo a proporcionalidade entre o ar que passa por esse capilar e o tubo primário. É possível determinar a vazão de ar através desse tubo medindo o gradiente de temperatura nele.

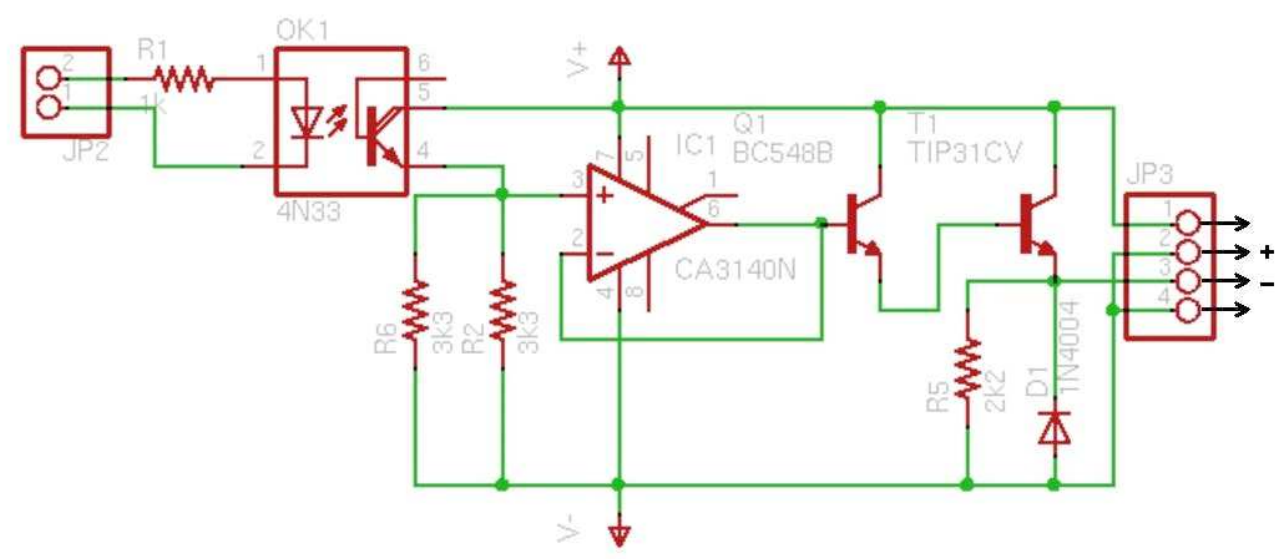

Figura 3.2: Amplificador da corrente gerada pelo controlador de vazão.

O controlador de vazão é do tipo proporcional, integral e diferencial (PID). Ele recebe um sinal de corrente enviado pelo medidor de vazão e envia uma resposta de controle para a válvula solenóide. Com esse controlador podemos manter a vazão de ar constante e alterar a vazão linearmente utilizando o gerador de rampa. A corrente gerada pelo controlador é amplificada pelo um circuito mostrado na figura 3.2 antes de ser enviada para a válvula solenóide.

\subsection{Sistema de Aquisição}

Logo acima do bico borbulhador temos um laser focalizado em um fotodiodo. Eles estão dispostos em lados opostos à coluna de bolhas, o que permite medir o tempo entre as bolhas formadas no bico. Conforme mostra a figura 3.3(a), o fotodiodo conduz apenas quando é iluminado pelo laser e uma tensão de $5 \mathrm{~V}$ 
aparece sobre o resistor R. O feixe de laser é espalhado quando uma bolha começa a cruzá-lo, escurecendo assim o fotodiodo que deixa de conduzir até a passagem ser completada. Dessa maneira podemos medir os pulsos induzidos sobre o resistor $\mathrm{R}$ detectando as transições claro/escuro indicadas na figura 3.3(b), com uma placa contadora de resolução de $1 \mu \mathrm{s}$ [Pinto, 1999]

(a)

(b)

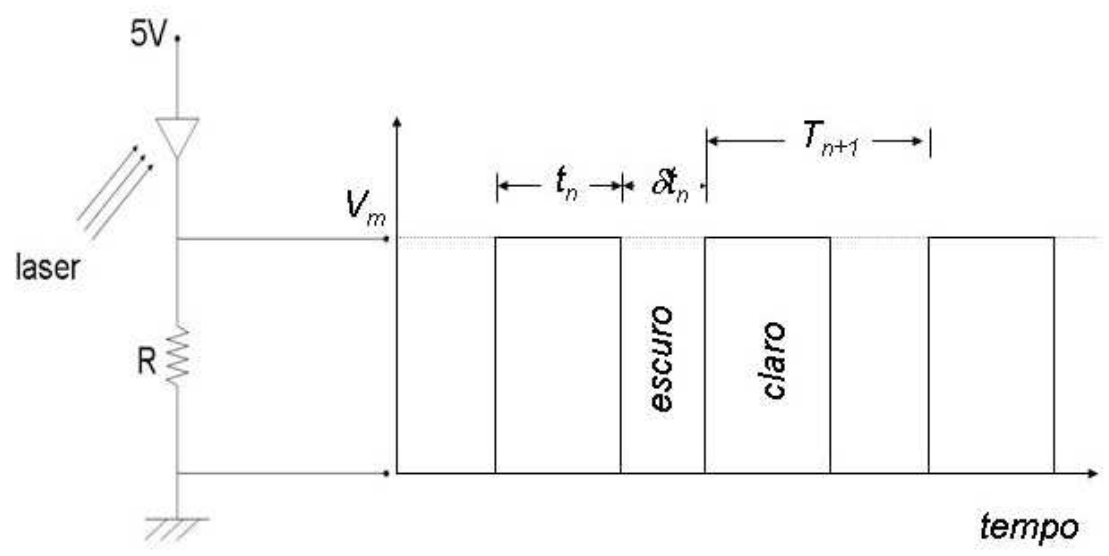

Figura 3.3: (a) Circuito com fotodiodo receptor. Quando o fotodiodo é iluminado pelo laser uma corrente passa pelo circuito de modo que uma tensão $V_{m}$ é enviada para o computador. (b) Enquanto o fotodiodo permanece iluminado registramos o tempo $t_{n}$, com o laser espalhado não há condução e portanto $V_{m}=0$ e registramos o tempo $\delta t_{n}$. Com uma placa contadora inserida no computador registramos o tempo $T_{n}=t_{n}+\delta t_{n}$ a partir do sinal registrado no fotodiodo.

A medida de tempo entre duas bolhas subsequentes $\left(T_{n}\right)$ é feita considerando a soma de dois intervalos de tempo medidos. Primeiro o tempo $\delta t$ que a bolha leva para cruzar o feixe de laser e depois o tempo $t$ que o fotodiodo permanece iluminado até sua interrupção pela próxima bolha.

A dinâmica é caracterizada com a construção de mapas de primeiro retorno $T_{n+1} v s . T_{n}$ e diagramas de bifurcações $T_{n} v s$. $p$ onde $p$ é um parâmetro de controle que pode ser a vazão de ar ou a amplitude da perturbação. 


\subsection{Perturbação do sistema}

Aplicamos uma perturbação controlada utilizando um gerador de funções Tektronix AFG320 acoplado a um amplificador de áudio Aiwa, que envia um sinal a um altofalante de bobina móvel colocado no topo do tubo. A freqüência sonora foi sintonizada em $135 \mathrm{~Hz}$ que é freqüência de ressonância do tubo.

Medimos a amplitude da onda sonora dentro do tubo borbulhador a $20 \mathrm{~cm}$ da superfície do líquido em função da amplitude fornecida pelo gerador de funções. O microfone de teste está indicado no esquema do aparato experimental da figura 3.1. A relação linear entre os dois sinais mostrada pela figura 3.4 justifica a utilização da própria amplitude fornecida pelo gerador como medida de parâmetro de controle da perturbação.

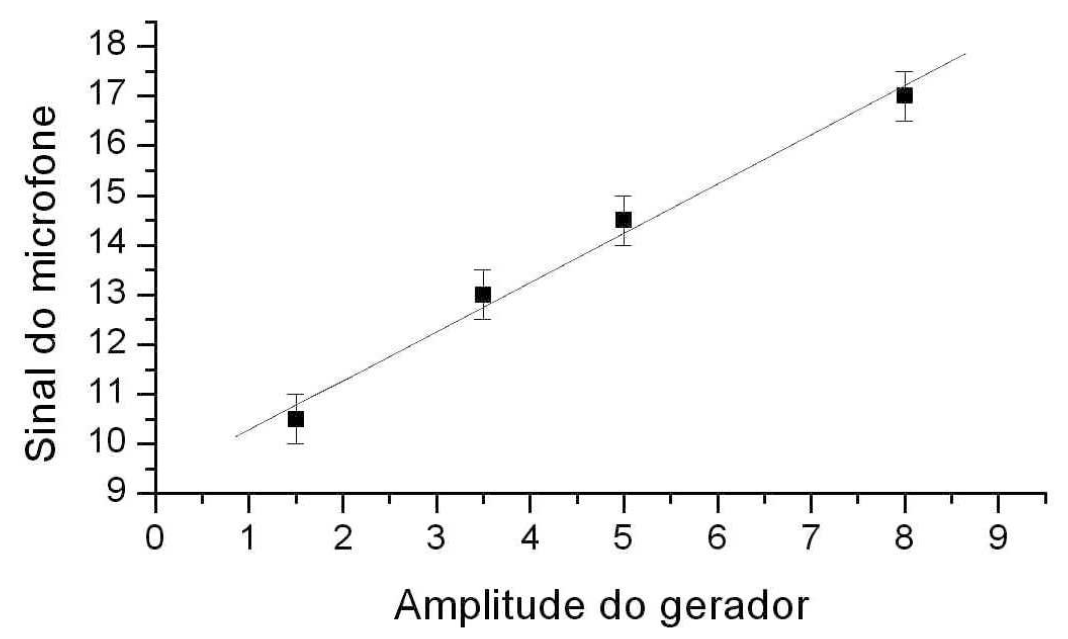

Figura 3.4: Sinal do microfone vs. Amplitude do gerador de funções. 


\section{Capítulo 4}

\section{Resultados e Discussões}

\subsection{Bolha de Bifurcação e Adição de Período}

Estudamos o tempo entre bolhas $\left(T_{n}\right)$ tomando a vazão de ar como parâmetro de controle. Para analisar a variação do efeito dissipativo da mangueira conectora, vide figura 3.1, utilizamos mangueiras de oito comprimentos diferentes.

Para cada comprimento de mangueira obtivémos séries temporais variando a vazão contínua e vagarosamente, e construímos diagrams de bifurcação $\left(T_{n}\right.$ vs.vazão). Também obtivémos algumas séries temporais a vazão constante para a construção de diagramas de primeiro retorno $T_{n+1}$ vs. $T_{n}$.

\subsubsection{Diagramas de Bifurcação}

A figura 4.1 e 4.2 temos diagramas de bifurcação obtidos com diferentes comprimentos de mangueira. Na figura 4.1(a) mostramos um diagrama de bifurcação $T_{n}$ vs.vazão obtido com a menor mangueira, de $10 \mathrm{~cm}$ de comprimento. Como podemos ver o tempo entre bolhas decai em função da vazão porém observamos uma inflexão em torno do valor de $90 \mathrm{ml} / \mathrm{min}$.

A figura 4.1(b) mostra o comportamento do sistema com a mangueira de $50 \mathrm{~cm}$ de comprimento. Inicialmente o borbulhamento se dá em período 1, quando atinge a vazão de $71 \mathrm{ml} / \mathrm{min}$ ocorre uma bifurcação para período 2 e para $83 \mathrm{ml} / \mathrm{min}$ 


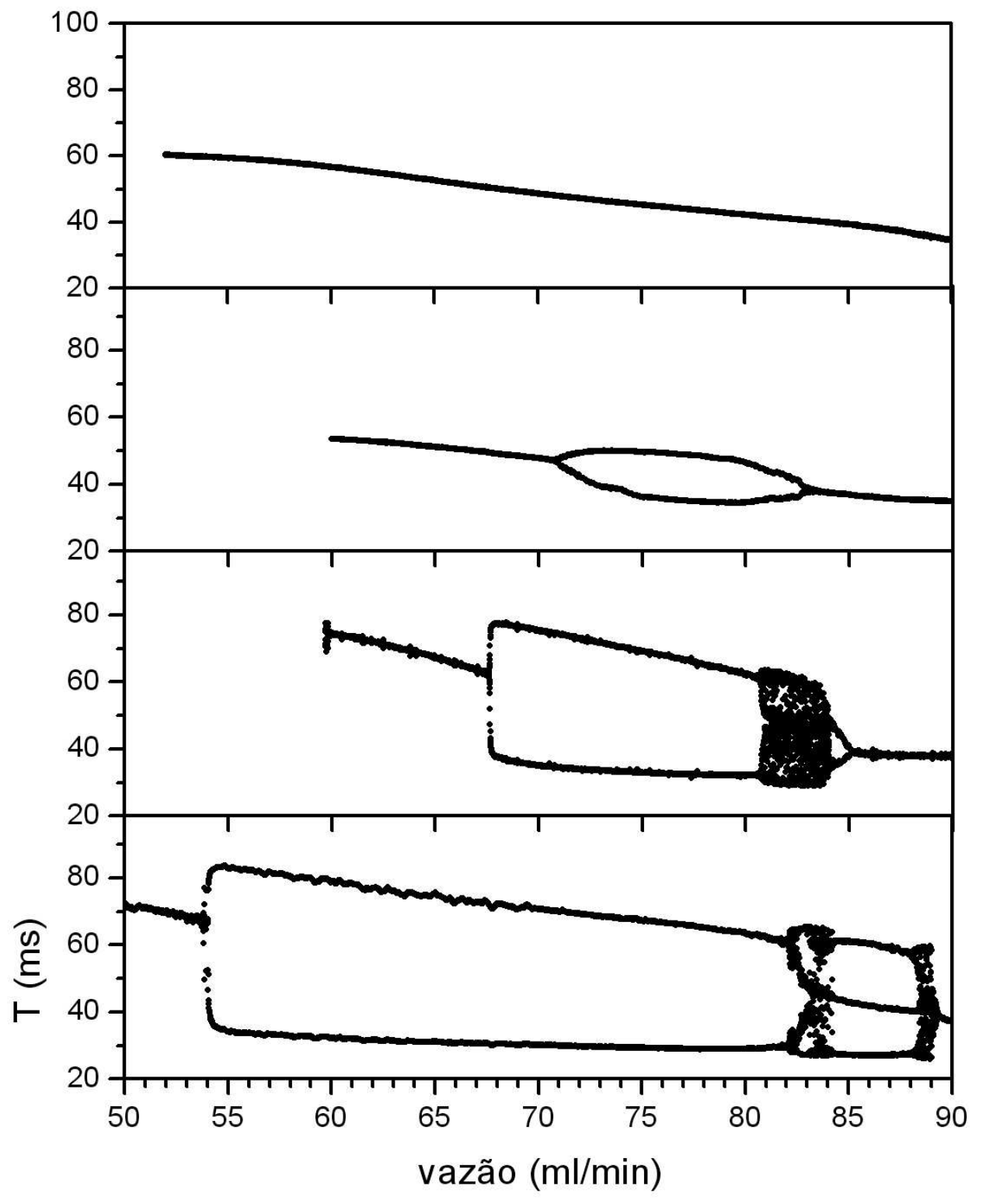

Figura 4.1: Diagramas de bifurcação, $T_{n}$ vs.vazão, para mangueira com comprimento (a) $10 \mathrm{~cm} 20$, (b) $50 \mathrm{~cm}$, (c) $130 \mathrm{~cm}$ e (d) $140 \mathrm{~cm}$. 
observamos uma bifurcação inversa, voltando o borbulhamento para período 1. Este tipo de estrutura onde observamos período 1 seguido de multiperíodos e depois retornando ao período 1 chamamos de bolha de bifurcação.

Com a mangueira de $130 \mathrm{~cm}$, figura 4.1(c), observamos uma bolha de bifurcação que além do borbulhamento periódico apresenta comportamento caótico entre duas janelas com período 2 .

A figura 4.1(d) mostra um diagrama de bifurcação ( $T_{n}$ vs.vazão) obtido com a mangueira conectora de $140 \mathrm{~cm}$ de comprimento. Com o aumento da vazão, observamos bifurcação de período 1 para período 2 (vazão= $71 \mathrm{ml} / \mathrm{min})$ e em torno de $88 \mathrm{ml} / \mathrm{min}$ observamos rotas de duplicações de período em cada ramo, levando a comportamento caótico. Com vazão igual a $92 \mathrm{ml} / \mathrm{min}$ observamos o surgimento de uma janela de período 3, com vazão próxima a $94 \mathrm{ml} / \mathrm{min}$ observamos outra bifurcação levando a perído 2 e em seguida ao período 1.

Na figura 4.2(a) mostramos um diagrama de bifurcação ( $T_{n}$ vs.vazão $)$ para a mangueira de $190 \mathrm{~cm}$. Observamos uma bifurcação de período 1 para período 2 para vazão de $59 \mathrm{ml} / \mathrm{min}$. Para vazão de $94 \mathrm{ml} / \mathrm{min}$ observamos o surgimento de uma região caótica a partir de uma rota de duplicação de período e para 97,5 $\mathrm{ml} / \mathrm{min}$ surge novamente um período 2 e o retorno ao período 1 em torno de 100 $\mathrm{ml} / \mathrm{min}$.

A figura 4.2(b) mostra um diagrama de bifurcações obtido utilizando a mangueira de $200 \mathrm{~cm}$ de comprimento. Encontramos aqui a presença de uma bolha de bifurcação com o surgimento de um período $2 \mathrm{em} 52 \mathrm{ml} / \mathrm{min}$. Para vazão em torno de $86 \mathrm{ml} / \mathrm{min}$ temos uma bifurcação levando o sistema do período 2 para período 3 e para $96 \mathrm{ml} / \mathrm{min}$, com a presença de um transiente caótico o sistema retorna a um período 2 e posteriormente ao período 1 .

A figura 4.2(c) mostra um diagrama de bifurcação ( $T_{n}$ vs.vazão) obtido com a mangueira de $235 \mathrm{~cm}$. Para vazão de $65 \mathrm{ml} / \mathrm{min}$ mostrada na figura observamos período 2 e para $71 \mathrm{ml} / \mathrm{min}$ observamos o surgimento de um período 3 . Em torno de $88 \mathrm{ml} / \mathrm{min}$ surge uma região caótica que colapsa em período 2 para vazão igual a $94 \mathrm{ml} / \mathrm{min}$, em seguida temos o período 1 novamente. 


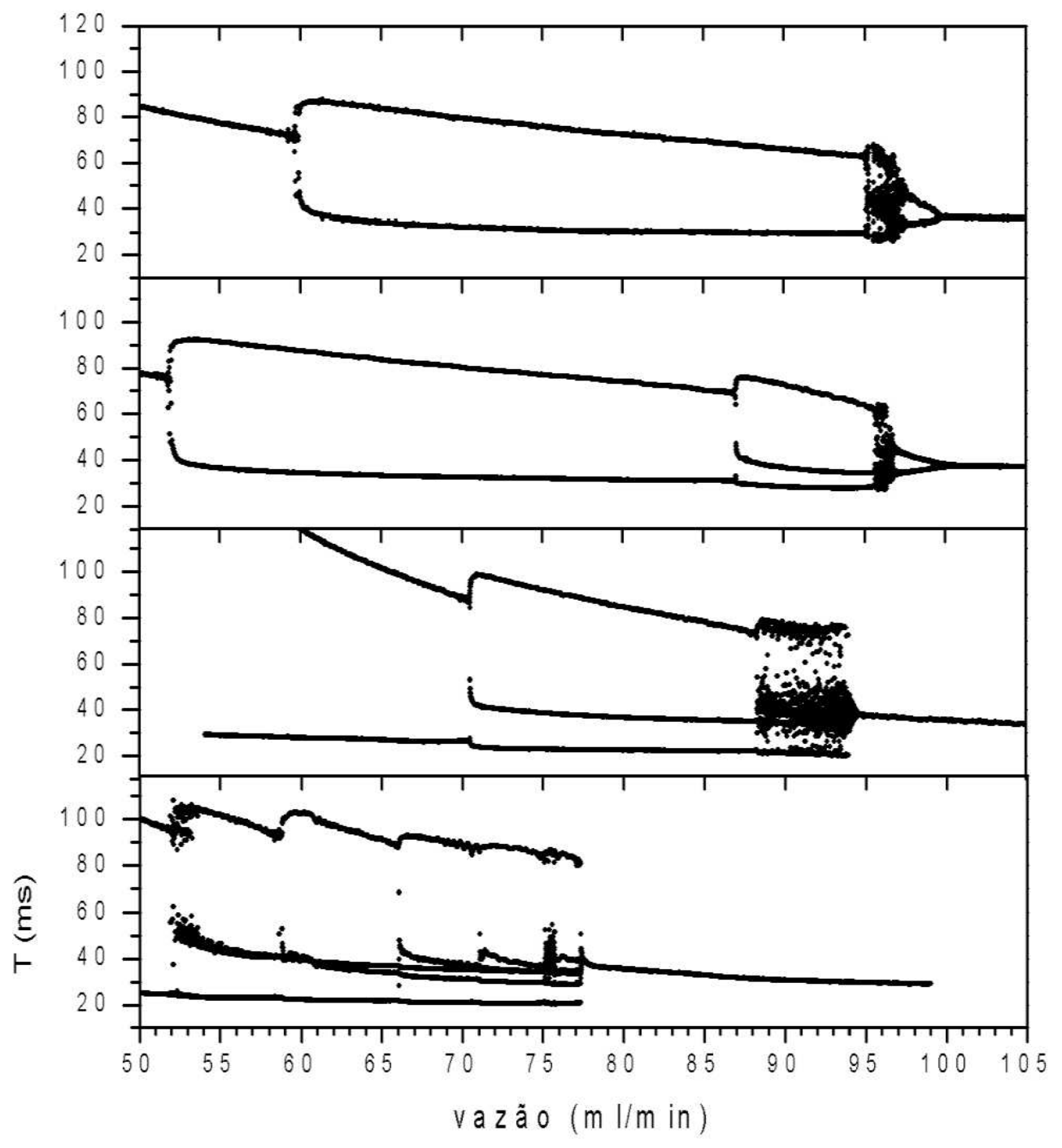

Figura 4.2: Diagramas de bifurcação, $T_{n}$ vs.vazão, para mangueira com comprimento (a) $190 \mathrm{~cm}$, (b) $200 \mathrm{~cm}$, (c) $235 \mathrm{~cm}$ e (d) $300 \mathrm{~cm}$. 
Com uma mangueira de comprimento maior, a influência do sistema pneumático se torna mais evidente. A figura 4.2(d) mostra o diagrama de bifurcações $T_{n}$ vs.vazão obtido com a mangueira de 300 cm. Observamos neste diagrama várias bifurcações, para vazão de $53 \mathrm{ml} / \mathrm{min}$ vemos uma bifurcação de período 2 para período 3, para $59 \mathrm{ml} / \mathrm{min}$, de período 3 para 4 , para $66 \mathrm{ml} / \mathrm{min}$ de período 4 para 5 , para 70,5 $\mathrm{ml} / \mathrm{min}$ de período 5 para 6 e para $75 \mathrm{ml} / \mathrm{min}$ de período 6 para 7 . O surgimento do período 1 característico ao final de todas as bolhas de bifurcação ocorre para a vazão de $77 \mathrm{ml} / \mathrm{min}$. Esta sequência de bifurcações caracteriza o que chamamos de rota de adição de período.

Uma maneira de analisar a seqüência de bifurcações observadas na figura 4.2(d) é calcular o número de rotação $r$ para cada valor de vazão, usando a série $\left\{T_{n}\right\}=$ $\left\{T_{1}, T_{2}, \ldots, T_{N}\right\}$. As partições $\left\{J_{n}\right\}$ atribuindo 0 para valores de $T_{n}>68 \mathrm{~ms}$ (ramo superior do diagrama da figura $4.2(\mathrm{~d})$ ) ou 1 para $T_{n}<68 \mathrm{~ms}$ (ramo inferior do diagrama). Isolamos assim o ramo superior do diagrama através do número de rotação $r$ :

$$
r=\lim _{N \rightarrow 50} \frac{\sum_{n=1}^{N} J_{n}}{N}
$$

A figura 4.3(a) mostra uma escada do diabo obtida para vazão de ar entre 80 e $140 \mathrm{ml} / \mathrm{min}$, utilizando a mangueira de $300 \mathrm{~cm}$. As janelas periódicas correspondem a estados ressonantes de borbulhamento com a formação de patamares para diferentes valores de número de rotação. Podemos notar que alguns patamares se sobrepõem, por exemplo na figura 4.3(b), com a ampliação para valores de vazão entre 51 e $55 \mathrm{ml} / \mathrm{min}$, podemos observar que o patamar 2:3 inicia antes do patamar 1:2 deixar de ser visitado caracterizando biestabilidade.

Como vimos na seção 2.9 sobre mapas descontínuos, as regiões de biestabilidade ocorrem devido ao surgimento de uma órbita estável de período $k+1$ antes do desaparecimento da órbita estável de período $k$, sendo estas as regiões de biestabilidade características de mapas descontínuos. 
(a)

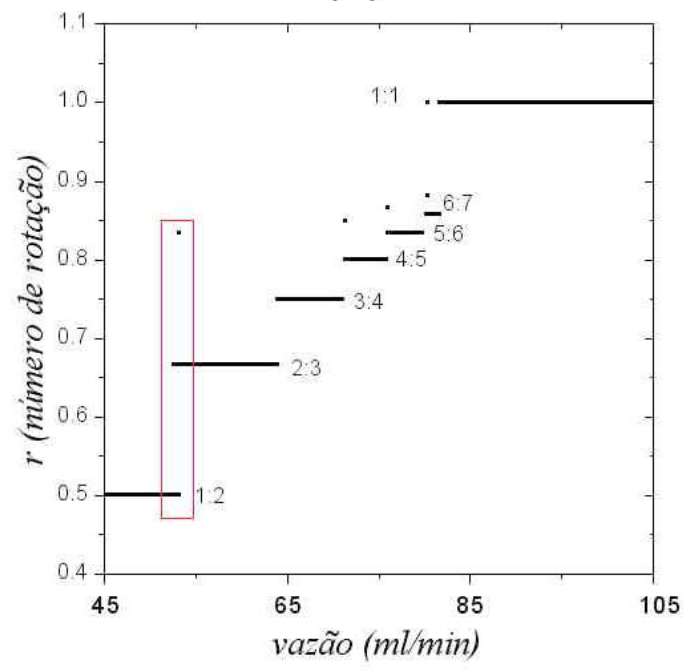

(b)

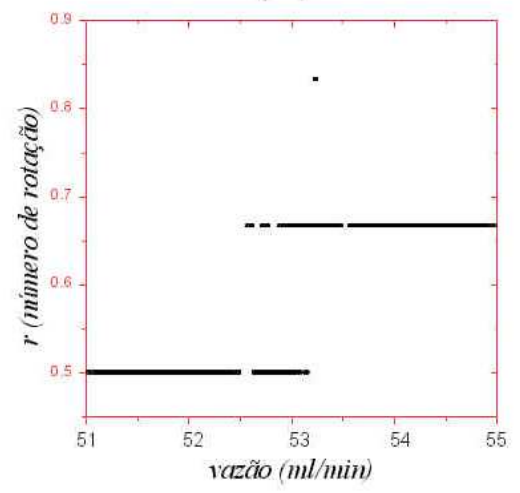

Figura 4.3: Número de rotação $r$ em função da vazão de ar. Em (a) para todo o intervalo de vazão tratado e em (b) ampliando a região de transição entre os patamares 1:2 e 2:3.

\subsubsection{Reconstruções de primeiro retorno}

A figura 4.4 mostra um diagrama de primeiro retorno $\left(T_{n+1}\right.$ vs. $\left.T_{n}\right)$ construído para vazão igual a $89 \mathrm{ml} / \mathrm{min}$ com a mangueira de $140 \mathrm{~cm}$. Este atrator foi analisado e serviu de base para a construção de um modelo para a formação de bolhas que apresentaremos mais adiante.

A figura 4.5 mostra uma reconstrução de primeiro retorno $\left(T_{n+1}\right.$ vs. $T_{n}$ para dados obtidos a vazão de $89 \mathrm{ml} / \mathrm{min}$ com a mangueira de $235 \mathrm{~cm}$ de comprimento. Esse atrator é qualitativamente diferente do apresentado na figura 4.4, para mangueira de $140 \mathrm{~cm}$, embora mantenha algumas similaridades. A comparação desses dois atratores será discutida juntamente com a construção de um modelo para formação de bolhas mais adiante.

$\mathrm{Na}$ figura 4.6 temos as reconstruções de primeiro retorno dos dados obtidos com vazão constante correspondentes a cada região periódica mostrada na figura 4.2(d). Esses atratores foram utilizados na busca de uma função unidimensional que pudesse representar a dinâmica da formação de bolhas que será apresentada 


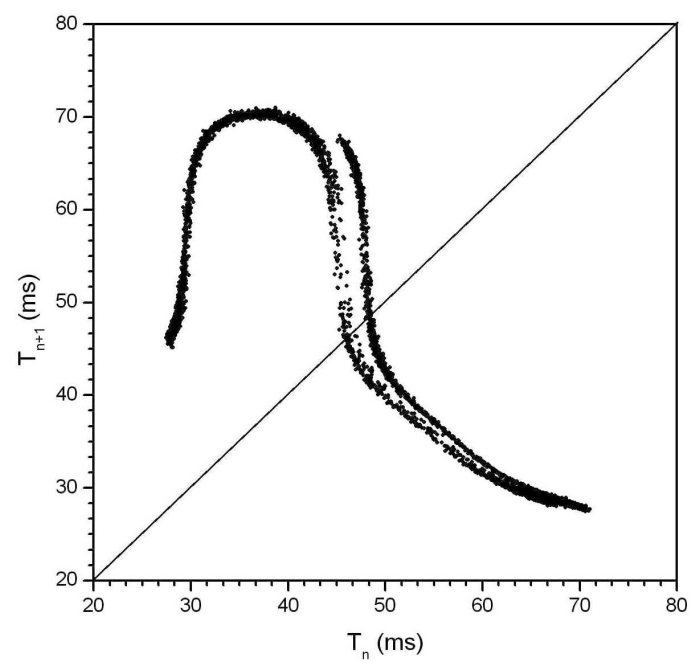

Figura 4.4: Reconstrução de primeiro retorno $T_{n+1} v s . T_{n}$ para mangueira com 140 cm de comprimento com a vazão de ar fixa em $89 \mathrm{ml} / \mathrm{min}$.

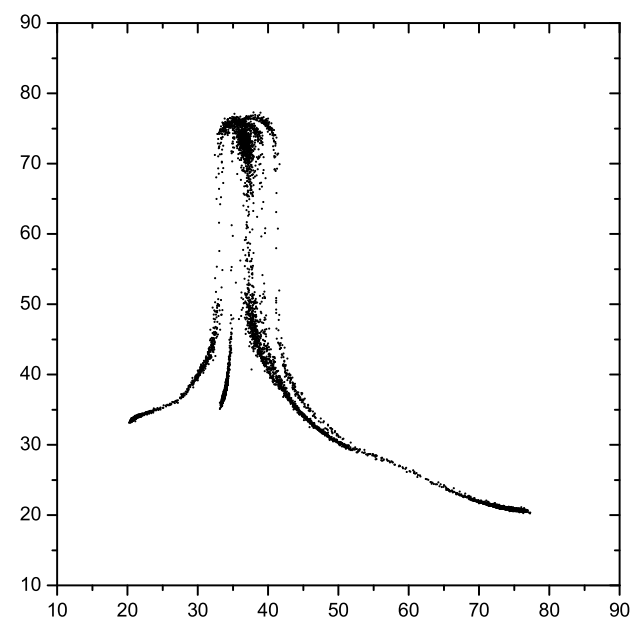

Figura 4.5: Reconstrução de primeiro retorno $T_{n+1}$ vs. $T_{n}$ para mangueira com 235 cm de comprimento com a vazão de ar fixa em $89 \mathrm{ml} / \mathrm{min}$ 


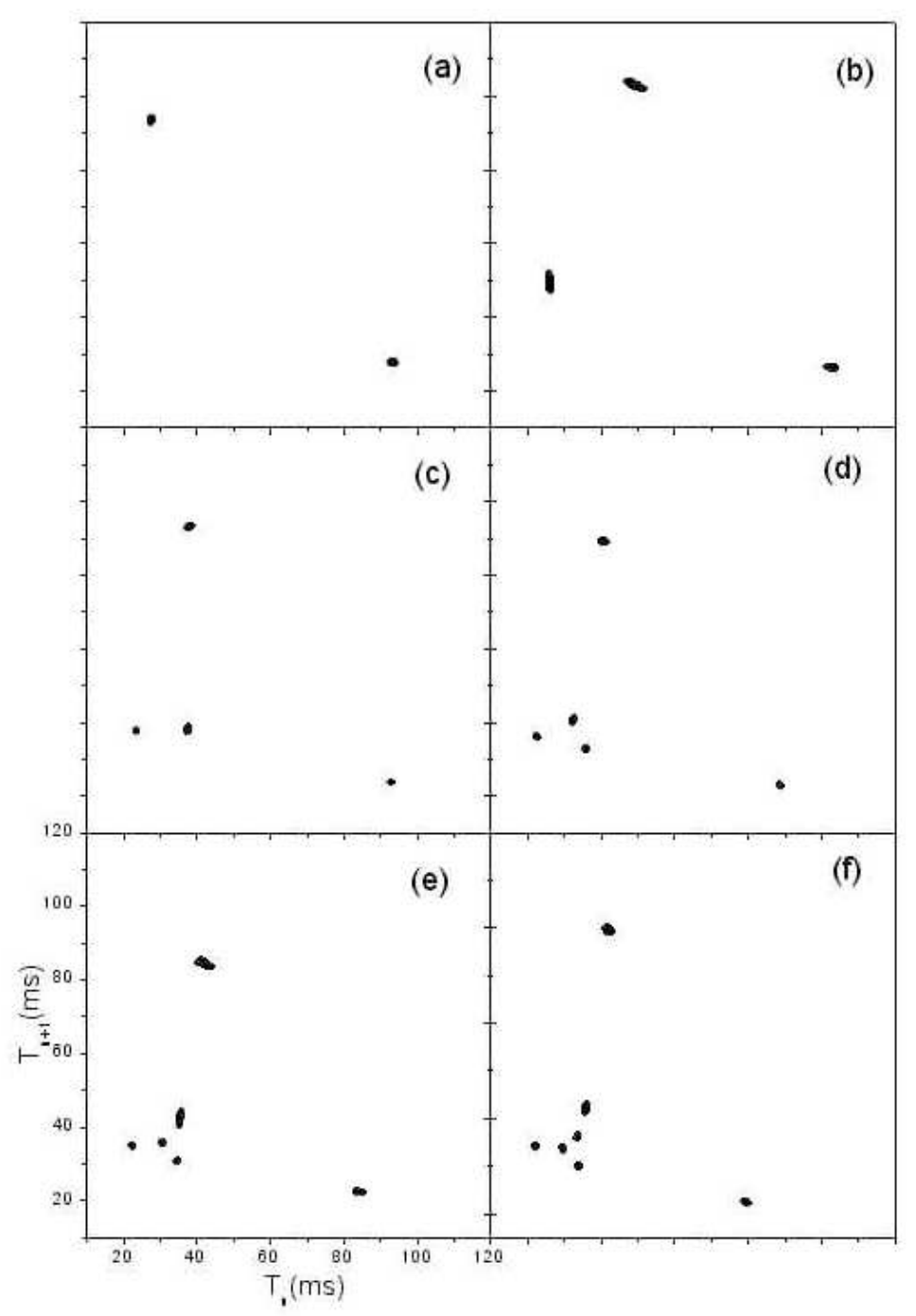

Figura 4.6: Reconstruções de primeiro retorno $T_{n+1}$ vs. $T_{n}$ para mangueira com $300 \mathrm{~cm}$ de comprimento obtidas a partir de séries temporais com valores de vazão de ar fixos em (a) $49 \mathrm{ml} / \mathrm{min}$ (período 2), (b) $55 \mathrm{ml} / \mathrm{min}$ (período 3), (c) $65 \mathrm{ml} / \mathrm{min}$ (período 4), (d) $70 \mathrm{ml} / \mathrm{min}$ (período 5), (e) $73 \mathrm{ml} / \mathrm{min}$ (período 6) e (f) $77 \mathrm{ml} / \mathrm{min}$ (período 7). 
mais adiante.

\subsection{O mapa cúbico descontínuo}

Em uma rota de duplicação de período a sequência de períodos pode ser representada por $2^{n}$ enquanto em uma rota de adição de períodos esta sequência é dada por $n+1$. Mapas lineares descontínuos podem ser utilizados para obter rotas de adição de período, no entanto, rotas mais complexas são encontradas com a utilização de mapas não lineares, apresentando duplicação de período e caos entre os períodos sequenciais característicos.

Para análise de resultados experimentais procuramos mapas sugeridos pelos diagramas de primeiro retorno experimentais da figura 4.6 (mangueira de $300 \mathrm{~cm}$ ) procurando uma função ajustada a estes que pudesse representar a dinâmica observada, veja a linha cinza na figura 4.7. Estes resultados foram publicados na revista Chaos no final de 2002 e o artigo pode ser encontrado no Apêndice 1.

Apesar do ponto (34 ms, $30 \mathrm{~ms}$ ) presente no atrator indicar a necessidade de um espaço com dimensão maior que 2 para representar toda a dinâmica presente, as principais propriedades para a adição de período desses atratores estão embebidas em codimensão 1 e portanto, podemos tratá-los dentro de um espaço bidimensional.

Ajustamos inicialmente uma parábola aos pontos à esquerda da diagonal da figura 4.7, no entanto, a família de mapas obtida não apresentou resultados satisfatórios.

Um resultado melhor foi obtido com mapas cúbicos descontínuos, onde uma função cúbica representa os pontos à esquerda da diagonal $T_{n+1}=T_{n}$ enquanto uma função linear representa os pontos à direita da diagonal. A equação a seguir apresenta um mapa cúbico escolhido, com a descontinuidade definida em $f(x)=1$.

$$
x_{n+1}= \begin{cases}f\left(x_{n}\right)=a_{1}\left(x_{n}-\mu\right)^{3}-b_{1}\left(x_{n}-\mu\right)^{2}+c_{1}\left(x_{n}-\mu\right)+d_{1}, & \text { sef }\left(x_{n}\right)<1, \\ g\left(x_{n}\right)=a_{2} x_{n}+b_{2}, & \text { sef }\left(x_{n}\right) \geq 1\end{cases}
$$

onde $\mu$ é o parâmetro de controle e $a_{1}, b_{1}, c_{1}, d_{1}, a_{2}$ e $b_{2}$ são constantes. 


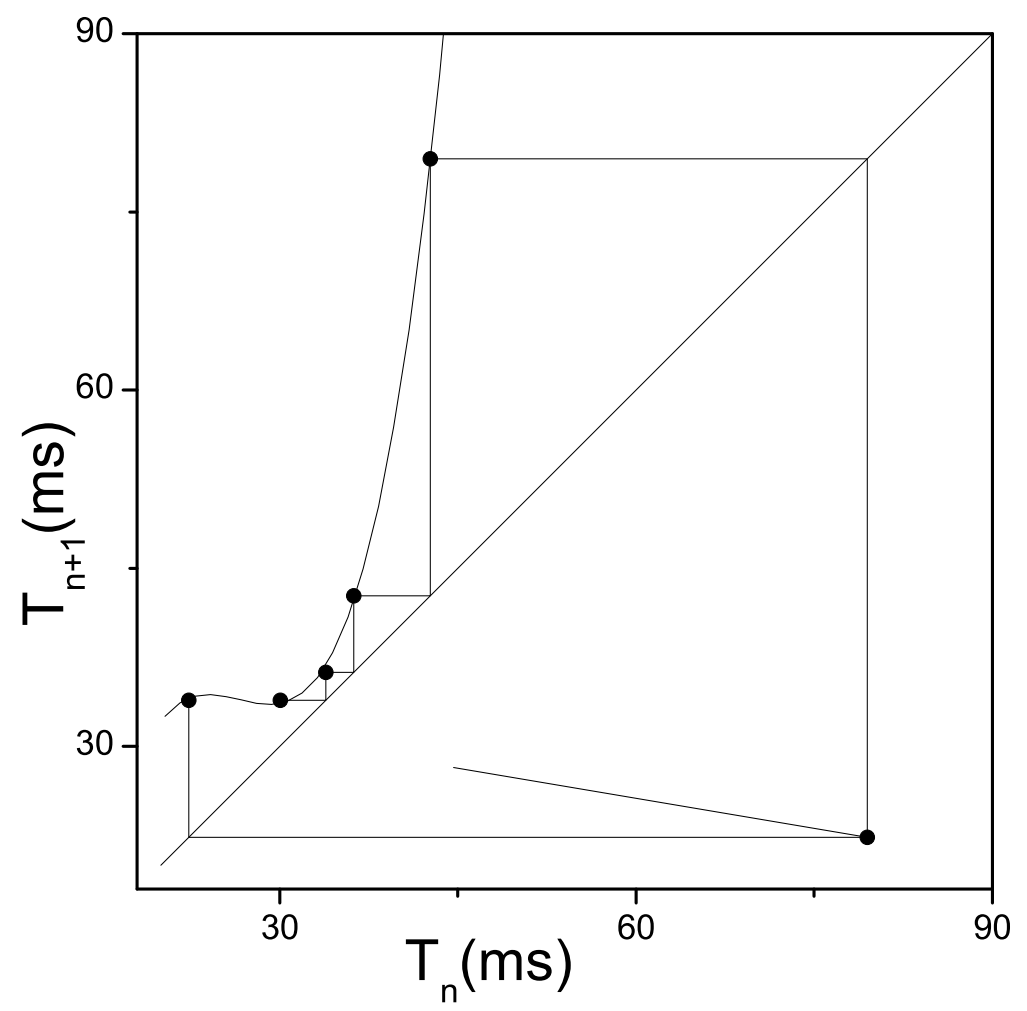

Figura 4.7: Atrator reconstruído e ajuste do mapa 
A figura 4.8 mostra um exemplo numérico das estruturas formadas pelas bifurcações obtidas com esse mapa. Observamos uma rota de adição de período ao diminuir o parâmetro $\mu$, onde identificamos período 4 (próximo de $\mu=0,07$ ), 5 , 6 e 7 , sendo que quanto maior o período mais estreita é a janela periódica. Para cada período característico observamos duplicações de período levando a comportamento caótico antes do surgimento de um novo período da rota.

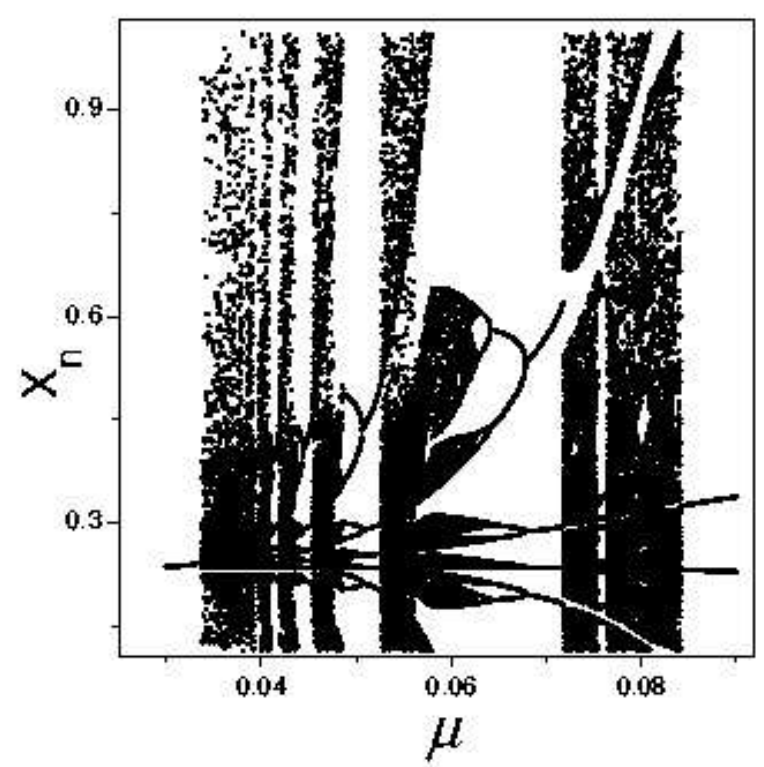

Figura 4.8: Diagrama $x_{n} v s . \mu$ obtido com o mapa 4.2 sendo os coeficientes $a_{1}=$ $119,0, b_{1}=-73,0, c_{1}=14,1, d_{1}=-0,56, a_{2}=-0,1703$ e $b_{2}=0,28648$. Neste diagrama podemos observar uma rota de adição de período com a presença de duplicações de período e caos.

A figura 4.9 mostra atratores obtidos com o mapa 4.2 para diferentes valores do parâmetro de controle $\mu$. Para obter uma sequência crescente de períodos escolhemos $\mu=0,0705$ para período 4 , figura 4.9(a), $\mu=0,052$ para período 5 , figura 4.9(b), $\mu=0,0447$ para período 6 , figura 4.9(c), e $\mu=0,0415$ para período 7, figura $4.9(\mathrm{~d})$.

Nesta sequência de valores do parâmetro de controle, o mapa cúbico está cada vez mais próximo da função identidade, tornando necessário um maior número de iterações para que o sistema retorne ao lado direito do mapa. Uma bifurcação 


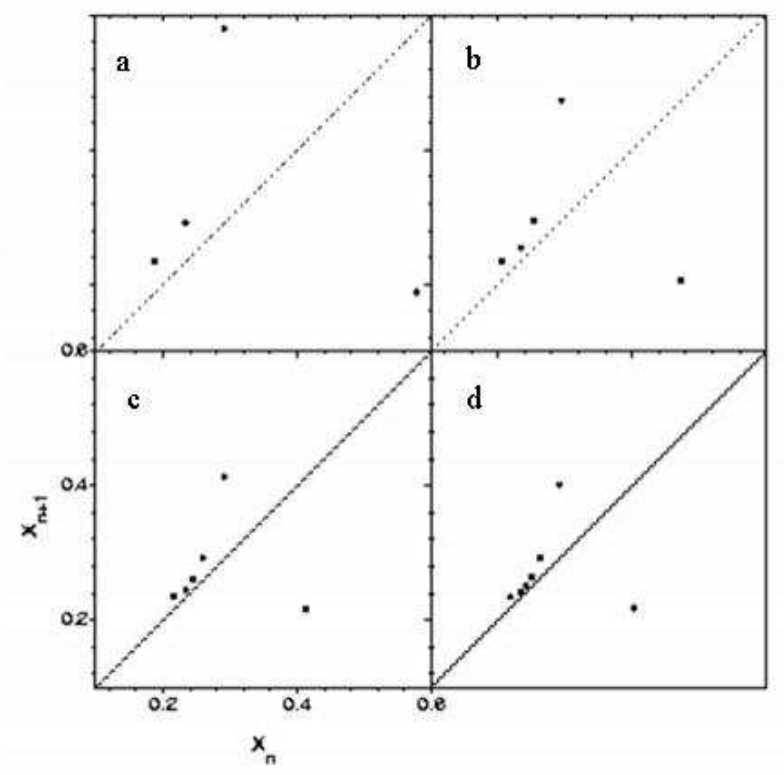

Figura 4.9: Atratores obtidos com o mapa 4.2 para valores de $\mu$ iguais a (a) 0,0705, (b) 0,052, (c) 0,0447 e (d) 0,0415. 
tangente ocorre quando o mapa cúbico tangencia a função identidade, pondo fim a rota de adição de período com o surgimento de um ponto fixo de período 1 .

\subsection{Análise de imagens de bolhas em formação}

Uma forma de analisarmos geometricamente as bolhas de ar em formação é o estudo de imagens. Esta técnia muito utilizada [Sarnobat, 2004] nos permite analisar o formato das bolhas em formação e identificar padrões por elas formados.

Utilizamos uma câmera VHS para obter imagens das bolhas de ar em formação com a mangueira de $50 \mathrm{~cm}$ conectada ao sistema. Escolhemos dois valores diferentes de vazão de ar, $65 \mathrm{ml} / \mathrm{min}$ e $90 \mathrm{ml} / \mathrm{min}$, respectivamente abaixo e acima da região onde observamos a bolha de bifurcação, veja figura 4.1(b), ambos com comportamento em período 1. Para cada valor de vazão analisamos o perfil da bolha em formação e obtivémos seu diâmetro médio aparente em função do tempo, isto é, o diâmetro da parte visível da bolha.

\section{Vazão de $65 \mathrm{ml} / \mathrm{min}$}

A figura 4.10 mostra imagens de uma bolha de ar se formando no bico com vazão $65 \mathrm{ml} / \mathrm{min}$. Inicialmente mostramos a bolha em formação presa ao bico, figura 4.10(a), em seguida ela se afasta, figura 4.10(b), mas continua presa ao bico por um pescoço que se estreita e rompe, figura 4.10(c). Estudos recentes [Keim, 2006; Burton, 2005] mostram que o estreitamento do pescoço obedece leis de escala e se dá continuamente, sem que ocorra uma ruptura repentina.

Após o escape da bolha vemos no bico uma pequena bolha remanescente mostrada na figura 4.10(d), estabelecendo as condições iniciais para a formação de uma nova bolha. A bolha remanescente é retraída para dentro do tubo, figura 4.10(e) antes que a nova bolha comece a se formar.

Esta retração da bolha remanescente é um caso extremo onde o líquido entra no bico borbulhador afetando assim o sistema pneumático. Isto significa que embora a vazão seja controlada e em média seja constante, ocorrem flutuações locais de 


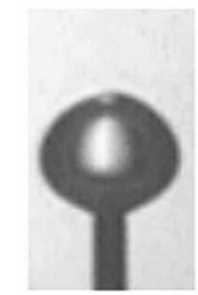

(a)

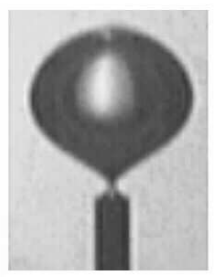

(c)

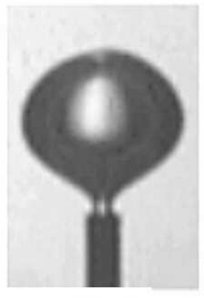

(b)

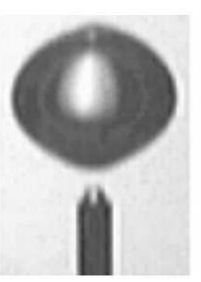

(d)

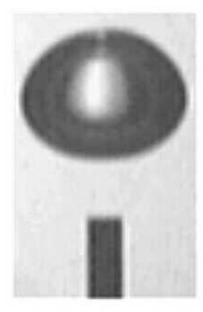

(e)

Figura 4.10: Imagens representando uma bolha em formação com vazão de ar de $65 \mathrm{ml} / \mathrm{min}$.

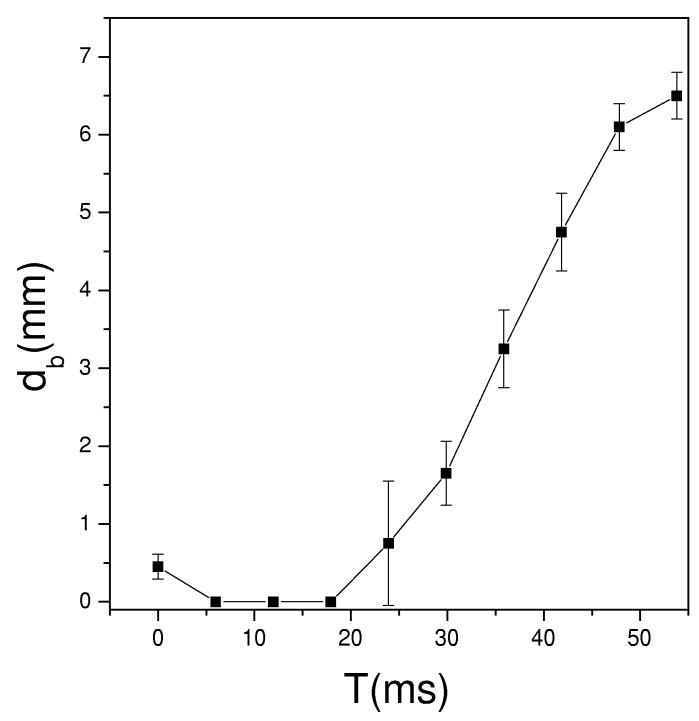

Figura 4.11: Evolução do diâmetro da bolha de ar aparente em função do tempo sendo a vazão de ar de $65 \mathrm{ml} / \mathrm{min}$. 
vazão em função do tempo próximo ao bico o que altera significativamente as características do borbulhamento.

A figura 4.11 mostra o diâmetro médio aparente da bolha em formação em função do tempo. O tempo igual a 0 corresponde ao momento em que a bolha anterior rompeu e pescoço e se separou do bico. Vemos inicialmente um diâmetro de $0,5 \mathrm{~mm}$ correpondente à bolha remanescente no bico. O diâmetro se torna zero para $t=6 \mathrm{~ms}$ e começa a crescer novamente para $t=18 \mathrm{~ms}$. O tempo total de formação da bolha é de $53 \mathrm{~ms}$ com diâmetro final de 6,5mm.

\section{Vazão de $90 \mathrm{ml} / \mathrm{min}$}

A figura 4.12 mostra imagens da bolha em formação quando a vazão é $90 \mathrm{ml} / \mathrm{min}$. Na figura 4.12(a) vemos a bolha presa ao bico por um pescoço e em (b) a imagem de uma bolha logo após se soltar do bico. Neste caso, quando a bolha escapa do bico não observamos a retração da bolha remanescente no bico, figura 4.12, mas um crescimento contínuo.

Na figura 4.13 temos o diâmetro da bolha em função do tempo. Vemos que a bolha inicia sua formação já com $0,5 \mathrm{~mm}$ e permanece crescendo. O diâmetro final da bolha é o mesmo observado para a vazão de $65 \mathrm{ml} / \mathrm{min}, 6,5 \mathrm{~mm}$. Como não observamos aqui a retração de ar o tempo total de formação até o escape é menor, $33 \mathrm{~ms}$. Portanto, vemos que com o mesmo tipo de comportamento, período 1, a formação de bolhas não se dá da mesma maneira.

\subsection{Modelo para adição de período e biestabili- dade}

Baseados no estudo do equilíbrio de forças atuantes em uma bolha em formação, seção 2.9, e nos resultados de mapas descontínuos, seção 2.10, construímos o modelo para adição de períodos. Os resultados que serão aqui apresentados foram publicados na revista Physical Review E em 2004. O artigo se encontra no Apêndice 2. 


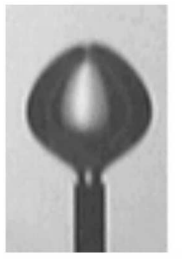

(a)

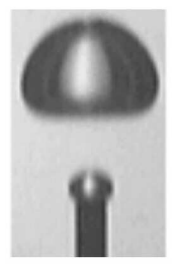

(c)

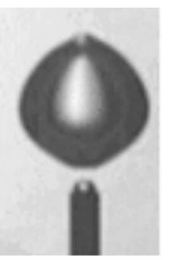

(b)

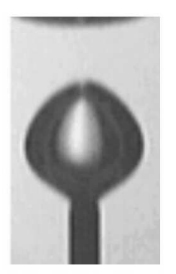

(d)

Figura 4.12: Imagens representando uma bolha em formação com vazão de ar de $90 \mathrm{ml} / \mathrm{min}$.

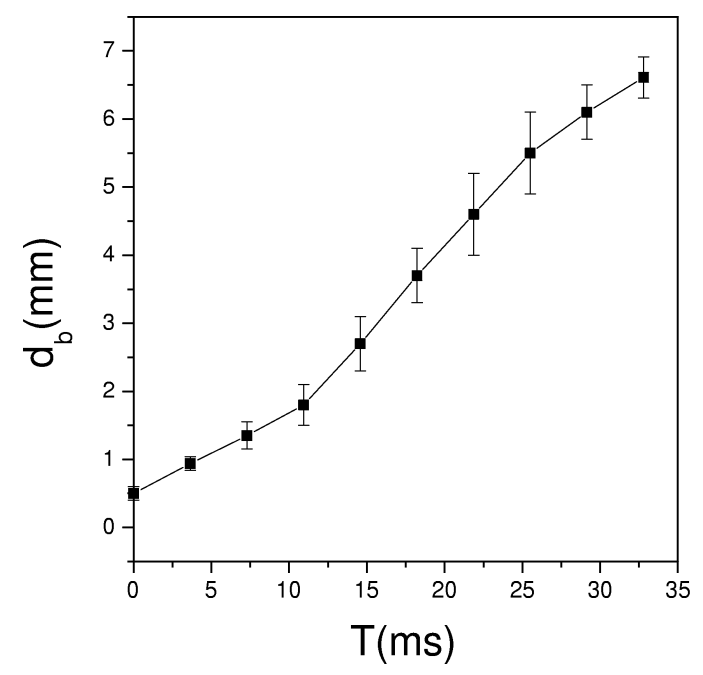

Figura 4.13: Evolução do diâmetro aparente da bolha de ar em função do tempo sendo a vazão de ar de $90 \mathrm{ml} / \mathrm{min}$. 
As relações abaixo apresentam esse modelo.

$$
T_{n+1}=-\phi+t_{n}
$$

sendo que $t_{n}$ é a maior raiz da função:

$$
\begin{array}{r}
f(t)=T_{n}+m\left(t-d\left(T_{n}\right)\right)^{3}-l\left(t-d\left(T_{n}\right)\right) \\
\operatorname{com} d\left(T_{n}\right)=-A\left(1-\tanh \left(T_{n}+B\right)\right) .
\end{array}
$$

Os parâmetros $m, A$ e $B$ são fixos e valem 0.4, 2.4 e 1.4 respectivamente.

Neste modelo de dois mapas acoplados, um deles tem como variável $t_{n}$ e com parâmetro de controle $\phi$ e o outro tem $T_{n}$ como variável e $l$ como parâmetro de controle. Embora tratemos o modelo como unidimensional,

$$
T_{n+1}=f\left(T_{n}\right),
$$

temos dois parâmetros de controle definindo sua dinâmica.

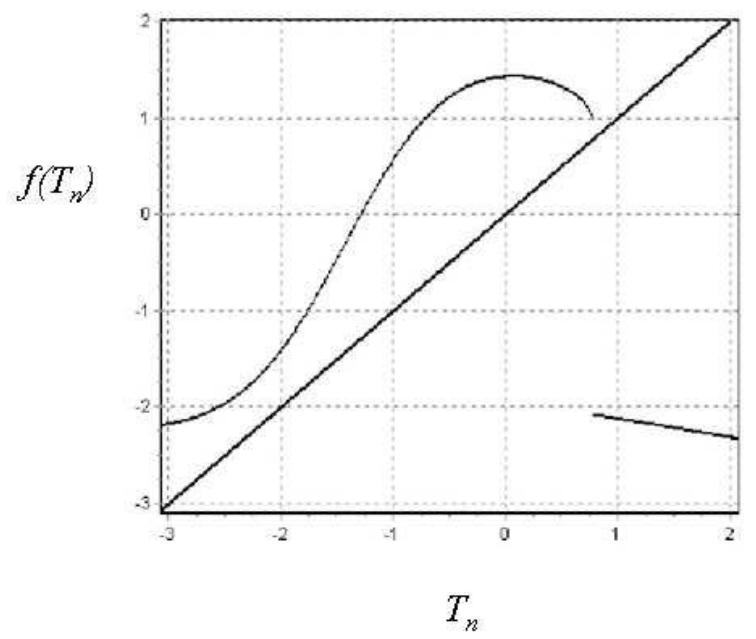

Figura 4.14: (a) Função para $l=1.2$ e $\phi=0.03$. 

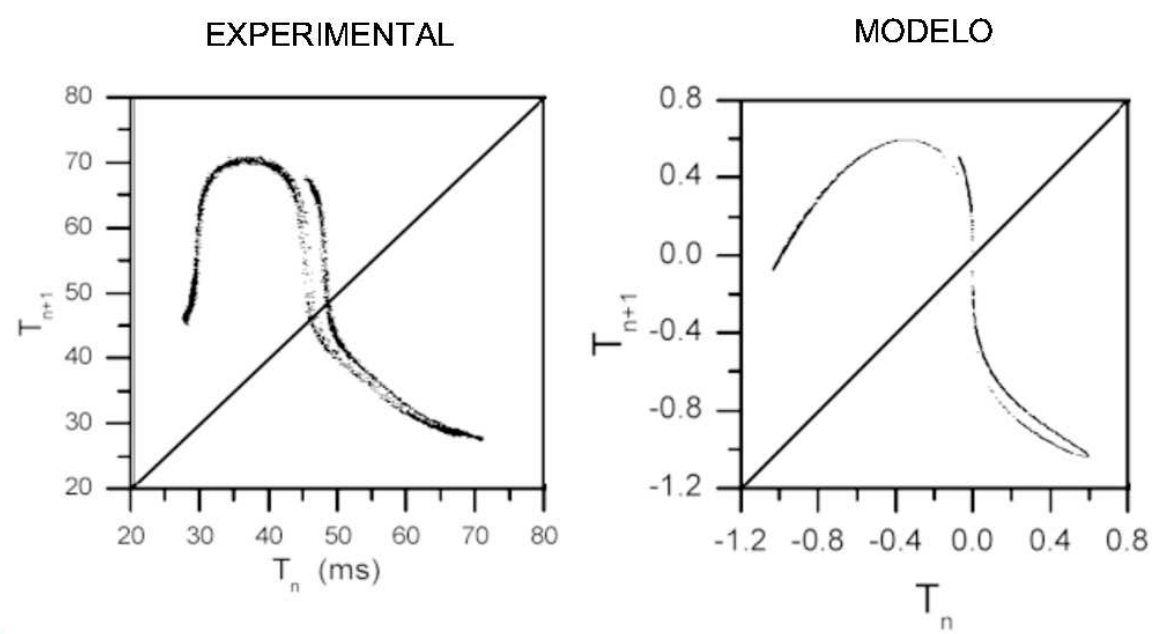

Figura 4.15: Diagramas $T_{n+1}$ vs. $T_{n}$ obtidos experimentalmente, à esquerda, e através do modelo (1-2), à direita.).

A figura 4.14 mostra $f\left(T_{n}\right)$ para $-3<T_{n}<2$. O formato da função acompanha o que observamos experimentalmente para o tempo de formação de bolhas em comportamento caótico.

Com uma dobra tipo Hénon, que preserva as propriedades topológicas do mapa, o resultado obtido com este modelo é bastante similar ao resultado experimental. A figura 4.15 mostra mapas de primeiro retorno $T_{n+1}$ vs. $T_{n}$. Em 4.15(a) o mapa apresenta tempo entre bolhas obtido experimentalmente para mangueira de 140 cm com vazão de $100 \mathrm{ml} / \mathrm{min}$. Em 4.15(b) o mapa foi obtido iterando o mapa modelo 4.3.

A figura 4.16 mostra diagramas de bifurcação obtidos experimentalmente e com o mapa modelo 4.3. Em (a) e (b) os diagramas $T_{n}$ vs. vazão foram obtidos com mangueiras de $50 \mathrm{~cm}$ e $140 \mathrm{~cm}$, respectivamente. Em (A) e (B) os diagramas $T_{n}$ vs. $\phi$ foram obtidos para $l=-0,55$ e $l=0$, respectivamente. Percebemos que (a) e (A) apresentam bolhas de bifurcação onde o comportamento passa de período 1 para período 2 e em seguida retorna ao período 1. Em (b) e (B) vemos, tanto no diagrama experimental como no diagrama obtido com o mapa modelo uma bifurcação de período 1 para período 2, seguida de uma região caótica. Desta região surge o comportamento periódico de período 3 depois seguido do encerramento da 
bolha de bifurcação.
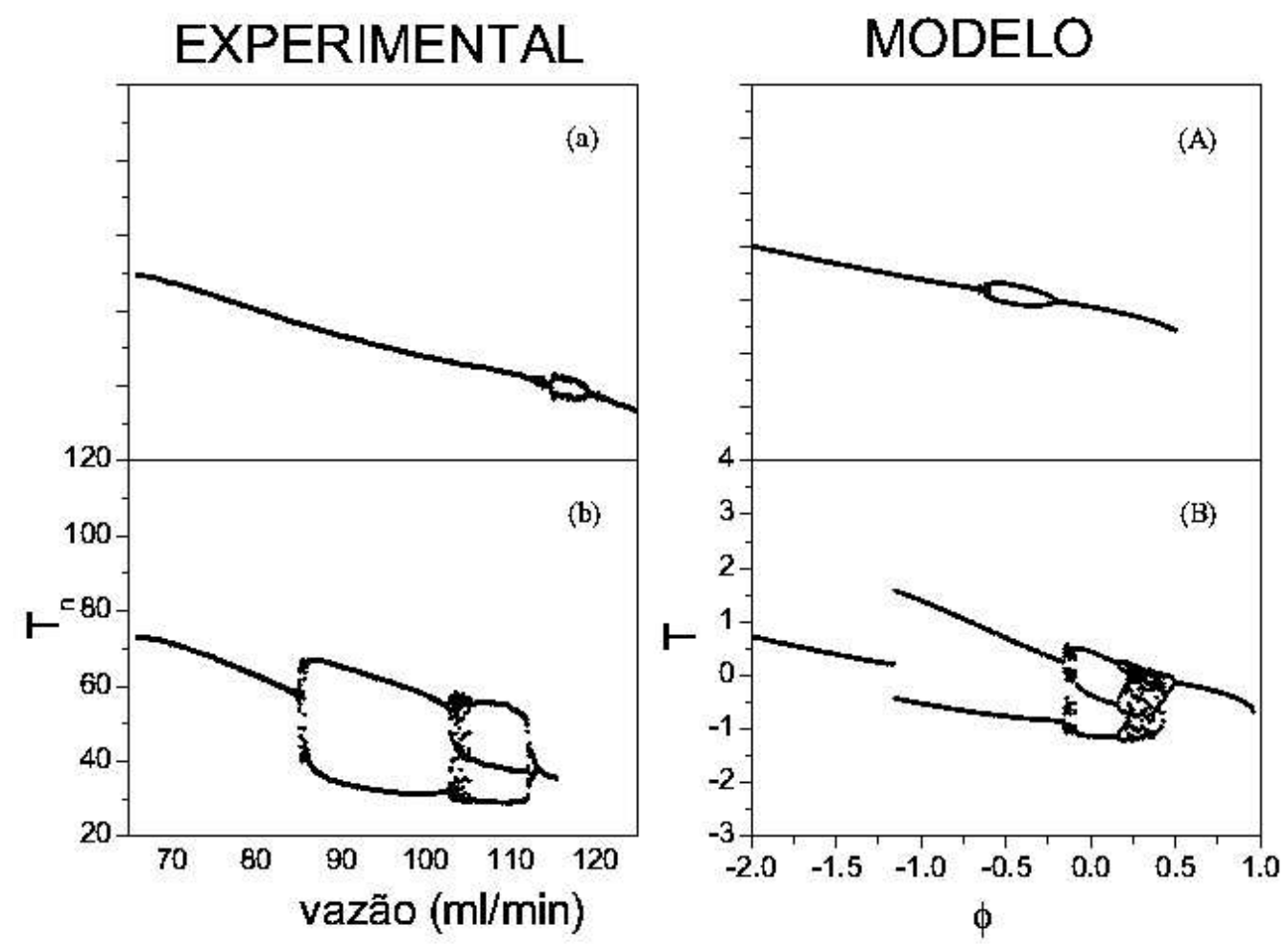

Figura 4.16: Diagramas de bifurcação, $T_{n}$ vs. vazão, obtidos experimentalmente com mangueiras de comprimento (a) $50 \mathrm{~cm}$ e (b) $135 \mathrm{~cm}$, comparados com diagramas, $T_{n}$ vs. $\phi$, obtidos através do mapa modelo 4.3 sendo o parâmetro $l$ fixo em (A) $-0,55$ e (B) 0 .

Uma das propriedades observadas na formação de bolhas de ar em regime de baixa vazão é a biestabilidade. Para verificar a biestabilidade experimentalmente fixamos um valor de vazão de ar e perturbamos o sistema através de um alto falante fixo no alto do tubo borbulhador, ligado a um gerador de funções. Com isto, impomos ao sistema visitar diferentes valores de $T_{n}$, e assim, ao retirarmos a perturbação, o sistema tende ao equilíbrio a partir de diferentes condições iniciais. A figura 4.17 mostra uma série de dados obtidos com pulsos de perturbação ao sistema. A vazão é $70 \mathrm{ml} / \mathrm{min}$.

O tratamento unidimensional foi seguido pela simplicidade já que apresenta as mesmas características do mapa com a dobra tipo Hénon. A descontinuidade 


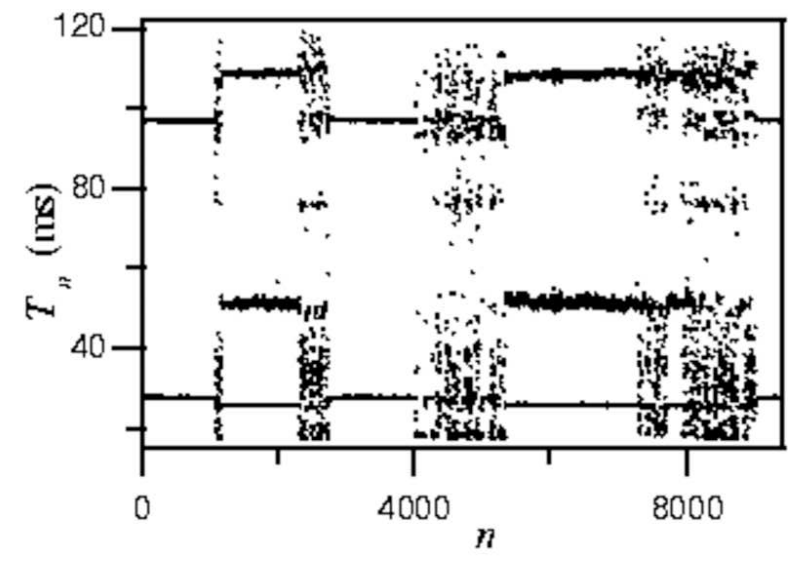

Figura 4.17: Série de bolhas obtidas à vazão de $70 \mathrm{ml} / \mathrm{min}$ aplicando perturbação aperiodicamente.

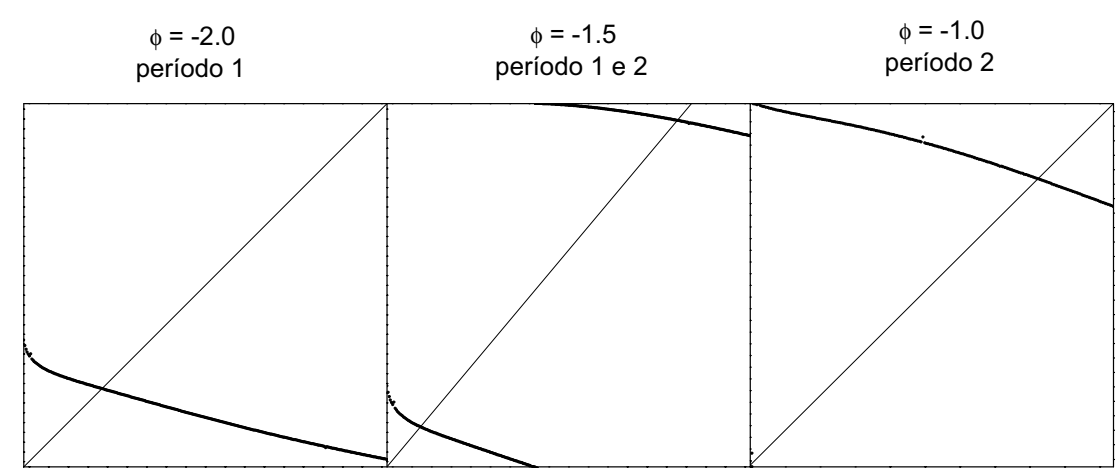

Figura 4.18: Mapas de retorno de um intervalo $I$ do modelo (1-2) $\operatorname{com} l=0.5$. 
observada na figura 4.14 permite definirmos um intervalo $I$ à sua direita para $T_{n}<f\left(T_{n}^{M A X}\right)$, onde $T_{n}^{M A X}$ corresponde ao máximo da função.

Para alguns valores do parâmetro $l$ o mapa modelo não apresenta descontinuidade. Nesse caso o intervalo $I$ é definido a partir do ponto de inflexão observado após o máximo da função.

Aumentando o parâmetro $\phi$ a curva à esquerda da descontinuidade se aproxima da diagonal $T_{n+1}=T_{n}$ provocando o aumento do número de iteradas necessárias para que ocorra o retorno à região de $I$. A construção de funções de retorno, como as contruídas para o mapa descontínuo apresentado na seção 2.9 permite identificar o surgimento de novas órbitas.

A figura 4.18 mostra funções de retorno para 3 valores do parâmetro $\phi$ mantendo $l$ fixo em 0,5. Na figura.4.18(a) temos a função de retorno cruzando a diagonal e definindo a existência de um ponto fixo estável, de período 1 , para $\phi=-2,0$. Em (b), $\phi=-1,5$, a função de retorno apresenta dois trechos, um deles cruza a diagonal indicando a existência de um ponto fixo de período 1 enquanto o outro trecho indica a existência de um ponto fixo com período 2, ambos estáveis. Isso mostra que, tal como observamos experimentalmente, o mapa modelo 4.3 apresenta biestabilidade. A figura 4.18(c) mostra a existência agora de apenas um ponto fixo estável de período $2, \phi=-1,0$.

Normalmente, quando obtemos um diagrama de bifurcação numericamente, podemos escolher a condição inicial conveniente e assim podemos identificar diferentes órbitas possíveis em um mesmo diagrama. Já no caso experimental, a condição inicial está limitada ao estado atrator do valor de parâmetro anterior. Isto faz com que, aumentando ou diminuindo a vazão de ar, observemos diferentes comportamentos para os mesmos valores de parâmetro quando existe biestabilidade. Para simular o mesmo efeito, obtivémos os diagramas numéricos considerando como condição inicial, de cada passo do parâmetro, o valor final obtido para o parâmetro anterior.

A figura 4.19 mostra a comparação de diagramas de bifurcação obtidos aumentando e diminuindo o parâmetro de controle. Em (a) e (b) temos diagramas 

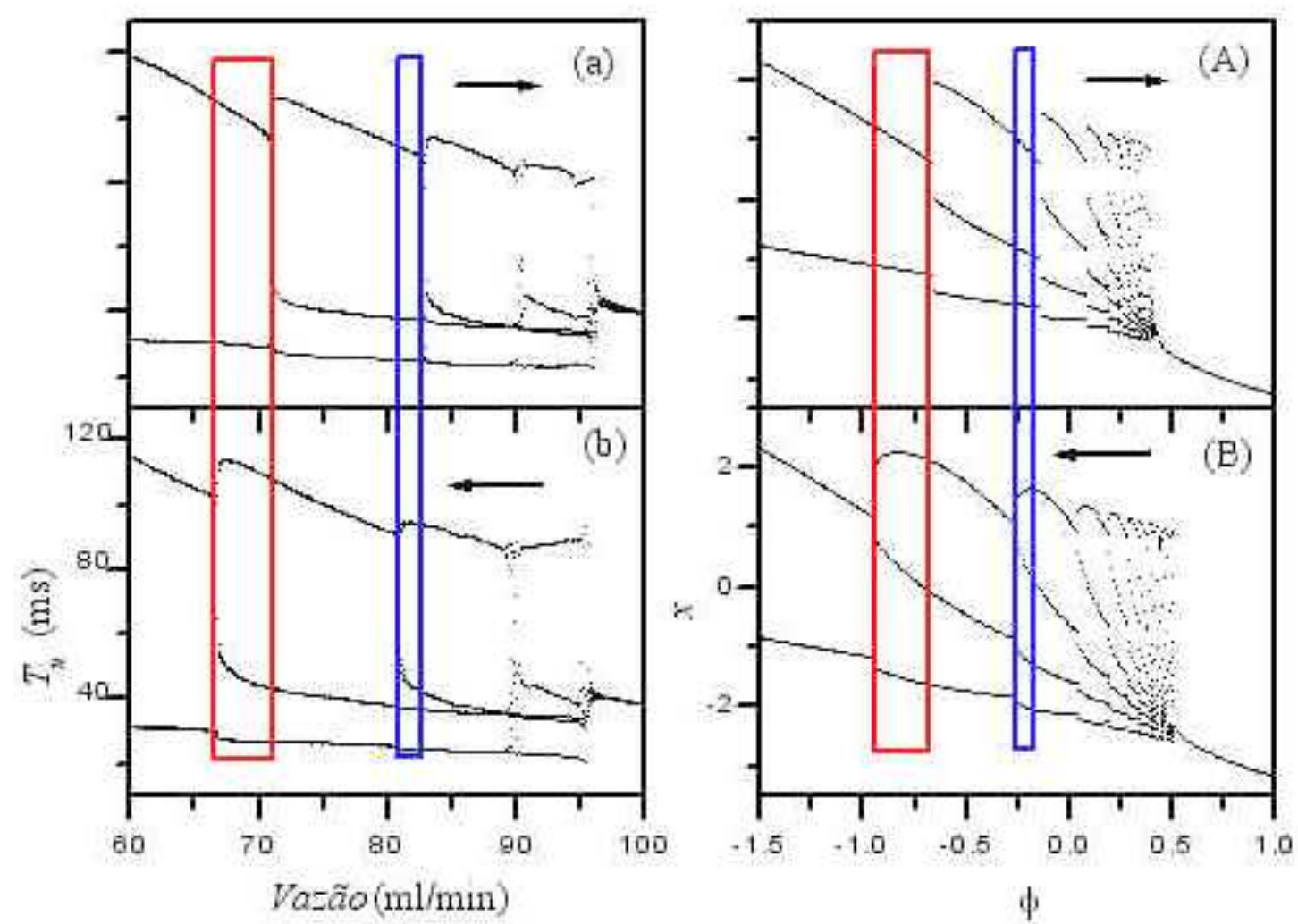

Figura 4.19: Comparação de diagramas de bifurcação obtidos experimentalmente e numericamente. Em (a) e (b) temos $T_{n}$ vs. vazão obtidos aumentando e diminuindo a vazão, respectivamente, quando a mangueira tem comprimento igual a $300 \mathrm{~cm}$. Em (A) e (B) temos o resultado obtido com o mapa modelo $4.3 \mathrm{com}$ o parâmetro $l$ fixo em 1,2 , aumentando e diminuindo o parâmetro $\phi$ respectivamente. Os retângulos vermelhos mostram comportamento biestável, com coexistência de período 2 e 3 . Os retângulos azuis mostram comportamento em período 3 e 4 coexistindo. 
obtidos experimentalmente com a mangueira de $300 \mathrm{~cm}$ de comprimento tomando a vazão como parâmetro de controle. Em (A) e (B) temos diagramas obtidos com o mapa modelo 4.3 sendo $l=1,2$ e tomando $\phi$ como parâmetro de controle.

\subsection{Caos homoclínico}

Uma órbita homoclínica é uma órbita biassintótica à um conjunto invariante no espaço de fases, ou seja, tende ao conjunto invariante tanto para $t \rightarrow \infty$ quanto para $t \rightarrow-\infty$. Este conjunto invariante pode ser um ponto fixo. A dinâmica de um sistema próximo de uma órbita homoclínica apresenta um comportamento característico que chamamos de caos homoclínico.

O estudo destas órbitas geralmente é feito a partir das equações do sistema e da análise do espaço de fases. Papoff [Papoff, 1991] mostrou que para um sistema com um ponto fixo tipo sela com solução periódica estruturalmente estável é possível identificar a aproximação tangente da órbita com uma bifurcação homoclínica. Outros métodos vem sendo desenvolvidos para que sistemas onde as equações não são conhecidas possam ser analisados sobre a ocorrência ou não de caos homoclínico.

Zeni [Zeni et al., 1998] analisando um modelo para laser LSA (Laser com absorção e saturação) obteve resultados que apresentam semelhança topológica com os atratores que apresentamos para a formação de bolhas e mostrou que as propriedades identificadas são realmente evidências de caos homoclínico.

A figura 4.20 mostra a evolução temporal da intensidade do laser $I$ para parâmetros escolhidos próximo a uma janela periódica de período 5. Uma série de eventos foi obtida a partir da evolução temporal da intensidade do laser $I$ considerando a intersecção com a superfície constante $I=I_{\text {const }}$ e $\frac{d I}{d t}<0$, figura 4.20 (a) e determinando o tempo $t_{i}$ entre sucessivas intersecções. A reconstrução de primeiro retorno $\left(t_{i} v s . t_{i+1}\right)$ dessa série de eventos, figura $4.20(\mathrm{~b})$, e outras que podem ser obtidas apresenta estrutura dupla, tipo Hènon.

Baseando-se nas abcissas da reconstrução mostrada na figura 4.20(b), Zeni in- 


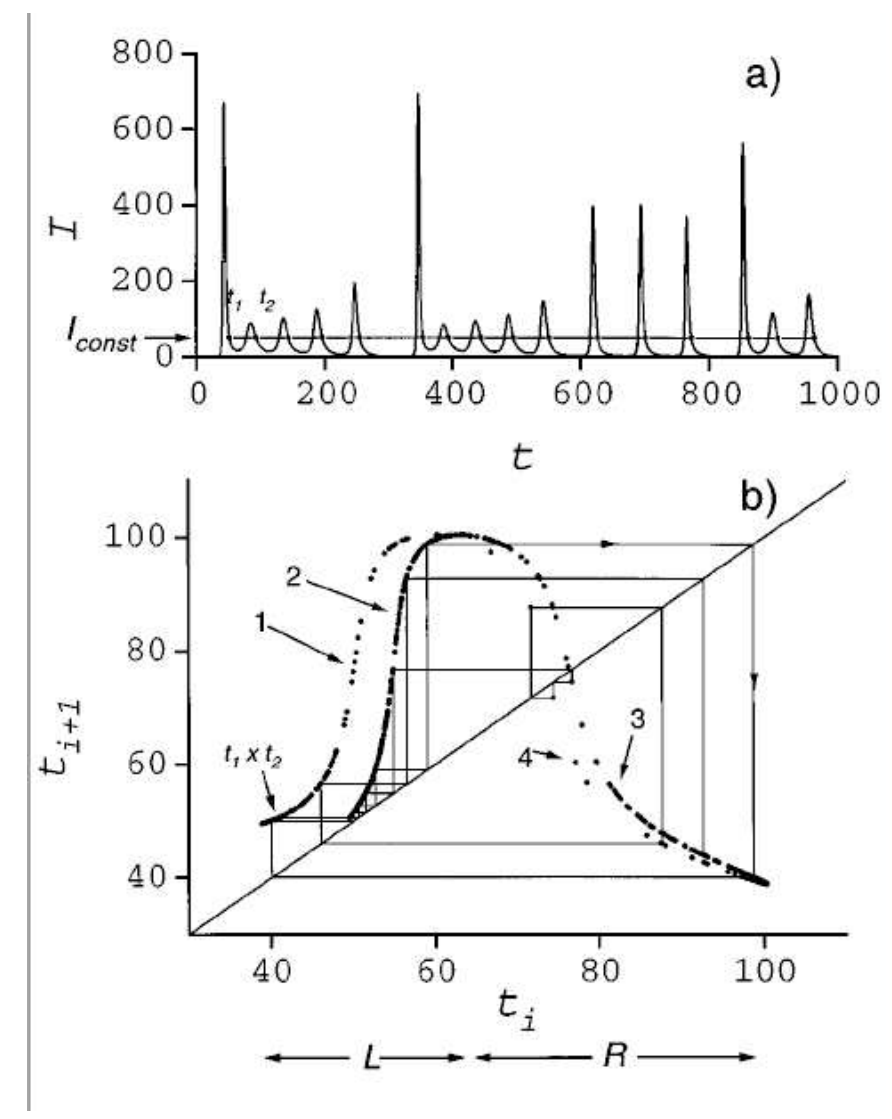

Figura 4.20: Figura adaptada de Zeni et al, 1998.Em (a) temos a evolução temporal da intensidade do LSA obtida numericamente. A linha horizontal indica um valor constante escolhido $I=I_{\text {const }}$. Em (b) temos o mapa de retorno obtido nas mesmas condições da evolução temporal com algumas iterações indicadas. $R$ e $L$ referem-se ao lado direito e esquerdo do mapa, respectivamente.

troduziu um código simbólico associando L (left), para as iteradas que visitam os dois ramos ascendentes (ramos 1 e 2), e R (right) para as iteradas que visitam os ramos descendentes (ramos 3 e 4) que serviu para o estudo da função de retorno. A figura 4.21 mostra a função de retorno obtida para o resultado da figura 4.20(b). Nesta função identificamos 5 ramos evidenciando a estrutura multiramificada característica de caos homoclínico.

Como nesse sistema o espaço de fases pode ser obtido, uma análise topológica foi feita identificando caos homoclínico. Como qualquer seção conserva as propriedades dinâmicas do sistema, mesmo que a seção obtida na figura 4.20(b) não 


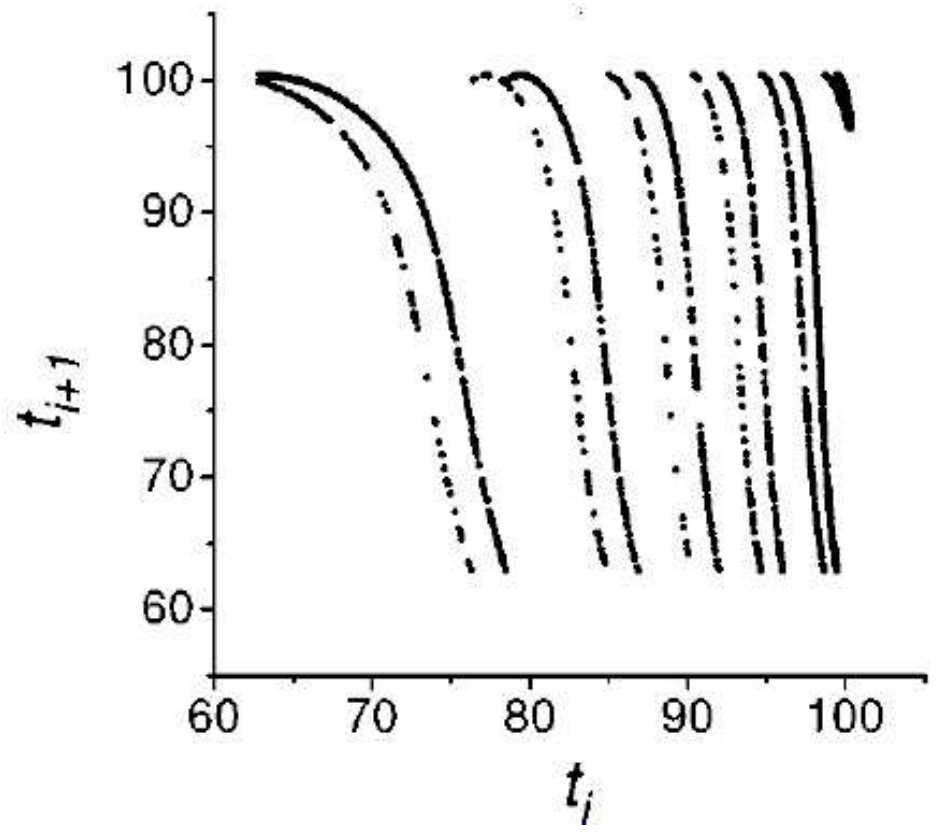

Figura 4.21: Figura adaptada de Zeni et al, 1998. Função de retorno.

apresente estrutura única ela representa o comportamento do sistema

A transição de uma janela com comportamento periódico para comportamento caótico se dá por uma seqüência de duplicações de período. A transição de comportamento caótico para comportamento periódico se dá por bifurcação tangente.

Uma reconstrução do espaço de fases do laser LSA obtida por Zeni está na figura 4.22. Neste espaço de fases existem dois pontos fixos, um sela-foco e um sela-nó. Diferentes comportamentos podem ser observados de acordo com a presença de órbitas que acoplam ou não esses pontos.

Para essa situação em que o modelo se aproxima da órbita homoclínica do ponto sela-foco, os pontos fixos não estão acoplados e o ponto fixo sela-nó não interfere no comportamento observado. A figura 4.22 mostra a presença do ponto fixo selafoco $\left(I_{+}, D_{+}, S_{+}\right)$. O ponto sela-nó está no plano $I=I_{0}$ que é uma superfície invariante da qual as órbitas são repelidas. Com posse do espaço de fases, para obter o mapa de retorno com estrutura simples basta escolher a seção de corte adequada do espaço de fases, localizando o início ou o fim do processo de reinjeção.

Os ramos 1, 2, 3 e 4 indicados na figura 4.26 podem ser entendidos por comparação com o espaço de fases. Os ramos 1 e 2 estão relacionadosà primeira e à 


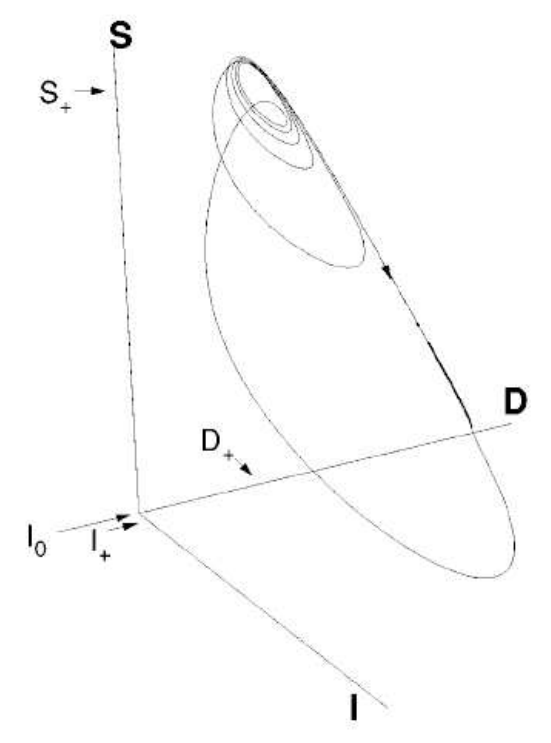

Figura 4.22: Figura adaptada de Zeni et al, 1998. Extraído da órbita caótica de $A=0,44$ projetado no espaço (I,D,S), para o modelo de LSA. O ponto sela-foco está indicado pelas coordenadas $\left(I_{+}, D_{+}, S_{+}\right)$. Apenas a componente $I_{0}=o$ do ponto sela-nó aparece na figura porque $D_{0} \simeq 45 D_{+}$, e $S_{0} \simeq 45 S_{+}$.

segunda volta em torno do ponto sela-foco que são pequenas oscilações em torno do ponto fixo. O ramo 3 corresponde a uma oscilação maior onde ocorre a volta de reinjeção. Se ocorrer mais de uma volta durante a reinjeção o ramo 4 é visitado também. Por exemplo, na figura 4.20(a) vemos entre $t=0$ e $t=600$ duas sequências com pequenas oscilações e apenas uma grande oscilação representando a reinjeção, estas sequências não visitam o ramo 4 da figura 4.20(b).

Com as medidas de tempo entre bolhas observamos atratores com propriedades que indicam a presença de caos homoclínico. Tomemos como exemplo o atrator obtido com a mangueira de $140 \mathrm{~cm}$ e vazão $89 \mathrm{ml} / \mathrm{min}$ apresentado na figura 4.4. O atrator é do tipo Hénon e podemos analisar a função de retorno aos ramos descendentes, ou seja, com derivada negativa. Dividimos então o atrator pela linha indicada em vermelho na figura $4.23(\mathrm{a})$, em $T_{*}=36 \mathrm{~ms}$. Iteradas com $T_{n}>T_{*}$ estão à direita da partição (região D).

Na figura 4.23(b) temos a função de retorno ao lado direito para esse atrator. 
Identificamos nessa figura dois ramos principais que cruzam a diagonal $T_{n_{0}+1}=$ $T_{n_{0}}$. Podemos dizer que para valores de vazão próximos de $89 \mathrm{ml} / \mathrm{min}$ a função, que define o comportamento do sistema, tem formato parecido ao do atrator. O cruzamento dessa função com a diagonal define a existência de uma órbita de período 2. A dobra de cada ramo é devida a dobra observada no mapa de retorno.

Tomando o atrator obtido com a mangueira de $235 \mathrm{~cm}$ a vazão de $90 \mathrm{ml} / \mathrm{min}$ (figura 4.5) e reproduzido na figura 4.24 observamos comportamento semelhante. Identificamos a presença de dois ramos ascendentes e dois ramos descendentes, mantendo a estrutura dupla. Fizemos a partição do atrator em $T_{*}=35 \mathrm{~ms}$, indicado pela linha vermelha na figura 4.24(a) construindo a função de retorno ao lado direito do atrator (região D) que está na figura 4.24(b). Essa função de retorno mostra 3 ramos principais cruzando a diagonal e indicando a existência de uma órbita de período 3.

Esta análise nos mostra evidências de que o comportamento observado na formação de bolhas de ar é caos homoclínico. A análise destes atratores se completa com a observação dos diagramas de bifurcação reunidos na figura 4.25. Se fixamos a vazão em $90 \mathrm{ml} / \mathrm{min}$, podemos ver que o sistema passa de período 2, para comportamento caótico, em seguida vemos um período 3 e posteriormente o comportamento caótico representado pelo atrator da figura 4.24. Portanto, é observada uma rota de adição de período do tipo característico aos sistemas onde há órbitas homoclínicas.

Seguindo esse raciocínio, os ramos descendentes da figura 4.23 (mangueira de $140 \mathrm{~cm}$ ) devem caracterizar dois ciclos de um processo de reinjeção enquanto o ramo ascendente deve estar relacionado com oscilações em torno do ponto fixo. Também o resultado observado na figura 4.24 (mangueira de $235 \mathrm{~cm}$ ) apresenta dois ramos descendentes mostrando o mesmo tipo de reinjeção mas apresenta dois ramos ascendentes indicando que o sistema oscila mais em torno do ponto fixo que o caso anterior. Para que uma análise mais fundamentada desse comportamento possa ser feita se faz necessário obter a medida contínua de alguma variável para que com isso possamos identificar com veracidade o início e o final dos processos 

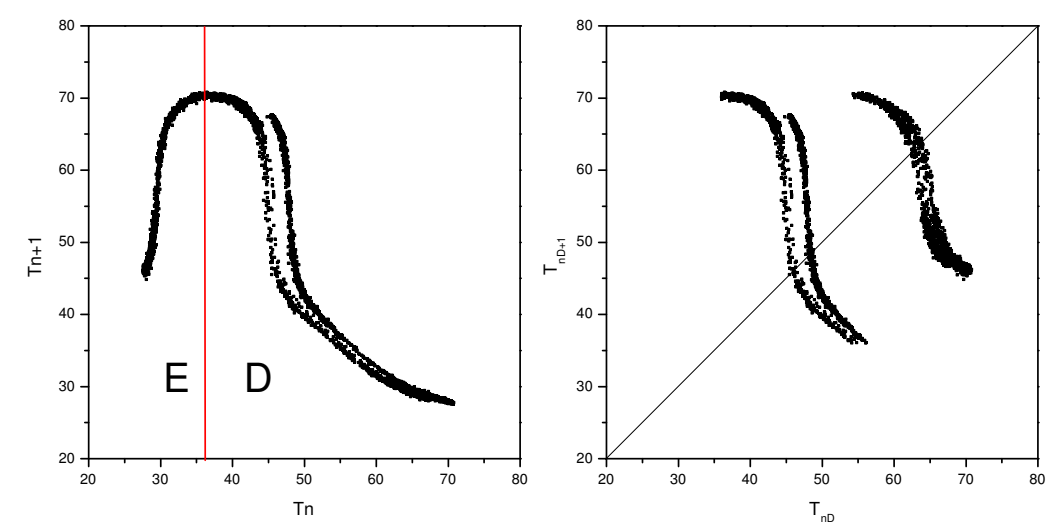

Figura 4.23: Em (a) temos o mapa de primeiro retorno obtido com a mangueira de $140 \mathrm{~cm}$ à vazão de $89 \mathrm{ml} / \mathrm{min}$. A linha vermelha indica a partição feita no atrator em $T_{*}=36 \mathrm{~ms}$, A letra $\mathrm{E}$ indica região à esquerda da partição e a letra $\mathrm{D}$ representa a região à direita. Em (b) temos um mapa de retorno construído com $\left\{T_{n_{0}}\right\}$, sequência obtida com os valores de $T_{n}>36 \mathrm{~ms}$
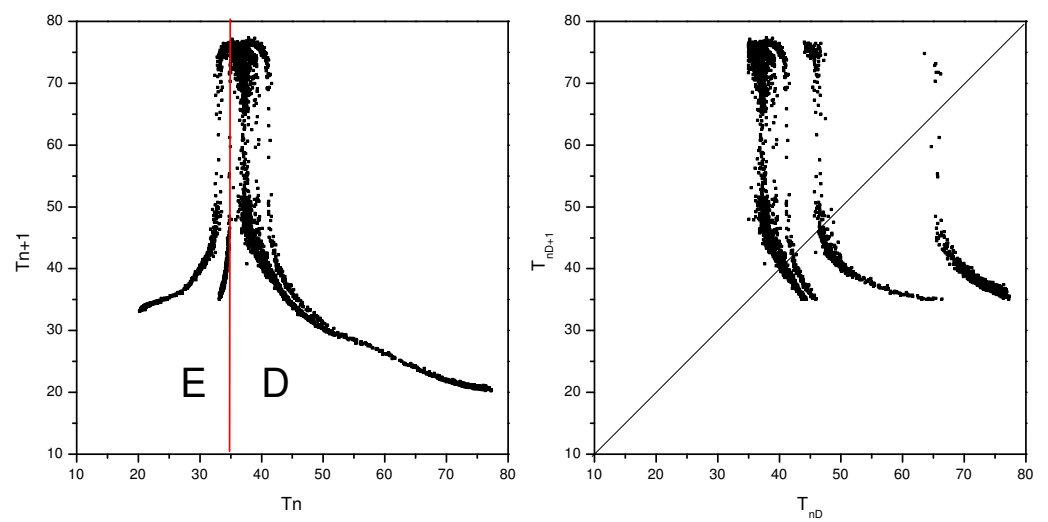

Figura 4.24: Em (a) temos o mapa de primeiro retorno obtido com a mangueira de $235 \mathrm{~cm}$ à vazão de $90 \mathrm{ml} / \mathrm{min}$. A partição feita no atrator em $T_{n}=35 \mathrm{~ms}$ está indicada pela linha vermelha. Em (b) temos um mapa de retorno à região D, à direita da partição, onde $\left\{T_{n_{0}}\right\}$ é a sequência obtida quando $T_{n}>35 \mathrm{~ms}$ 


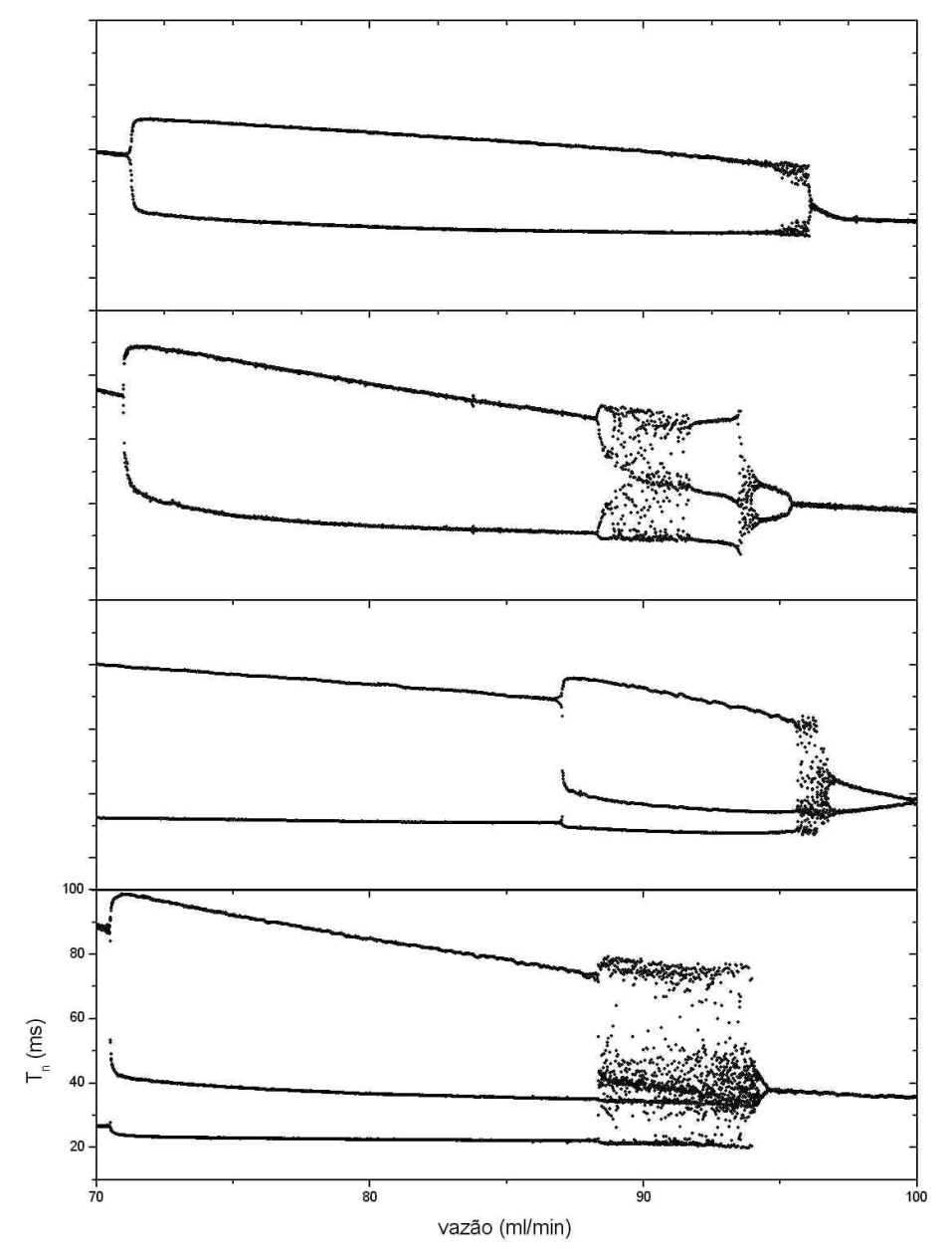

Figura 4.25: Diagramas de bifurcação para vários comprimentos de mangueira, evidenciando a nova rota de adição de período. Vemos que para vazão de $90 \mathrm{ml} / \mathrm{min}$ observamos período 2, comportamento caótico, período 3 e novamente comportamento caótico quando olhamos os diagramas de cima para baixo, na direção do aumento do comprimento da mangueira. 


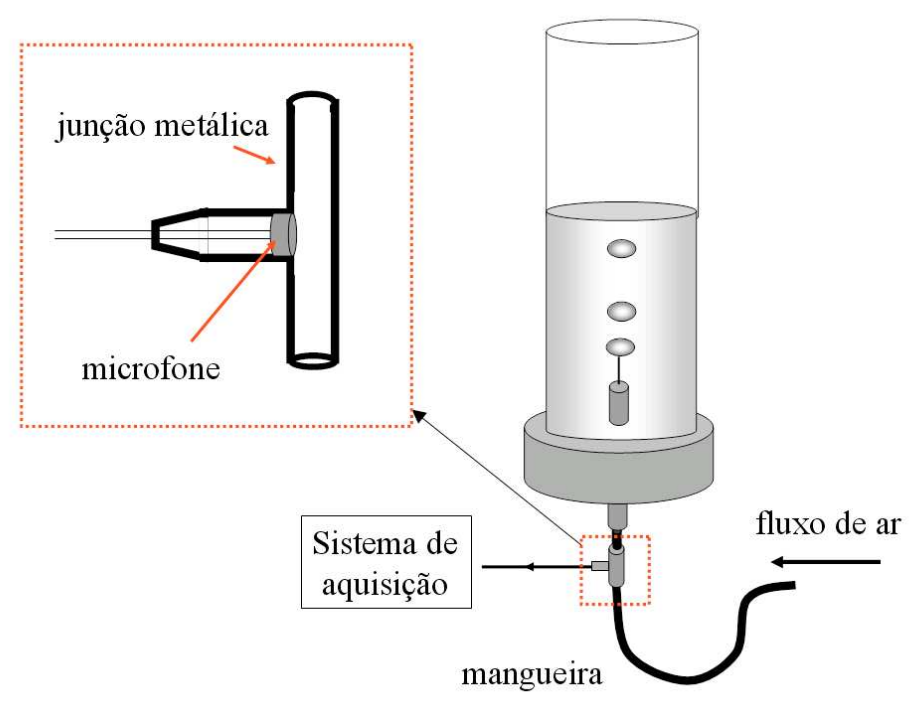

Figura 4.26: Esquema da junção metálica utilizada para instalar o microfone.

de reinjeção. Uma medida que nos permite obter as informações necessárias para esclarecer esta questão é a intensidade da onda de pressão no interior da mangueira conectora entre o sistema de controle de vazão e o bico borbulhador. Medidas da onda de pressão no interior da mangueira

A formação da bolha de ar envolve a saída de ar de dentro do bico. Enquanto a bolha em formação aumenta de tamanho o momento do ar que entra na bolha é positivo, ou seja, o ar está saindo do bico. Quando a bolha se destaca o ar repentinamente para de sair do bico e algumas vezes apresenta momento negativo.

Esta variação na direção e na intensidade do momento do gás provoca o surgimento de uma onda de pressão dentro da mangueira conectora. A intensidade dessa onda de pressão varia de acordo com a formação e o escape das bolhas o que torna esta uma variável interessante de ser estudada.

Para isso construímos uma junção metálica com um microfone piezoelétrico embutido entre o bico borbulhador e a mangueira conectora para medir a amplitude da onde de pressão. A figura 4.26 mostra um esquema da peça construída. O diâmetro interno da peça foi escolhido próximo ao diâmetro interno da mangueira para que não houvesse grande alteração no comportamento da onda de pressão. O sinal obtido com o microfone é enviado para um computador com uma placa ADC 
que permite obter medidas contínuas da tensão gerada no microfone.

Medimos a amplitude da onda de pressão para vários valores de vazão utilizando a mangueira de $190 \mathrm{~cm}$. As figuras 4.27 e 4.28 mostram reconstruções de retorno obtidos a partir das medidas realizadas. A figura 4.27(a) mostra o resultado obtido com a vazão de $70 \mathrm{ml} / \mathrm{min}$. Neste caso o comportamento do sistema é periódico e analisando o tempo entre bolhas $T_{n}$ identificamos período 1. A figura 4.27(b) foi obtida com a vazão de $90 \mathrm{ml} / \mathrm{min}$. Vemos agora que a órbita apresenta duas voltas caracterizando um período 2 que foi confirmado também pela medida do tempo entre bolhas.

A figura 4.28(a) mostra a reconstrução de retorno obtida quando a vazão de ar é de $123 \mathrm{ml} / \mathrm{min}$. Para este valor de vazão o comportamento do sistema é irregular e não observamos uma linha bem definida como na figura anterior, mas sim, toda uma região do espaço é visitada. A figura 4.29 mostra o mesmo comportamento mas agora em dimensão 3. Vemos que agora o atrator está desdobrado indicando que sua dimensão de imersão é 3. Aumentando mais a vazão o comportamento volta a ser periódico com período 1 como mostra a figura 4.28(b).

Vemos que a órbita dá algumas voltas em espiral em torno de uma região do espaço de fases, segue para longe desta região e depois é reinjetada próximo do ponto fixo.

Dessa maneira, a dinâmica consiste no intercalar de um comportamento instável, o espiralamento em torno da região no diagrama de espaço de fases, e um comportamento estável, a volta de reinjeção. Os dois comportamentos estão conectados no espaço de fases onde o ponto sela-foco está presente.

\subsection{A influência da perturbação sonora.}

Para certas vazões a perturbação pode alterar qualitativamente o regime de borbulhamento, trocando um regime periódico por um caótico. Estudos sobre alterações no regime de borbulhamento em função da amplitude de perturbação [Piassi, 2002; Tufaile, 2001] para vazão de ar fixa mostraram semelhanças com a dinâmica do 
(a)

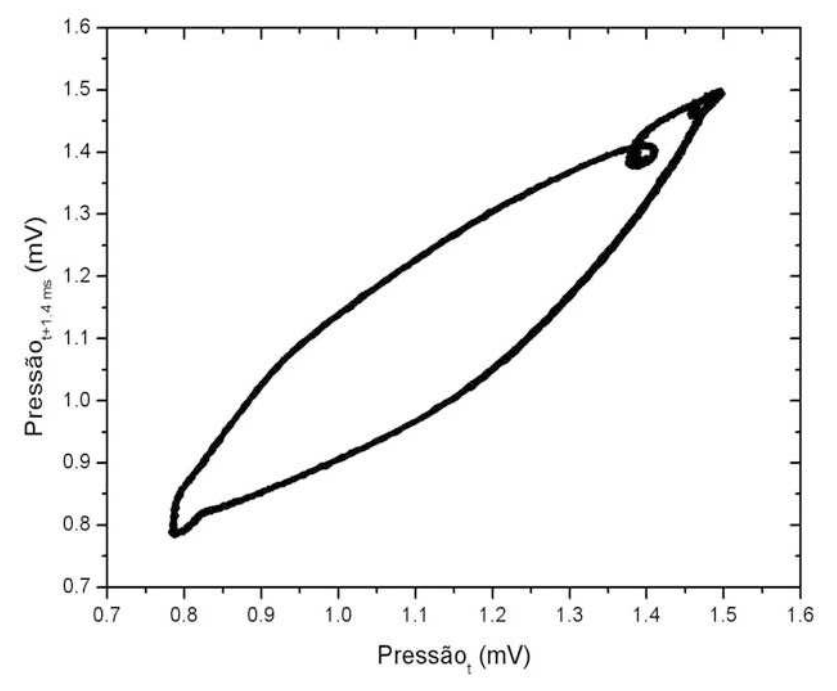

(b)

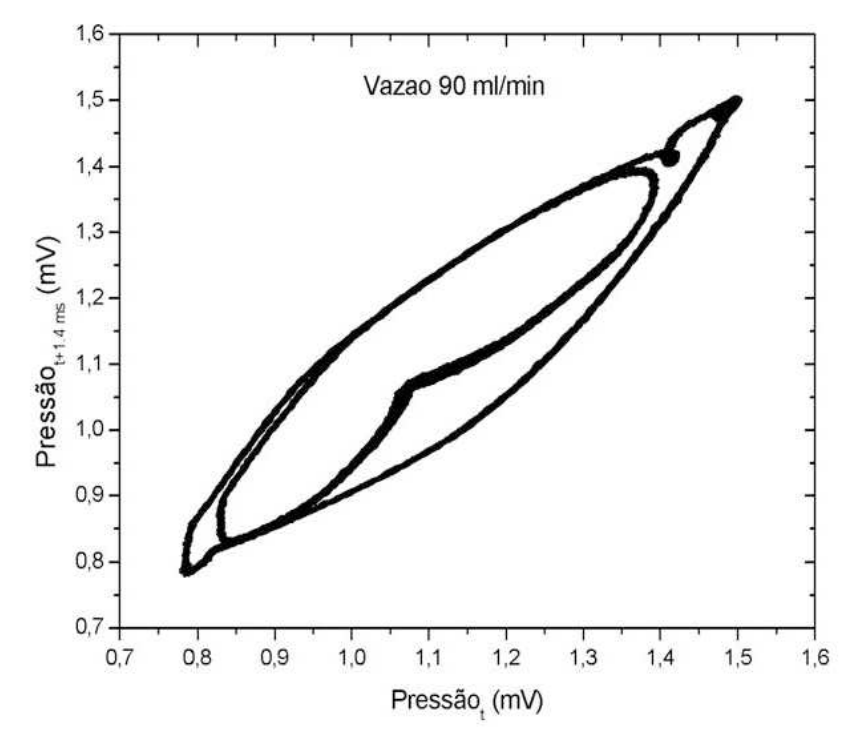

Figura 4.27: Reconstruções de retorno a cada 1,4ms utilizando a mangueira de $190 \mathrm{~cm}$ de comprimento. Em (a) temos comportamento periódico em período 1 obtido com vazão de $70 \mathrm{ml} / \mathrm{min}$. Em (b) o comportamento observado é periódico com período 2 e a vazão de ar é $90 \mathrm{ml} / \mathrm{min}$. 
(a)

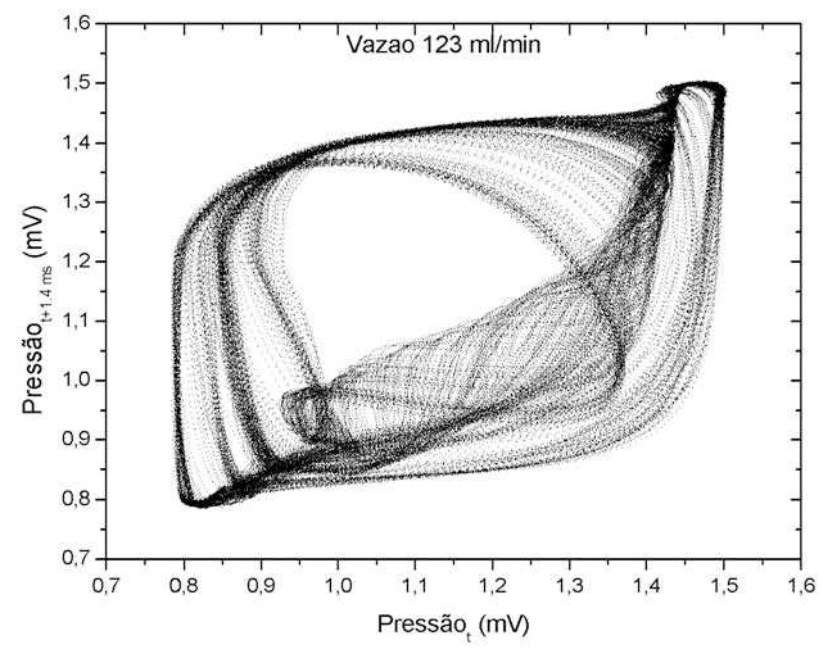

(b)

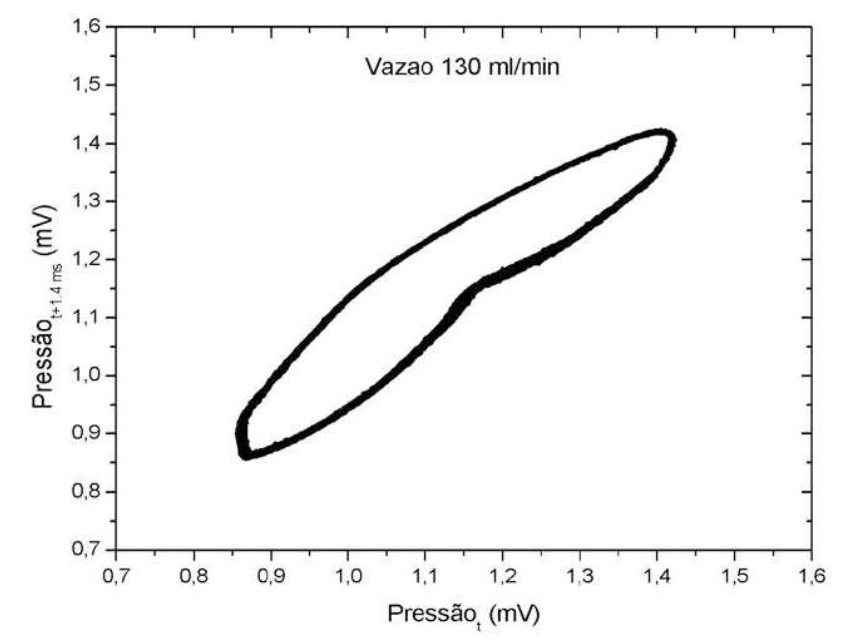

Figura 4.28: Reconstruções de retorno utilizando a mangueira de $190 \mathrm{~cm}$ de comprimento. Em (a) temos comportamento caótico observado com vazão de 123 $\mathrm{ml} / \mathrm{min}$, neste caso usamos um tempo de retorno de 1,4 ms. Em (b) a vazão é de $130 \mathrm{ml} / \mathrm{min}$ e o comportamento observado é periódico com período 1. 


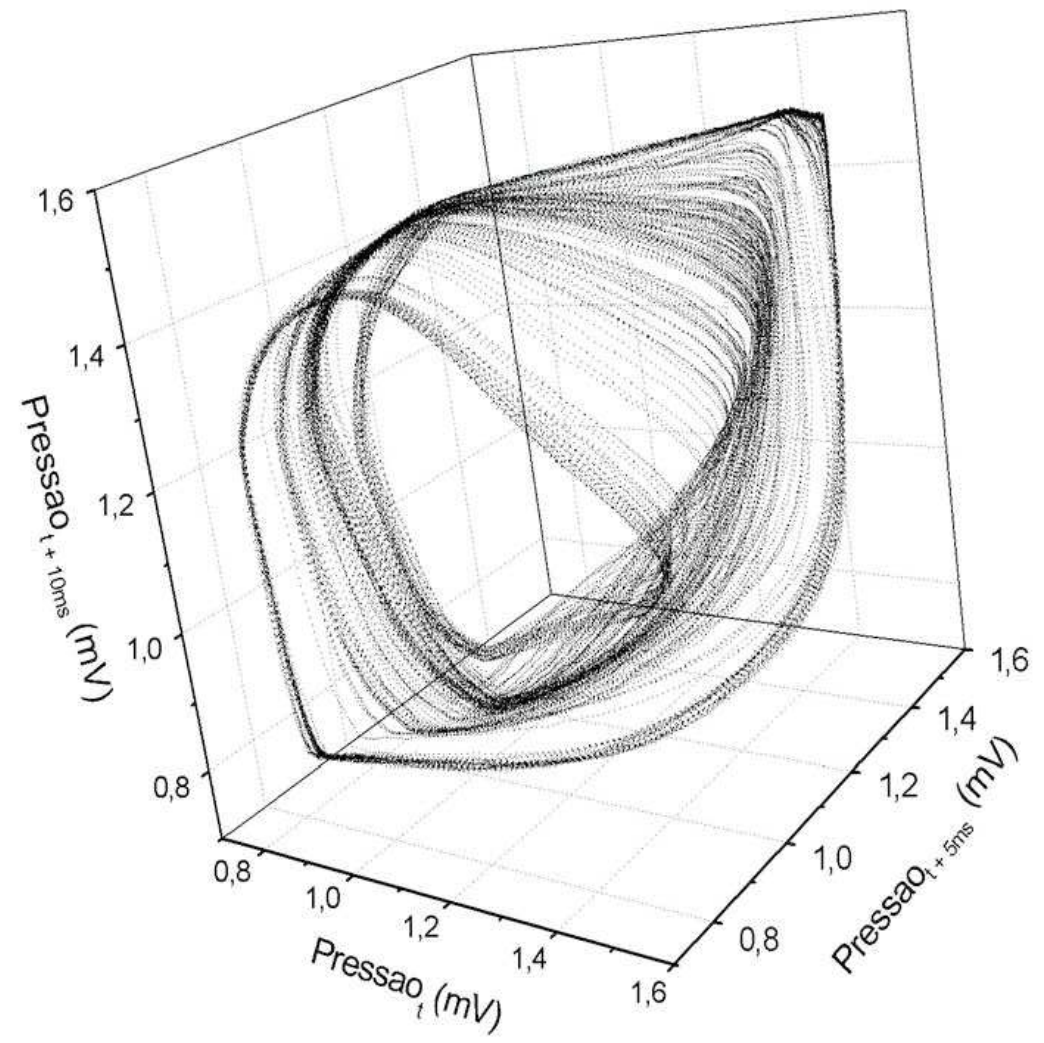

Figura 4.29: Reconstrução de retorno utilizando a mangueira de $190 \mathrm{~cm}$ de comprimento com vazão de $123 \mathrm{ml} / \mathrm{min}$ feita em dimensão 3 com um intervalo de tempo de atraso de $5 \mathrm{~ms}$. 
mapa do círculo bidimensional, conforme na seção 2.7 .

Uma outra maneira de analisar a influência da perturbação na formação de bolhas de ar é o estudo do sistema sob ação da onda sonora tomando como parâmetro de controle a vazão de ar injetado no bico borbulhador.

Mostramos na seção 4.1 que variando a vazão do ar injetado no bico borbulhador provocamos uma mudança no tempo entre bolhas $T_{n}$. O tempo entre bolhas sucessivas $T_{n}$ formadas a baixa vazão apresenta dependência algébrica com a vazão de $\operatorname{ar}(Q)$,

$$
T \propto Q^{-\beta}
$$

sendo $\beta$ um expoente que varia de acordo com a densidade do líquido [Tufaile, 2000]. Para o líquido utilizado neste trabalho vale aproximadamente 0,4 o que concorda com o resultado discutido anteriormente e apresentado na equação 2.15 .

Para estudar a influência da perturbação sonora tomamos como parâmetro de controle a vazão de ar e utilizamos a mangueira de conexão de $10 \mathrm{~cm}$ de comprimento, fixando a freqüência de perturbação em $135 \mathrm{~Hz}$. Alguns valores de amplitude da onda sonora, que forneceram boa caracterização do comportamento do sistema, foram escolhidos para a construção de diagramas de bifurcação $\left(T_{n} v s\right.$. vazão). Comparamos os diagramas obtidos experimentalmente com diagramas obtidos com um modelo determinístico baseado em uma dinâmica do tipo integrae-dispara discutida na seção 2.8 .

Supomos que o volume inicial do processo de crescimento da bolha no instante $t_{n}$ é determinado pelo valor da função $b(t)$ neste instante. Esta função define a condição inicial a partir de uma função senoidal com freqüência $f_{s}$ igual à freqüência da onda sonora e com parâmetro $A>0$ relacionado com a amplitude da perturbação,

$$
b(\tau)=-A \sin (2 \pi \tau)
$$

onde $\tau=f_{s} t$ é o tempo normalizado correspondente a um período da onda sonora. A coluna de ar cresce até atingir o limiar de escape dado por um volume crítico 
$V_{c}$, o que ocorre no instante $\tau_{n+1}{ }^{1}$.

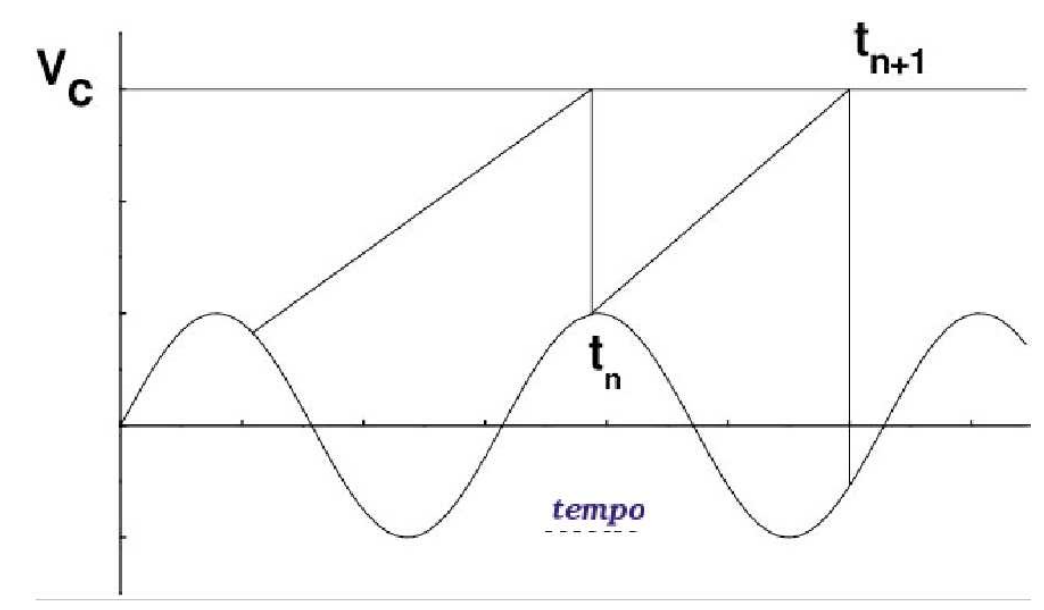

Figura 4.30: Modelo da dinâmica integra-e-dispara com as condições iniciais modeladas pela onda sonora.

Os tempos $\tau_{n}$ e $\tau_{n+1}$ podem ser relacionados por

$$
b\left(\tau_{n}\right)+\frac{\alpha}{f_{s}}\left(\tau_{n+1}-\tau_{n}\right)=V_{c}
$$

de onde podemos escrever:

$$
\tau_{n+1}=G\left(\tau_{n}\right)=\tau_{n}+\frac{f_{s}}{\alpha}\left[V_{c}+A \sin \left(2 \pi \tau_{n}\right)\right] .
$$

O mapa G é membro da família de mapas de Arnold que apresentam dois parâmetros de controle [Glass, 2001] como o mapa do círculo discutido na seção 2.7. Supondo que

$$
\alpha \sim Q^{\beta}
$$

encontramos assim um modelo capaz de emular os resultados experimentais obtidos para a formação de bolhas sob a influência de perturbações sonoras:

$$
t_{n+1}=G\left(t_{n}\right)=t_{n}+Q^{-\beta}\left[V_{c}+A \sin \left(2 \pi \tau_{n}\right)\right],
$$

onde $f_{s} V_{c} Q^{-\beta}$ é a freqüência de Arnold $\Omega$, e $A Q^{-\beta}$ é a amplitude $K$ (ver seção 2.7).

\footnotetext{
${ }^{1}$ Assim, o tempo necessário para a formação e escape da bolha anterior é $\tau_{n}$
} 
Obtivémos 4 diagramas de bifurcação experimentalmente, variando a vazão de ar enquanto a perturbação sonora era mantida fixa. Estes diagramas estão dispostos nas figuras 4.31(a), 4.32(a), 4.33(a) e 4.34(a) com valores de amplitude sonora $2 \mathrm{~V}, 4 \mathrm{~V}, 6 \mathrm{~V}$ e $8 \mathrm{~V}$ respectivamente.

Na figura 4.31(a) identificamos regiões de comportamento periódico de período 1 em meio a um cenário de comportamento quase-periódico. Estas regiões de comportamento periódico podem ser entendidas como patamares de travamento de freqüência entre o ciclo de formação de bolhas e a onda sonora. Eles ocorrem quando a taxa de borbulhamento é submúltipla da freqüência sonora. Percebemos que a largura do patamar aumenta com o valor da vazão de ar de modo que na região considerada os patamares não estão periodicamente distribuídos.

Fazendo ajustes qualitativos das contantes $V_{c}, A$ e $\beta$ do modelo apresentado na equação 4.9 obtivémos, figura 4.31(b), a simulação correspondente ao diagrama da figura 4.31(a). Também observamos neste diagrama patamares de travamento de freqüência.

A variável $R$ utilizada nos diagramas é o tempo entre bolhas multiplicado pela freqüência da perturbação, $R=f_{s} T_{n}$.

Entre os patamares observamos diferentes comportamentos relacionados a periodicidades maiores. O regime em período 2 é o mais visível e se localiza entre os patamares de período 1 , neste regime os valores de $R$ se alternam entre $k$ e $k+1$ de maneira que o patamar de período 2 se encontra em valores semi-inteiros, ou seja,

$$
\frac{f_{s}}{f_{b}}=\frac{k}{2}
$$

onde $f_{b}$ é a freqüência média de borbulhamento.

Na figura 4.32 vemos um diagrama de bifurcação experimental $R^{\exp }$ vs.Q obtido sob perturbação sonora com amplitude $4 V$ juntamente com a simulação obtida $R^{s i m}$ vs.Q fazendo os ajustes equivalentes para as constantes. Percebemos nestas figuras um alargamento dos patamares em relação à figura anterior, o que sugere um maior acoplamento entre a dinâmica de formação de bolhas e a perturbação sonora, também previsto pelo modelo. A largura do patamar de período 2 também 


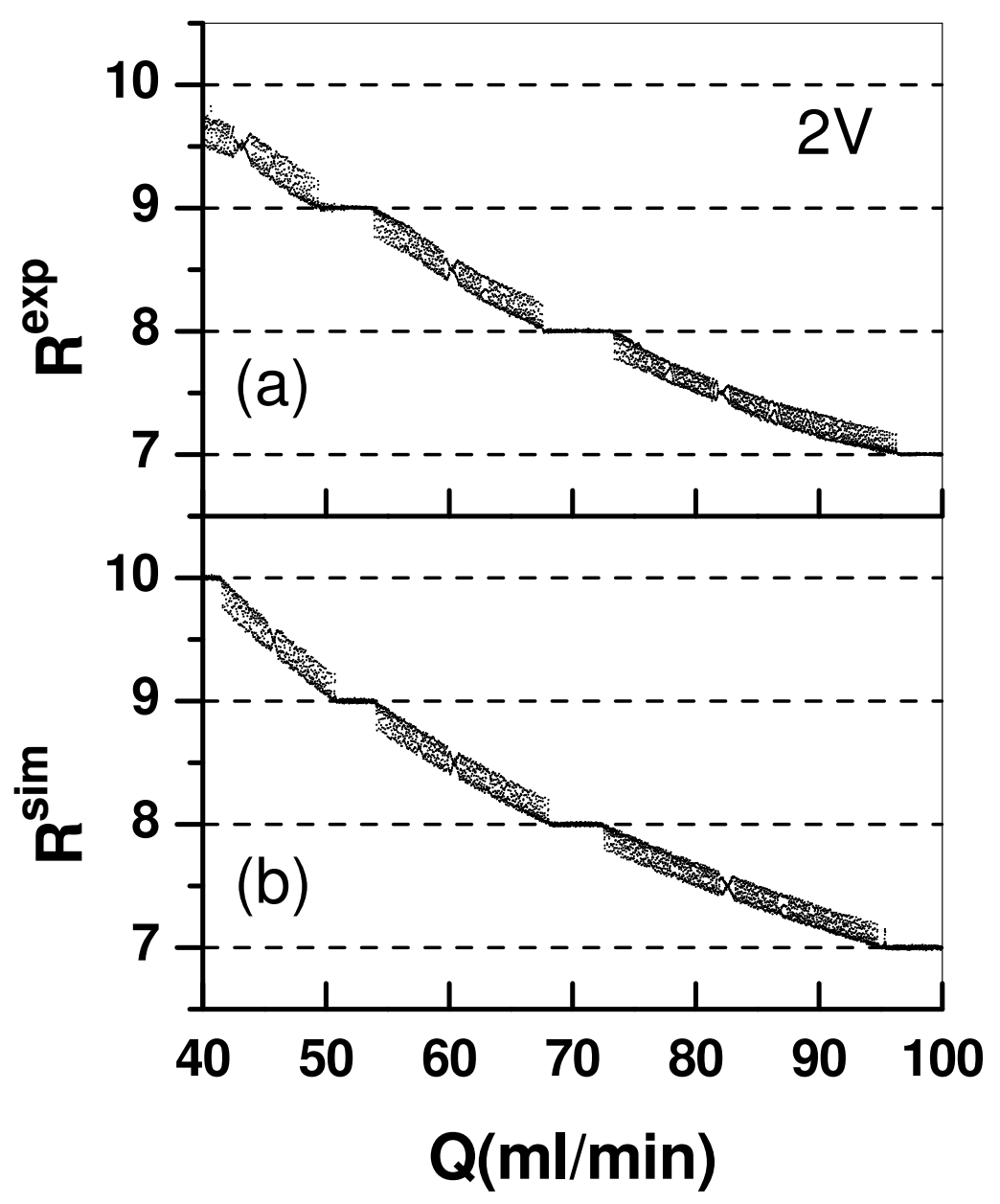

Figura 4.31: Diagramas de bifurcação $R_{n}$ vs. $Q$ obtidos experimentalmente (a) com amplitude de perturbação igual a 2V e pela simulação, em (b), com $A=0,73 \cdot 10^{-3}$, $V_{c}=0,0631$ e $\beta=0,40$. O travamento de freqüência é bem identificado por $k$ inteiro como também por $k$ meio inteiro. 


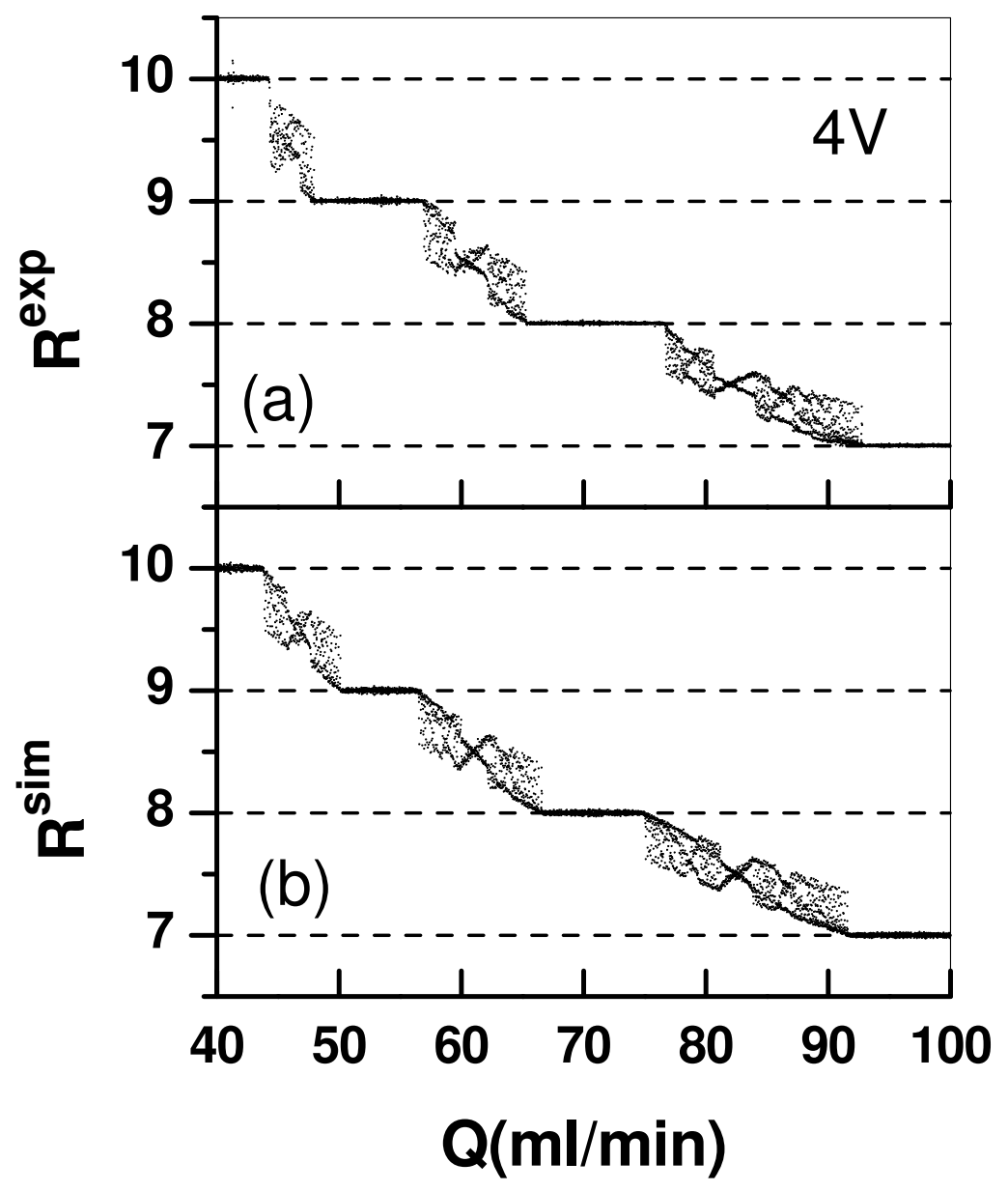

Figura 4.32: Diagramas de bifurcação $R_{n}$ vs. $Q$ obtidos experimentalmente (a) com amplitude de perturbação igual a $4 \mathrm{~V}$ e pela simulação, em (b), $\operatorname{com} A=1,42.10^{-3}$, $V_{c}=0,0634$ e $\beta=0,415$. Observamos travamento de freqüência em período 3. 
aumenta e aparece nitidamente um período 3 em torno de $80 \mathrm{ml} / \mathrm{min}$, entre $k=7$ e $k=8$. Nessa região o valor de $R$ alterna entre 3 valores.

Com amplitude de perturbação igual a $6 \mathrm{~V}$ obtivémos o diagrama apresentado na figura 4.33 juntamente com a simulação correspondente. Neste diagrama observamos nos patamares com vazão mais baixa, onde $k>=9$, ocorre uma duplicação de período seguida de um retorno ao período 1. Esta bolha de bifurcação tem natureza distinta da apresentada na seção 4.4. Ela é resultado do maior acoplamento entre as duas dinâmicas. Para amplitudes de perturbação maiores a dinâmica dos patamares $k=9$ e $k=10$ evoluem para comportamento caótico. A figura 4.34 mostra esta evolução e a propagação do comportamento para patamares inferiores $R=7$ e $R=8$.

Ao longo das últimas figuras identificamos diferentes comportamentos simulados com resultado amplamente satisfatório. É importante uma análise dos valores das constantes utilizadas. A constante $A$ relacionada com a amplitude de perturbação teve valor crescente, como se esperava. A constante $V_{c}$, relacionada com o volume máximo que a bolha atinge antes de se desprender do bico, teve um aumento constante, mas bastante pequeno, menos de $1,5 \%$. A constante $\beta$ oscilou em torno de 0,41 , com variação de $3,9 \%$.

\subsubsection{Espaço de parâmetros}

Uma forma de compreender melhor os resultados apresentados nos 4 diagramas anteriores é analisando como eles se localizam no espaço de parâmetros $(\Omega, K)$ da família de Arnold. Mantendo fixas as constantes $\beta, V_{c}$ e $A$, em cada um dos diagramas, construímos curvas parametrizadas no espaço $(\Omega, K)$ em função da vazão $Q$, sendo

$$
\Omega(Q)=\frac{V_{c} f_{s}}{Q^{\beta}} \text { e } K(Q)=\frac{A f_{s}}{Q^{\beta}}
$$

Estas curvas são as retas com inclinação $A / V_{c}$ indicadas na figura 4.35. As retas traçadas cruzam várias regiões do espaço de parâmetros indicadas na figura. A reta indicada com o número 4 por exemplo, referente ao diagrama apresentado na figura 


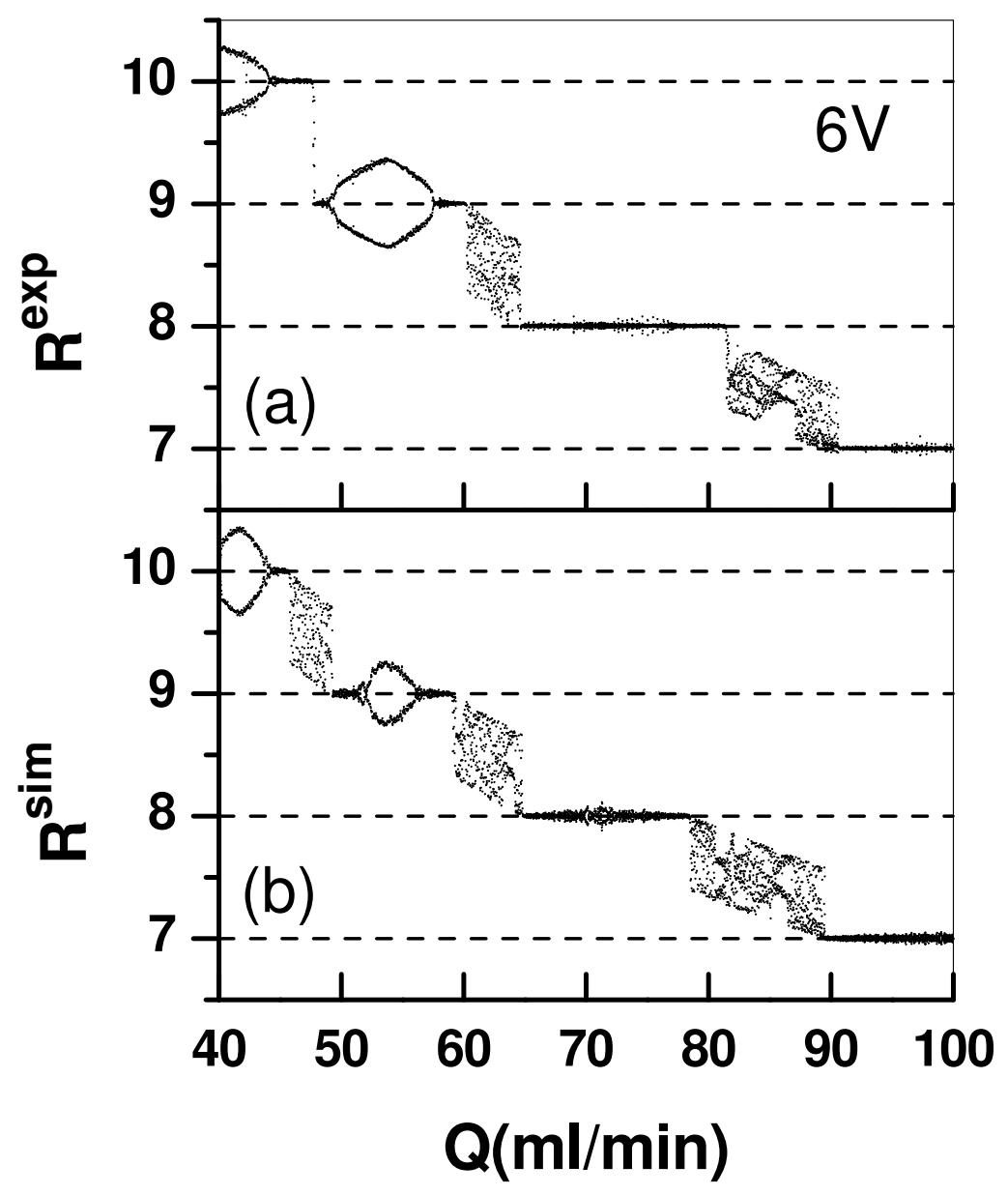

Figura 4.33: Diagramas de bifurcação $R_{n}$ vs. $Q$ obtidos experimentalmente (a) com amplitude de perturbação igual a $6 \mathrm{~V}$ e pela simulação, em (b), com $A=2,48 \cdot 10^{-3}$, $V_{c}=0,0637$ e $\beta=0,414$. Vemos bolhas de bifurcação em alguns patamares de travamento de freqüência. 


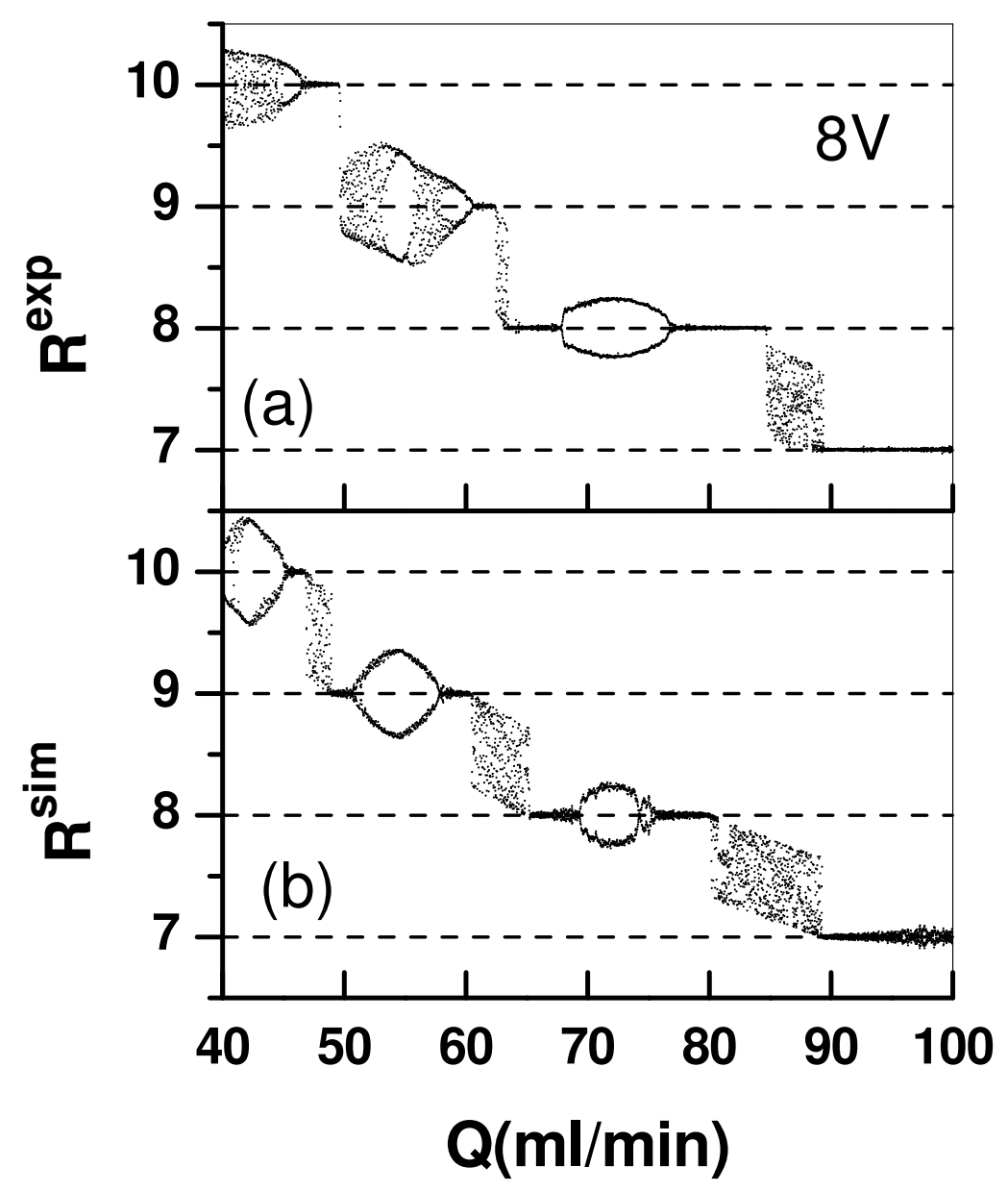

Figura 4.34: Diagramas de bifurcação $R_{n}$ vs. $Q$ obtidos experimentalmente (a) com amplitude de perturbação igual a $8 \mathrm{~V}$ e pela simulação, em (b), $\operatorname{com} A=2,8.10^{-3}$, $V_{c}=0,064$ e $\beta=0,416$. Vemos bolhas de bifurcação em alguns patamares de travamento de freqüência. 


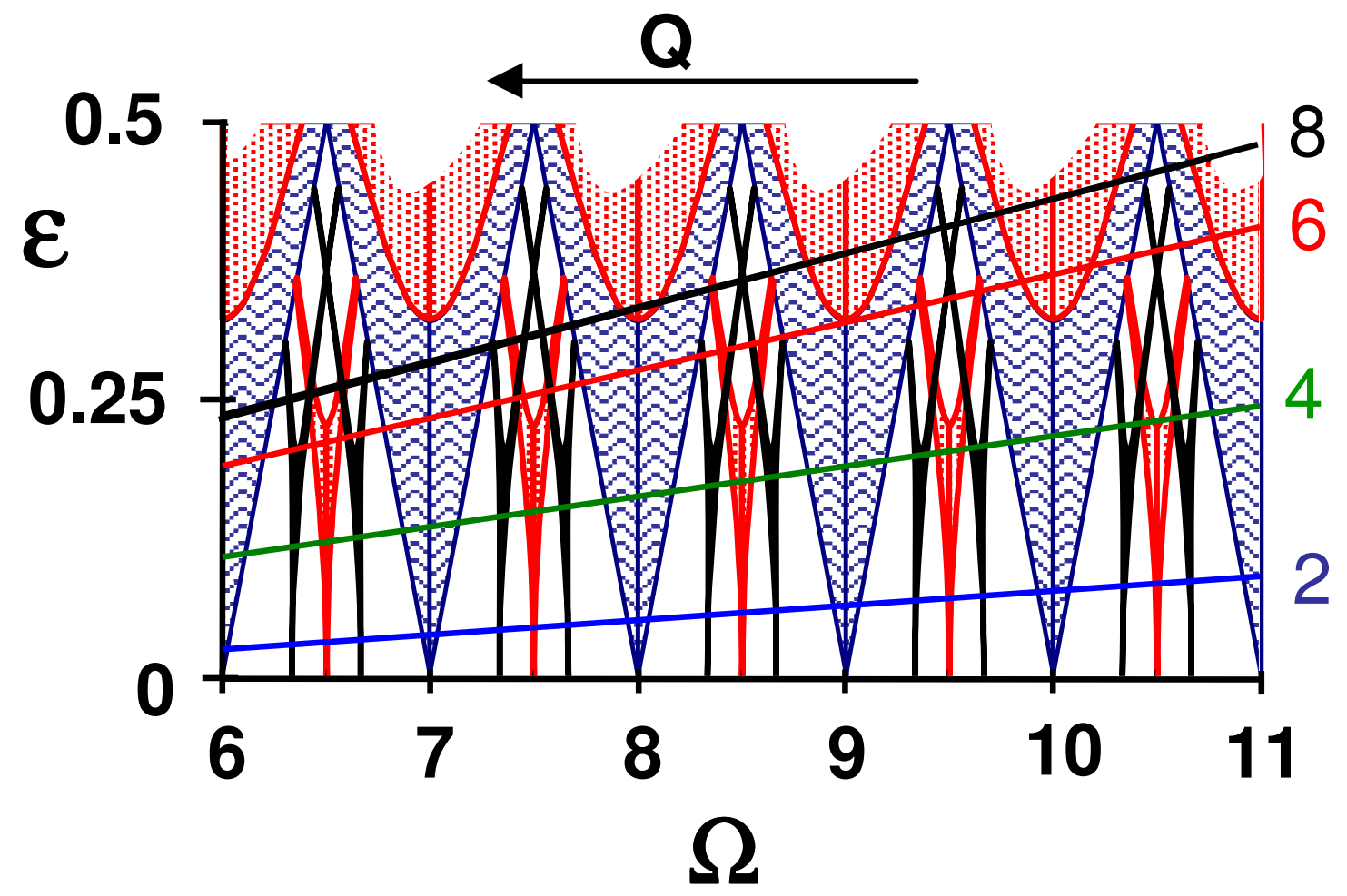

Figura 4.35: Espaço de parâmetros da família de Arnold. As regiões marcadas em azul indicam comportamento periódico com período 1 , em vermelho período 2 , em preto período 3 e em branco com comportamento quase-periódico ou com periodicidade maiores. As retas indicam as trajetórias dos 4 diagramas de bifurcação analisados nas figuras anteriores.

4.32, inicia em um região com período 1 (azul), cruza uma região branca onde o comportamento é quase-periódico, atravessa uma região com período 3 (preto), volta a outra região de quase-periodicidade, cruza uma região com período 2 (vermelho) e continua seu caminho visitando regiões que repetem na ordem inversa os mesmos comportamentos até voltar ao período 1. Como o espaço de parâmetros é periódico, ou seja, $K(\Omega)=K(\Omega+1)$, este comportamento se repete ao longo de toda a curva. Para valores maiores de $K$, a dinâmica da família Arnold fica mais complicada o que justifica o comportamento observado nos patamares com maior intensidade de perturbação $A$. 


\section{Capítulo 5}

\section{Considerações Finais}

Estudamos a dinâmica da formação de bolhas de ar em uma solução de água e glicerina utilizando vários parâmetros de controle.

A análise do sistema pneumático e a alteração de um componente dissipativo permitiu a definição de um novo parâmetro de controle, o comprimento da mangueira injetora. Para diferentes comprimentos de mangueira, o aumento da vazão de ar permitiu observar bolhas de bifurcação, rotas de adição de período e comportamento caótico. As rotas de adição de período foram caracterizadas segundo a presença ou não de comportamento caótico, sendo também identificadas regiões onde órbitas periódicas distintas coexistem. Um modelo baseado nos estudos de mapas descontínuos e com forma cúbica foi desenvolvido para simular a rota de adição de período.

Com o auxílio de imagens das bolhas em formação identificamos, para vazão abaixo de $70 \mathrm{ml} / \mathrm{min}$, uma retração das bolhas durante sua formação alterando significativamente o comportamento do sistema ao longo da variação de vazão ou mesmo mudança no comprimento da mangueira injetora.

Um modelo foi desenvolvido levando em conta a retração das bolhas em baixa vazão e a observação de biestabilidade. Com este modelo pudemos explicar o surgimento de novos períodos dado pela descontinuidade do modelo, além de justificar o final repentino da rota de adição de período.

Utilizando a menor mangueira injetora possível, a fim de diminuir a dissipação 
deste item do sistema pneumático, identificamos patamares com travamento de freqüência quando variamos a vazão de ar sob a ação de uma perturbação sonora. Elaboramos um modelo, com base na dinâmica integra-e-dispara, que permitiu reproduzir com grande veracidade os resultados obtidos experimentalmente Construindo o espaço de parâmetros desse modelo pudemos compreender o surgimento de bolhas de bifurcação que evoluem para comportamento caótico nos patamares.

Um estudo mais detalhado do sistema pneumático levou a construção de um conector com microfone para medir a amplitude da onda de pressão próximo ao bico injetor. A análise de atratores obtidos com as medidas do tempo de entre bolhas juntamente com o estudo da amplitude da onda de pressão evidenciou a existência de comportamento homoclínico o que ainda necessita de mais resultados. 


\section{Capítulo 6}

\section{Referências Bibliograficas}

Ambika, G., Sujatha, N.V. (2000): Bubbling and bistability in two parameter discrete systemas, Pramana - Journal of physics 54, 5, 751-761.

Argyris, J., et al. (1994): An Exploration of Chaos, NOrth-Holland, Amsterdam.

Baker, G. L., Gollub, J. P. (1990): Chaotic dynamics: an introduction, Cambridge University Press, New York.

Buyevich, Yu A., Webbon, B.W. (1996): Bubble formation at a submerged orifice in reduced gravity, Chem. Eng. Sci. 51, 4843.

Davidson, J.F., et al. (1960): Bubble formation at an orifice in a viscous liquid, Trans. Inst Chem. Engrs, 38, 144-154.

Di Marco, P., et al. (2003): Influence of electric field on single gas-bubble growth and detachment in nicrogravity, Int. J. Mult. Flow, 29, 559.

Glass, L. (2001): Synchronization and rhythmic processes in physiology, Nature 410, 277.

Gonçalves, W.M. (1996): A experiência da Torneira Gotejante, Tese de doutorado, IFUSP. 
Halse, C., Homer, M., di Bernardo, M. (2003): C-bifurcations and period-adding in one-dimensional piecewise-smooth maps, Chaos, Solitons and Fractals 18, 953.

Holden, A.V., Fan Y. (1992): From Simple to Complex Oscillatory Behavior via Intermittent Chaos in the Rose-Hindmarsh Model For Neuronal Activity, Chaos, Solitons \& Fractals 2, 4, 349.

Izhikevich, E.M. (2000): Neural excitability, spiking and burstin, Int. J. Bif. Chaos 10, 6, 1171.

Liger-Belair, G., et. al. (2005): Period-adding route in sparkling bubbles, Ann. Phys, Paris, 27, 1.

Lorenz, E.N. (1980): Atractor sets and quase-geostrophic equilibrium, J. Atmos. Sci 37, 1685-1699.

Mittoni, L., et al. (1995): Deterministic chaos in the gas inlet pressure of gasliquid bubbling systems, Phys. Fluids 7, 891.

Papoff, F., Fioretti, A., Arimondo, E. (1991): Return maps for intensity and time in a homoclinic-chaos model applied to a laser with a saturable absorber, Phys. Rev. A 44, 7, 4639.

Piassi, V.S.M. (2002): Dinâmica da formação de bolhas de ar em fluidos, Dissertação de mestrado, IFUSP.

Pinto, R.D. (1999): Comportamento Complexo na Experiência da Torneira Gotejante, Tese de doutorado, IFUSP.

Pisarchik, A. N., et al. (2000) Discrete homoclinic orbits in a laser with feedback, Phys. Rev. E 62, 6, 8823..

Pisarchik, A. N., et al. (2003) Theorical and experimental study of discrete behavior of Shilnikov chaos in a $\mathrm{CO}_{2}$ laser, Eur.Phys.J.D, 13, 385. 
Rajesh, S., Ananthakrishna, G. (2000) Relaxation oscillations and negative strain rate sensitivity in the Portevin-Le Chatelier effect, Phys. Rev. E 61, 4, 3664.

Ren, W., et al. (1997) Period-adding Bifurcation with Chaos in the Interspike Intervals Generated by an Experimental Neural Pacemaker, Int. J. Bif. Chaos $7,8,1867$.

Sartorelli, J.C., et al.(1994) Crisis and intermittence in a leaky-faucet experiment, Phys Rev. E 49, 3963.

Tanaka, G.M. et al., (2003) Bifurcation Structures of Period-adding phenomena in an ocean internal wave model, Int. J. Bif. Chaos 13, 11, 3409.

Tufaile, A.(2000) Estudo da formação de bolhas em líquidos viscosos: Uma abordagem usando a Teoria do Caos, Tese de Doutorado IFUSP.

Tufaile, A., Sartorelli, J.C. (2000b) Chaotic Behavior in bubble formation dynamics, Physica A 275, 336 .

Tufaile, A., Sartorelli, J.C. (2001) The circle map dynamics in air bubble formation, Phys. Let. A $2 \underline{8} 7$ 74-80.

Zhang, L., Shoji, M., (2001) Aperiodic bubble formation from a submerged orifice, Chem. Eng. Sci.59, 5371-5381.

Zeni, A.R., et. al, (1998) Characterization of homoclinic chaos through doublevalued return time maps, Phys. Rev. E 57, 1, 288. 


\section{Capítulo 7}

\section{Apêndices}

\section{Period-adding bifurcation and chaos in a bubble column}

Publicado na revista Chaos em maio de 2004

\section{Bistability in bubble formation}

Publicado na revista Physical Review E em dezembro de 2004

\section{Arnold Family in Acoustically forced air bubble formation}

A ser enviado para publicação aguardando resposta. 